\title{
DEVELOPMENT OF AN INTACT MUSCLE PORK FLAVOR LEXICON
}

\author{
A Thesis \\ by \\ SARAH KATHERINE CHU \\ Submitted to the Office of Graduate and Professional Studies of \\ Texas A\&M University \\ in partial fulfillment of the requirements for the degree of \\ MASTER OF SCIENCE
}

$\begin{array}{ll}\begin{array}{l}\text { Chair of Committee, } \\ \text { Committee Members, }\end{array} & \begin{array}{l}\text { Rhonda K. Miller } \\ \text { Christopher R. Kerth } \\ \text { Luis Cisneros-Zevallos } \\ \text { Koushik Adhikari }\end{array} \\ \text { Head of Department, } & \text { Boon Chew }\end{array}$

May 2015

Major Subject: Food Science

Copyright 2015 Sarah Katherine Chu 


\begin{abstract}
A fresh intact muscle pork flavor lexicon was developed by obtaining cuts of pork (pork loins, shoulders, picnics, tenderloins, fresh ham legs, bellies, enhanced picnics and pork chops) from retail grocery stores. Varying cooking temperatures, cooking techniques, and cuts induced differences in flavors and aromas. These cuts were cooked to various internal temperature endpoints $\left(57.2^{\circ} \mathrm{C}, 62.7^{\circ} \mathrm{C}\right.$ for roasts, $68.3^{\circ} \mathrm{C}$, and $79.4^{\circ} \mathrm{C}$ ) utilizing a high temperature cooking method for chops, and roasting and/or braising for whole muscle cuts.

Five highly trained panelists identified and defined twenty-four aroma and flavor attributes. Pork identity, brown/roasted, bloody/serumy, metallic, and fat-like flavor aromatics, and astringent feeling factors, and 4 of the 5 basic tastes were most prevalent in samples. Validation of the pork lexicon was performed. Trained panelists evaluated tenderloin medallions, and loin chops, inside ham chops, and shoulder chops cooked to four internal endpoint temperatures $\left(62.7^{\circ} \mathrm{C}, 68.3^{\circ} \mathrm{C}, 73.8^{\circ} \mathrm{C}\right.$, and $\left.79.4^{\circ} \mathrm{C}\right)$. Pork identity, brown/roasted, fat-like, bloody/serumy, metallic, liver-like, and nutty flavor aromatics, and astringent feeling factors, and sweet, sour, salty, bitter, and umami basic tastes were present in samples. All attributes but bitter basic taste $(\mathrm{P}>0.05)$ differed across cuts $(\mathrm{P}<0.05)$. All samples had moderate levels of pork identity flavor aromatics. Umami basic taste and liver-like, nutty, and fat-like flavor aromatics and astringent feeling factors were barely detectable. Shoulder chops were higher in pork identity and fat-like flavor aromatics and umami basic taste. Inside ham chops were
\end{abstract}


higher in astringent feeling factors and metallic flavor aromatics, and sour and bitter basic tastes. Brown/roasted, bloody/serumy, and metallic flavor aromatics, and astringent feeling factors, and sour and bitter basic tastes differed across internal endpoint temperatures $(\mathrm{P}<0.05)$. As internal endpoint temperatures increased, brown/roasted flavor aromatics increased, while bloody/serumy flavor aromatics and astringent feeling factors, and sour and bitter basic tastes decreased.

Gas chromatography with olfactory sniff ports detected volatile aromatic compounds $(\mathrm{n}=157)$ found in the samples. Stepwise linear regression equations and simple correlation coefficients were calculated. Stepwise equations used 50,42, 43, 58, $33,37,75,53$, and 42 compounds to account for $93,91,83,94,77,87,96,88$, and $83 \%$ of pork identity, brown/roasted, fat-like, bloody/serumy, and metallic flavor aromatics, and astringent feeling factors, and sour, salty, and bitter basic tastes, respectively which determined volatile aroma compounds that may explain variance of trained descriptive attributes. Sulfur-containing compounds, nitrogen-containing compounds, aldehydes, ketones, acids, alkanes, alkenes, furans, pyrazines, and benzenes influenced pork flavor. Aldehydes were quantitatively higher than other compound classes. Aromatic compounds that clustered with treatments and flavor aromatic attributes varied in partial least squares regression biplots, with a large number of treatments and attributes that clustered with aldehydes and alcohols, and treatments that were cooked to higher internal endpoint temperatures clustered with compounds such as pyrazines and thiazoles. 


\section{DEDICATION}

This work is dedicated to my family, friends, and colleagues who have supported me throughout my career at Texas A\&M University and my time as a graduate student. I am so blessed to have such an amazing support team that continues to root for me even in my most challenging journeys. 


\section{ACKNOWLEDGMENTS}

I would like to thank my committee chair, Dr. Miller, and my committee members, Dr. Kerth, Dr. Cisneros-Cevallos, and Dr. Adhikari, for all of the guidance and support throughout my academic journey. They were great mentors who will continue to encourage future graduate students. Additionally, many thanks go out to Roger Johnson with Farmland Foods for donating inside hams for this project. This project would not be possible without his support in this research.

Thanks also go to my friends, colleagues and the faculty and staff at Texas A\&M University for making my time here a great experience.

Finally, many thanks to my mother, father, and sister for their encouragement and to my boyfriend, Eric Umrigar, for his patience and love. I would not have made it through this part of my life without my cheering squad. 


\section{TABLE OF CONTENTS}

Page

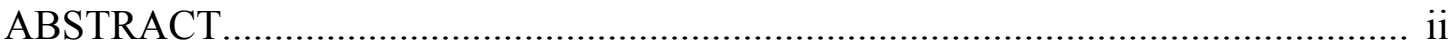

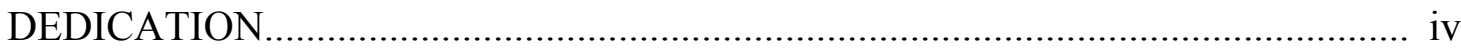

ACKNOWLEDGMENTS............................................................................... v

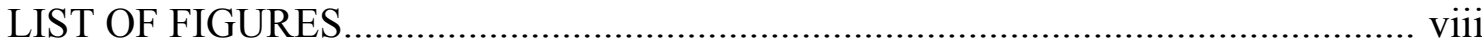

LIST OF TABLES....................................................................................... ix

CHAPTER I INTRODUCTION.......................................................................... 1

CHAPTER II LITERATURE REVIEW........................................................... 3

Biological Detection of Flavor.............................................................. 3

Intrinsic Meat Flavor Components....................................................... 6

Extrinsic Meat Flavor Components.................................................... 13

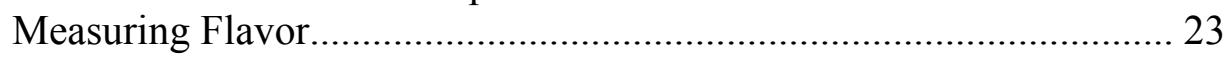

CHAPTER III MATERIALS AND METHODS..................................................... 31

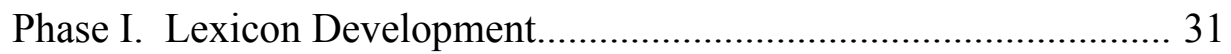

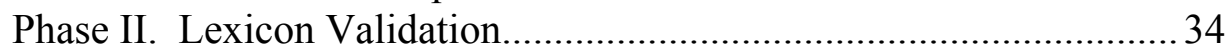

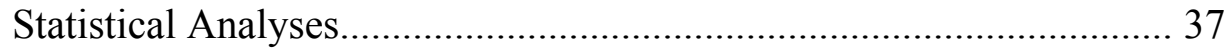

CHAPTER IV RESULTS AND DISCUSSION.................................................... 39

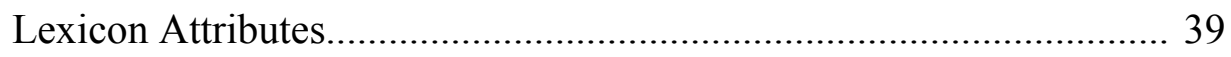

Lexicon Validation........................................................................... 45

Volatile Aromatic Compounds........................................................... 48

Simple Correlation Coefficients................................................ 52

Stepwise Linear Regression Equations........................................ 55

Partial Least Squares Regression................................................. 59

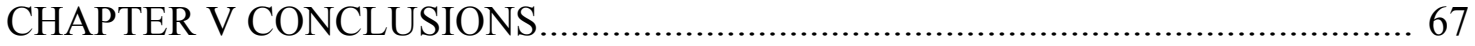

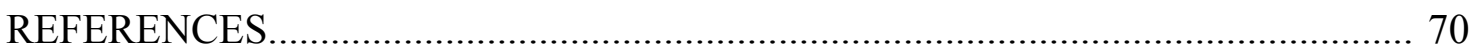




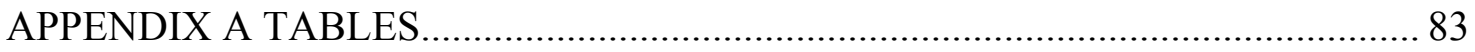

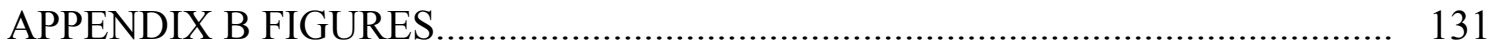




\section{LIST OF FIGURES}

Page

Figure 1. Flavor aromatic compound categories least squares means for the cut by internal endpoint degree of doneness interaction...

Figure 2. Partial least squares regression biplot $\left(\mathrm{R}^{2}=92.6 \%\right)$ of trained descriptive flavor attributes from the Pork Lexicon (blue), volatile aromatic compound categories (red), and 16 treatments (green)....... 132

Figure 3. Partial least squares regression biplot $\left(\mathrm{R}^{2}=82.0 \%\right)$ of trained descriptive flavor attributes from the Pork Lexicon (blue), 157 volatile aromatic compounds (red), and 16 treatments (green) 


\section{LIST OF TABLES}

Page

Table 1. Sample descriptions, muscle categories, cooking methods and endpoint temperatures used in the lexicon development

Table 2. Definitions and references for pork flavor attributes, where $0=$ none and $15=$ extremely intense

Table 3. Pork flavor attribute $(0=$ none; $15=$ extremely intense $)$ least squares means for pork cuts and degrees of doneness using the Pork Lexicon. 86

Table 4. Overall means and standard deviation values for volatile, aromatic chemicals identified by the GC/MS

Table 5. Flavor aromatic compound categories least squares means for pork cuts and degrees of doneness.

Table 6. Simple correlation coefficients between trained descriptive sensory attributes and volatiles.

Table 7. Simple correlation coefficients between trained descriptive sensory attributes and volatile compound categories

Table 8. Stepwise linear regression for prediction of pork identity flavor aromatics as the dependent variable and aromatic volatile compounds as independent variables.

Table 9. Stepwise linear regression for prediction of fat-like flavor aromatics as the dependent variable and aromatic volatile compounds as the independent variables.

Table 10. Stepwise linear regression for prediction of brown/roasted flavor aromatics as the dependent variable and aromatic volatile compounds as the independent variables

Table 11. Stepwise linear regression for prediction of bloody/serumy flavor aromatics as the dependent variable and aromatic volatile compounds as the independent variables 
Table 12. Stepwise linear regression for prediction of metallic flavor aromatics as the dependent variable and aromatic volatile compounds as the independent variables.

Table 13. Stepwise linear regression for prediction of astringent feeling factors as the dependent variable and aromatic volatile compounds as the

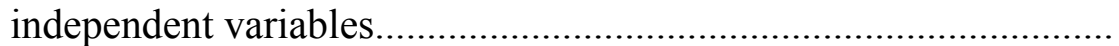

Table 14. Stepwise linear regression for prediction of sour basic taste as the dependent variable and aromatic volatile compounds as the independent variables.

Table 15. Stepwise linear regression for prediction of salty basic taste as the dependent variable and aromatic volatile compounds as the independent variables.

Table 16. Stepwise linear regression for prediction of bitter basic taste as the dependent variable and aromatic volatile compounds as the

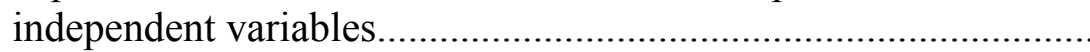




\section{CHAPTER I}

\section{INTRODUCTION}

Pork palatability has been studied by a large number of researchers to ensure that consumers receive the best quality meat at the best price (Ngapo and Gariepy, 2008; Deethardt and Tuma, 1971; Prusa et al., 2011; Wright et al., 2005). Pork palatability has been defined as juiciness, tenderness, and flavor and while adequate terms and scales have been used and developed for pork juiciness and tenderness (AMSA, 1995; AMSA, 2014), pork flavor attributes have not been clearly defined. Flavor is an important part in consumer liking and acceptance of foods. The Beef Flavor Lexicon was developed by Adhikari et al. (2011) and has been used by the beef industry to improve beef flavor. In this lexicon, attributes of beef flavor were defined. Flavor is a complex sensory attribute that is composed of multiple attributes. Civille and Lyon (1996) defined flavor attributes with references for food as many foods have multiple flavors. By developing a whole muscle pork flavor lexicon, a more complete and standardized measure of pork flavor and aroma can be applied across disciplines and utilized to manage pork flavor.

The objectives of this study were to develop an aroma and flavor descriptive attribute lexicon for fresh intact muscle pork and to validate the lexicon using trained panelists by evaluating various cuts of retail pork cooked to various endpoint temperatures to induce flavor and aroma differences. Additionally, the gas chromatograph-mass spectrometer with olfactory sniff ports was utilized to identify volatile aroma compounds present in the same pork samples that were presented to 
panelists. The volatile aroma compounds identified were used to identify the compounds that drive pork flavor and aroma as they relate to the pork lexicon attributes. 


\section{CHAPTER II}

\section{LITERATURE REVIEW}

\section{Biological Detection of Flavor}

Flavor can be categorized into aromas, tastes, and mouthfeels and takes place in the sense or stimulation portion of the nose and mouth (Spanier et al., 2001). These can be further subcategorized into volatile (odor/aromas) and non-volatile (tastes, mouthfeels) components. These components are combined in the food product to create what is perceived as flavor.

The basic tastes are made of soluble substances that are perceived on the tongue by taste buds that contain taste receptor cells located on the taste papillae or the epiglottis and palate (Voilley and Etievant, 2006). Inorganic salts contribute to the salty basic taste, organic acids contribute to the sour basic taste, hypoxanthine, caffeine, and amino acids contribute to the bitter basic taste, and sugars and some amino acids contribute to the sweet basic taste (Min and Smouse, 1989). For sour and salty basic tastes, ionization of the chemical compounds in solution elicits these basic tastes and both are mainly concentration dependent (Shallenberger, 1996). However, sour basic taste is a function of $\mathrm{pH}$ (Shallenberger, 1996). Hydrogen ions act as the molecule that induces the sour basic taste by increasing the hydrogen concentration and thus increasing acidity. Salty basic taste is exclusively dependent on the cation and anion, where sodium chloride is the purest of salty basic taste. Sweet basic taste is more dependent on functional groups and structure, as a specific pair of functional groups, usually dipolar 
molecules, results in the sweet basic taste, a proton donating $\mathrm{AH}$ auxogluc functional group and a proton accepting B glucophore functional group, that results in intermolecular hydrogen bonding with corresponding $\mathrm{AH}$ and $\mathrm{B}$ receptors on the tongue. The $\mathrm{AH} / \mathrm{B}$ theory is further explained for intensely sweet molecules, where a $\gamma$ site is attracted to the lipophilic regions of the sweet receptor on the tongue, however, it is not as important for sugar sweetness (Birch, 1981). Amino acids that contribute to bitter basic taste are associated with hydrophobic side chains (Min and Smouse, 1989). There are also many other classes of compounds that elicit bitter basic taste (Voilley and Etievant, 2006) such as caffeine, quinine, theobromine, and isohumulone. Additionally, the structure and receptor relationship is similar to that of sweet basic taste. Umami, a newer and less recognized basic taste, is triggered by glutamate and nucleotides that are present in protein-rich foods (Voilley and Etievant, 2006) and also has congruent taste receptors on the tongue. The most common substances used commercially are monosodium glutamate and the 5'-ribonucleotides such as inosine-5'-monophosphate and 5'-IMP (Kawamura and Kare, 1987), however, not all substances in these classes provide enhancing properties or umami basic taste. This class of compounds tends to contribute "meaty" and "brothy" flavors as well as enhance flavors present in the food matrix.

The sense of touch, or tactile sensitivity across the body, varies widely with the fingertips being most sensitive followed by the mouth and its encompassed parts (Guinard and Mazzucchelli, 1996). The feeling factors are perceived in the mouth as nerve ends in and around the mouth as well as in the nasal passages. These sensations 
can be described as mouthfeels and can be defined as all tactile properties perceived when a food enters the mouth until the time it is swallowed (Guinard and Mazzucchelli, 1996). For example, astringent feeling factors, which is a tactile sensation that has a trigeminal component (Guinard and Mazzucchelli, 1996), is the basis for the feeling of puckering or drying associated with the binding of compounds such as soluble proteins (Damodaran et al., 2008) to salivary components, thus reducing salivation in the mouth and stimulating receptors.

The olfactory system has the ability to discriminate among many different odors and can identify a large number at a time (Breer, 2008). The sense of smell is located in the olfactory epithelium, where odorant molecules are inhaled and dissolved into the mucus and detected by cilia (Breer, 2008). Cells that are in the posterior area of the nasal cavity recognize these odorant molecules and olfactory neurons send axons to the olfactory bulb to process the signal. The nose and mouth are intertwined when defining where gustation and odor perception are located in the body. At the back of the mouth is an area where molecules are in limbo between the gustation and olfactory process. This is where retronasal odor perception takes place. This process occurs during eating and swallowing, and is described as the volatiles from the mouth that travel to the nose and are detected in the olfactory epithelium (Lim and Johnson, 2011). This phenomenon is the key to the identification of flavor and aroma in the human body.

Specifically, meat flavor is a combination of all of these senses as detected in the body. It is understood to be the result of the various reactions that take place during cooking due to the lack of flavor in raw meat (Shahidi, 1994), however, the basic 
biology of the meat and antemortem and postmortem influences impact the end product flavor.

Intrinsic Meat Flavor Components

Flavor precursors relating to meat flavor include water-soluble components and lipids in the meat system (Mottram, 1998). The water-soluble components include sugars of varying types (phosphates, free sugars, and nucleotide sugars) and nitrogenous compounds (peptides, free amino acids, nucleotides, and others). Combinations of specific sugars and nitrogenous compounds have provided meat-like flavors, such as cysteine, a sulfur-containing amino acid, and ribose. Sugars that are present in the muscle come from the hydrolysis of glycogen or the hydrolysis of nucleotides, yielding the two main sugars available, glucose and ribose (Shahidi, 1994). Nitrogenous compounds originate from a variety of components such as free amino acids, proteins, and nucleotides. Each of these components is active in the formation of Maillard reaction products. More on these reactions will be presented in the Maillard reaction section.

Proteins play an important role in the function of muscle as well as being potential flavor precursors. Myofibrillar proteins have been found to provide flavor precursor compounds through the hydrolysis of the protein into sulfur-containing amino acids and non-sulfur-containing amino acids. Myosin contains much higher levels of methionine and cysteine compared to other myofibrillar proteins (Pearson et al., 1983). Other myofibrillar proteins that contain sulfur-containing amino acids are C-protein and G-actin at lower levels. The sulfur-containing amino acid, cysteine, can be broken down 
into ammonia, hydrogen sulfide, and acetaldehyde (Damodaran et al., 2008).

Acetaldehyde can then combine with other compounds to provide meat flavors. Sulfur compounds, such as hydrogen sulfide, have been shown to be a component in meaty flavors and aromas at low concentrations (Wasserman, 1972). Hydrogen sulfide can react with compounds such as furanones to form 2-methyl-3-furanthiol and bis-(2methyl-3-furyl) disulfide that present intense meaty flavors (Shahidi, 1994). Sulfur compounds can provide positive or negative flavors, and is very dependent on concentration and quantity. Hydrogen sulfide does not have a large presence in raw pork proteins (Gorbatov and Lyaskovskaya, 1980). Cooked pork contains 1-3 times more hydrogen sulfide when compared to cooked beef due to the higher number of free sulphydryls that are free for heating due to a number of reasons such as thiamine degradation. Other sulfur compounds have been found as well: methyl mercaptan, ethylene sulfide, and thiophene (Gorbatov and Lyaskovskaya, 1980). The sulfurcontaining amino acids are most notorious for combining with reducing sugars to produce meat-like flavors in the Maillard reaction (Shahidi, 1994). Myofibrillar proteins also provide amino acids that do not contain sulfur but have been proven to be flavor precursors (Pearson et al., 1983). Myosin provides the majority of these amino acids, with the most important for flavor generation being alanine, leucine, isoleucine, histidine, arginine, proline, glutamic and aspartic acids (Pearson et al., 1983). Some of these amino acids exhibit sweet notes, while others exhibit bitter tastes (Shahidi, 1994). Sarcoplasmic proteins, such as myoglobin and hemoglobin, have not been shown to 
contribute to flavor (Hornstein and Crowe, 1960; Pearson et al., 1983). However, myoglobin may have an effect as a prooxidant in lipid oxidation (Pearson et al., 1983).

Protein degradation occurs at about $30^{\circ} \mathrm{C}$, where amino acids or nucleotide fragments can be removed from the whole protein (Wasserman, 1972). At temperatures between $35^{\circ} \mathrm{C}$ and $50^{\circ} \mathrm{C}$, muscle fibers begin to lose shape and sulfur groups are exposed. Coagulation of proteins occurs from $55^{\circ} \mathrm{C}$ to $80^{\circ} \mathrm{C}$. Above $80^{\circ} \mathrm{C}$, disulfide bonds are formed and beyond $80^{\circ} \mathrm{C}, \mathrm{H}_{2} \mathrm{~S}$ molecules are released from the proteins.

Fats, or lipids, are stored in the adipose tissue or as intramuscular fat (marbling). A lipid consists of a head portion, which consists of a glycerol molecule, and a tail portion with three distinct fatty acids linked to the glycerol molecule by ester bonds yielding a triacylglycerol or triglyceride. Fatty acids vary in their functional properties and functions due to their varying lengths and the presence of double bonds (unsaturated fatty acids) versus the absence of double bonds (saturated fatty acids) within the hydrocarbon chain. The triglyceride, also known as a neutral lipid, makes up the majority of adipose tissue (Wood et al., 2008). Phospholipids are in a class of lipids that are present in most plant and animal membranes of aqueous cells (Min and Smouse, 1989). In meat, they are mainly present in the lean muscle in the cellular membranes (Wood et al., 2008). They are composed of a phosphate group and two long chain fatty acids attached to it. The polyunsaturated fatty acid (PUFA) reaction with the phospholipid amine base has the ability react and combine with reactive carbonyls to produce carbonyl-based off-flavors (Min and Smouse, 1989). 
Adipose tissue, also known generally as "fat", composition is comprised of amino acids, proteins, sugars, and salts (Wasserman, 1972). Wasserman and Spinelli (1972) determined that adipose tissue was the result of species-specific fat flavor, and the adipose tissue contained both nonpolar and polar lipids. Washing of the adipose tissue resulted in the loss of amino acids. They determined through a trained panel that adipose tissue extract of beef aromas was not easily distinguishable but were described as generally "meat-like" aromas, but lamb and pork extracts were distinguishable with words such as "piggy", "sour", and "goaty". Gas chromatography studies showed that the differences between washed and unwashed lipid composition was mostly quantitative. Washed lipids on heating had hot fat aromas and unwashed lipids had meat-like odors and the water washes contained "basic roast meat aromas". Speciesspecific differences in flavor are generally recognized to be not in the lean muscle but in the fat on the animal (Hornstein and Crowe, 1960; Mottram, 1998). This was first demonstrated in raw beef, and later in pork, by determining that flavors present in meat could be extracted using water, and then analyzing the fat for fatty acids and carbonyls as potential flavors (Hornstein and Crowe, 1960). The researchers found through analysis of the fat from both species that there were differences in fatty acids present (Hornstein and Crowe, 1960). The biggest difference in fatty acid composition was the high level of linoleic (18:2) and linolenic (18:3) acids in pork compared to beef. Pork fat and beef fat had many of the same fatty acids present but at different concentrations, where beef had higher palmitic acid and hexadecenoic acid. Results for carbonyls present in both samples of fat determined that pork fat had many more carbonyl 
compounds such as 2,4-dienals, 2-enals, and alkanals, than beef fat and at different concentrations.

Intramuscular fat (IMF) has been studied with its effects on flavor as well as other attributes (tenderness, juiciness). IMF, also known as marbling, is deposited in the muscle within the perimysium (Nishimura, 2010). The National Pork Board has determined a target range of 2-4\% IMF in pork (Meisinger, 2002) for pork quality. While this is a range that fits most studies that have been conducted, there are other studies that have not found any profound effect of IMF on flavor . The variability in these results is rather complex in that many other factors must be controlled to ensure that these studies are accurate (i.e. endpoint temperature, breed, aging, etc.; Ngapo and Gariepy, 2008).

Lipid oxidation is a major concern, where undesirable flavors such as painty, fishy, and rancid could potentially be present in the lean meat. However, autoxidation is a source of volatile compounds in pork (Shahidi, 1994). When oxidation occurs while cooking, the degradation reaction is quick, causing triglycerides and phospholipids to degrade via several different possible hydrolysis reactions, providing an array of desirable flavors (Mottram, 1998; Shahidi, 1994). Lipids in the meat contribute to many flavor-related volatile compounds. Several of these volatiles include hydrocarbons, ketones, alcohols, carboxylic acids, esters, and aldehydes (Mottram, 1998). Volatile compounds such as those listed are indicative of pork cooked at or below $100^{\circ} \mathrm{C}$ (Shahidi, 1994). Fats also have the ability to carry fat-soluble substances that can be detected by the nose (Shahidi, 1994). Cooked meat and meat that has been reduced in 
particle size or has been cooked causing protein denaturation is more readily available for lipid oxidation when compared to raw meat (Min and Smouse, 1989) due to the release of compounds that catalyze lipid oxidation such as free iron from color pigment compounds (Drumm and Spanier, 1991). Fatty acid oxidation is comprised of three steps that are a result of free radical reactions or the result of lipoxygenase (Ho and Chen, 1994). Initiation is the result of the formation of an alkyl radical from the removal of a hydrogen ion from the fatty acid (Ho and Chen, 1994) and is stabilized by the shifting of double bonds on a weaker unsaturated fatty acid. Heat, light, and metals further catalyze the initiation step. Propagation occurs when atmospheric oxygen is bonded to the alkyl radical. The result is a high-energy peroxyl radical that is available to remove hydrogen from a different fatty acid molecule. The result of this is a hydroperoxide molecule as well as the development of a new alkyl radical from another fatty acid molecule. Termination is the result of two free radicals that combine into a non-reactive compound. The unstable hydroperoxides eventually yield volatiles and offflavors such as aldehydes, ketones, furans, alcohols, and hydrocarbons that are unpleasant (Drumm and Spanier, 1991). Lipid oxidation is difficult to prevent once the free radical chain reaction has occurred, especially when raw meat has been subject to lipid oxidation. This would cause the lipid oxidation to be greater in the cooked meat (Min and Smouse, 1989).

Fatty acid composition was measured by Enser et al. (1996) in pork, beef, and lamb from retail supermarkets in the United Kingdom. The results indicated that the fatty acid composition was similar when comparing intramuscular fat and adipose tissue, 
as adipose tissue had more total fatty acids. Total fatty acid composition of the longissimus dorsi was highest in lamb, and lowest in pork. Pork had significant levels of long chain (C20-C22) n-3 PUFA in subcutaneous fat as well as the PUFA linoleic acid (18:2n-6), a dietary fatty acid that can be deposited upon digestion into the tissues (Wood et al., 2008) in both locations. Phospholipids containing 18:2 were greater in pigs in the longissimus dorsi muscle. Red muscle types have been shown to have higher phospholipid levels and thus higher levels of PUFAs than white fiber types (Wood et al., 2003). The results indicate that pork would most likely, overall, be more susceptible to lipid oxidation and thus possibly more susceptible to off-flavors from lipid oxidation in the meat.

Myoglobin is a globular protein with a heme ring that binds oxygen in the muscle and the level of it in the muscle varies across species, sex, physical fitness of the animal, and muscle type (Calkins and Hodgen, 2007). It is responsible for the red color of fresh meat (Winstanley, 1979). Across species, beef tends to have more myoglobin and have a higher hue angle than pork. Across sexes, females and castrates tend to have less myoglobin in their muscles when compared to intact males. The myoglobin differences across muscles are due to the frequency of each muscle fiber type in each muscle (red versus white fiber type present); (Winstanley, 1979). Myoglobin can react with several different compounds to induce color changes in the meat; however, its ability to partake in different reactions is dependent on its chemical state. 


\section{Extrinsic Meat Flavor Components}

Pork quality differed across breeds (Wood et al., 2004), and crossbreeding has become a common practice in the pork industry to engineer animals to meet production and meat characteristic demands. Common commercial breeds in the United States include Berkshire, Chester White, Duroc, Hampshire, Landrace, Poland China, Spotted Pig, and Yorkshire. Wood et al. (2004) performed a study on Duroc, Large White, Berkshire, and Tamworth identifying the effects of breed, diet, and muscle on fat deposition and quality. Their results showed that pork flavor was higher in Duroc and Large white, and abnormal flavor and flavor liking was higher in Berskhire and Tamworth. Researchers from the Danish Meat Research Institute conducted a study on crossbreeding Duroc and Landrace pigs with alternative breeds, Iberian and Mangalitza (Straadt et al., 2013) and studied the overall pork quality with emphasis on fatty acid composition and subcutaneous fat. The results indicated that no significant differences were found between the crossbreeds and traditional breeds in terms of flavor/taste and odor, with the only difference being improved texture. Additionally, Lu et al. (2008) evaluated the flavor and volatile aroma differences between crossbred pigs (Duroc $\mathrm{x}$ Landrace $\mathrm{x}$ Large White) and indigenous Chinese pigs and evaluated how intramuscular fat and total fatty acid composition, crude protein and amino acid content, volatile aroma compounds, and sensory evaluation affected flavor in these breeds. The crossbred pigs had lower levels of intramuscular fat, higher levels of PUFA phospholipids, higher levels of crude protein and thus higher levels of amino acids, and lower pork flavor intensity and flavor liking. The Rongchang and Laiwu breeds had higher levels of 
intramuscular fat and crude protein levels, the Rongchang breed had lower levels of PUFA phospholipids, and the Laiwu and Dauabai breeds had the highest rankings for pork flavor intensity and flavor liking. The Chinese breeds had the highest sulfur-, nitrogen-containing, and alcohol and ketone compounds, which correlated with the increased intensity and liking. The crossbred pigs also had the lowest concentration of Maillard reaction products.

Gender has an impact on pork quality. For example, intact males have a higher lean to fat ratio when compared to castrates and gilts and generally have values that fall in between the intact males and castrates ratios (Newell and Bowland, 1972; Walstra, 1974; Judge et al., 1990) which is beneficial and important to the pork industry for manufacturers to be able to receive more money for each pig. Therefore, it is important to mention gender impact on pork flavor, with particular interest in boar taint. Generally, males that have not been castrated tend to have increased levels of androstenone and skatole compounds in their fat, which provide an unpleasant odor or flavor (Babol and Squires, 1995). A study by Prusa et al. (2011) compared 5aandrostenone and skatole in the fat and lean portions in barrows, gilts, sows, and boars. The results showed that all types exhibited some boar taint with boar samples most prevalent in boar taint perception using both a trained sensory panel and GC-MS. However, although present in the market, the incidence of boar taint is low due to actions taken to reduce its presence during processing (Babol and Squires, 1995). Walstra (1974) quantified aspects of fattening boars, and determined that strong boar odor could not be detected or was perceived less frequently by consumers or expert 
panels from the Netherlands. Judge et al. (1990) supported this information by determining that higher lean meat was present in US facilities with low incidence of boar taint odor. However, the pork industry must still be aware of the percent of the population that can easily detect boar taint. Newell and Bowland (1972) found that 56\% of boar carcasses that were cooked during their study were perceived to have a sexual odor, where other carcasses did not impart such odor.

Age is generally associated with live weight and sexual maturity of an animal (Ngapo and Gariepy, 2008). According to Sink (1979) meat flavor intensity tends to increase with the age of the animal due to the increase in nitrogenous compounds in the muscle. No flavor differences besides intensity have been thoroughly researched, however, changes in metabolism, fat level, lipid composition, and muscle $\mathrm{pH}$ are present in older animals (Sink, 1979).

The diet of a pig consists of these compositional components: grain source, protein source, energy level, and trace or minor components (Melton, 1990). Fatty acids from the diet are digested differently and utilized differently in pigs than they are in other animals, as their fatty acids are utilized in the fat of the animal and deposited directly into the tissue (Ngapo and Gariepy, 2008), and consequently affect the flavor of the pork (Wood et al., 2003; Melton, 1990). A portion of the dietary fat is delivered to the body tissues where fatty acid composition in those tissues is reflective of the diet of the pig (Corino et al., 2002; Larick, et al., 1992; Miller et al., 1990). Two diets with varied fatty acid compositions were fed to castrated males and females to determine its effects on pork quality (Tikk et al., 2007). The study showed that C18:1n-9c in the polar 
lipid fraction found in the rapeseed oil influenced sensory attributes in oven roasts. For roasts, panelists found higher amounts of piggy flavor aromatics and sour basic tastes, when compared to the fried chops. The fried chops had higher sweet odor aromatics and metal flavor aromatics. Additionally, in the chops of female pigs, the polar lipid fraction fatty acids such as C18:2n-6c and C20:3n-6 were correlated with higher fried meat flavor aromatics and sweet odor aromatics from rapeseed oil. These data are in line with the industry view that certain fatty acids, and, as seen in this study, unsaturated fatty acids, influence pork flavor. Ngapo and Gariepy (2008) extensively reviewed the effects of protein source and trace components and concluded that changing these elements have not been shown to affect the flavor of pork.

Muscle cut is an important contributor when considering flavor, as there are a wide number of cuts of pork available to the consumer. These cuts can vary in muscle type and number, as well as myoglobin content, lipid composition, and proteins present (Cornet and Bousset, 1999). There are four different muscle fiber types that differentiate between muscles and group of muscles: slow twitch oxidative (Type I), fast-twitch oxidative-glycolytic (Type II), fast-twitch glycolytic (Type IIB) and Type IIX (Brooke and Kaiser, 1970; Lefaucheur et al., 1998) where glycolytic (carbohydrates are used as fuel in the muscle) and oxidative (fatty acids are used as fuel in the muscle) describe muscle groupings (Ngapo and Gariepy, 2008). Glycolytic muscles, such as the longissimus dorsi, oxidative muscles, such as masseter, and an intermediate muscle, such as trapezius, were compared for amino acid precursors to flavor (Cornet and Bousset, 1999). The major amino acids present in each of the three muscles were 
alanine and histidine evaluated together, glutamine, glutamic acid, taurine, hydroxyproline, and carnosine. Oxidative and glycolytic muscles presented different amino acids and at different concentrations, which demonstrated that there could be differences between muscles that could result in flavor differences.

Enhancement of pork was developed for extending shelf life and enhancing moisture retention in pork products in the retail case (Sutton et al., 1997). The process consists of pumping loins with salt and sodium phosphates or sodium lactates to improve tenderness, flavor, and overall quality. Specifically, the flavor enhancement from the pumped pork is theorized to be due to phosphate's ability to increase water-holding capacity in the proteins and prevent oxidation (Prestat et al., 2002) as well as increasing salt content. Despite these positive properties, phosphates can induce off-flavors, such as soapy flavors, at high concentrations. However, Prestat et al. (2002) found that offflavors were lower in pumped loins (sodium tripolyphosphate, salt, water) than the controls. Additionally, they found that pumped loins had an improved pork flavor, and pork flavor also increased, with decreasing evidence of off-flavors, as the endpoint temperature increased in pumped loins. These findings coincide with findings of other researchers (Sutton et al., 1997) as they found that pumped pork loins with sodium lactate and sodium tripolyphosphate had good sensory characteristics and moisture retention. Pork flavor increased with increased sodium lactate, and was masked by $0.4 \%$ phosphates in roasts and overall intensity was lower for roasts pumped with phosphates. The use of sodium lactate as a non-meat ingredient was also shown to reduce the decline 
of pork flavor over time, and can be used as a flavor enhancer and a basic taste enhancer (Sutton et al., 1997; Brewer et al., 1993; Papadopoulos et al., 1991).

Postmortem pork quality has been a major research area for a variety of reasons with key issues defined as water-holding capacity, ideal color, and desirable texture. There are four types of pork quality that can occur: pale, soft, and exudative (PSE), dark, firm, and dry (DFD), red, soft, and exudative (RSE), and red, firm, and non-exudative (RFN), all of which are segmented by changes in metabolites in the muscle (Aberle et al., 2012). Lactic acid buildup postmortem causes a decline in $\mathrm{pH}$, as normal porcine muscle starts at a $\mathrm{pH}$ of appoximately 7.4 and decreases to approximately 5.6 within 6-8 hours and finishes to approximately 5.3 within 24 hours (ultimate $\mathrm{pH}$ ) yielding red, firm, and non-exudative (RFN) pork muscle (Aberle et al., 2012). Other factors, such as stress, can affect the ultimate $\mathrm{pH}$ of a carcass. Stress can cause a more rapid drop in $\mathrm{pH}$ due to the rapid use of glycogen in the muscle. This situation can cause the muscle to be pale, soft, and exudative (PSE). The dark, firm, and dry (DFD) condition is a more extreme case, where glycogen reserves are completely used up. Many studies have been done on postmortem pork quality to determine tenderness and flavor attributes (Flores et al., 1999) as statistical significance was not reported for effects on meat flavor (Bennett et al., 1973). Studies have also been done on $\mathrm{pH}$ specifically, as researchers have attempted to identify the range where flavor is most acceptable. A range of $\mathrm{pH}$ 5.8-6.0 has been determined to be an ideal range for overall pork quality based on a culmination of studies (Ngapo and Gariepy, 2008). 
Bryhni et al. (2003) identified that an ultimate $\mathrm{pH}$ of 6.0 resulted in desirable meat flavors that consumers enjoyed (sweeter, less acidic, weaker meat flavor aromatics). Other studies have identified that a lower ultimate $\mathrm{pH}$ had less pork flavor and increased off-flavors (Huff-Lonergan et al., 2002). However, one study done by Jeremiah et al. (1990) investigated muscle quality and frozen storage as it relates to flavor and texture and developed profiles for each. Their results indicated that: 1) longperiod storage at freezing temperatures of at least $193 \mathrm{~d}$ initiated less balanced flavor and had a considerable amount of off-flavor chemical aromatic and higher amounts of appropriate porky and sweet aftertastes; 2) sour basic taste and bitter basic taste were noted in PSE meat and sweet basic taste decreased; 3) DFD meat had flavor notes relating to fatty and porky flavor aromatics, and sweet basic taste with increasing offflavors as DFD conditions worsened. A more recent study done by Moeller et al. (2010) evaluated the effects of ultimate $\mathrm{pH}$, intramuscular fat, color, and Warner-Bratzler shear force on the effects of eating quality of boneless pork loins. Trained panelists evaluated for cooked pork fat flavor aromatics, salt basic taste, cooked pork lean flavor aromatics, as well as other textural properties. Mean sensory scores as affected by $\mathrm{pH}$ were less favorable as $\mathrm{pH}$ decreased. Mean scores for fat flavor aromatics were higher in loins with $\mathrm{pH}$ values higher than 5.8. Lean flavor aromatics decreased slightly as $\mathrm{pH}$ increased over a $\mathrm{pH}$ range of 5.4 and 6.4 .

The aging of meat does not have as much influence on pork meat as it does on beef meat, and most have viewed it as a tenderization method only (Ngapo et al., 2012b). Aging consists of storing the product for a number of days to achieve myofibrillar 
protein breakdown. However, the process does influence flavor through the creation of nitrogen-containing compounds such as amino acids and peptides, which may contribute to the Maillard reaction. Ngapo et al. (2012b) compared cooking method, age, and marbling on pork loins for sensory quality. The investigators found the influence of aging on grilled pork, as opposed to roasted pork, to be minimal, influencing attributes (pork flavor/odor, meat flavor, cardboard odor, metal flavor, and vegetable flavor aromatics), with most influence occurring at around 8-12 d of age. Ngapo and Gariepy (2008) discussed that 6-10 d age had a positive effect on overall palatability as well as had greater impact on it when compared to other factors such as breed. The researchers that supported this claim found that pork flavor increased while off-flavor aromatics and sour basic taste decreased at 6-10 d age (Jeremiah and Gibson, 1997).

Effects of cooking conditions on flavor are not as clear for pork as has been shown for tenderness and juiciness. Wood et al. (1995) conducted two experiments, one with loin steaks and one with leg roasts, with the objective aimed at determining the effect of cooking conditions on the eating quality of pork. The grilled loin chops showed that an increase in final internal temperature from $65^{\circ} \mathrm{C}$ to $80^{\circ} \mathrm{C}$ influenced pork flavor aromatics with unit values increasing by 0.6 units. This same increase in final internal temperature affected the pork flavor aromatics of roasted leg roasts with unit values increasing by 0.3 units. The researchers recommended an ideal cook temperature for loin steaks to be $72.5^{\circ} \mathrm{C}$ and $80^{\circ} \mathrm{C}$ for leg roasts for optimal flavor. The results of these experiments obtained similar data when compared to a study done by Heymann et 
al. (1990). Interestingly, Wood et al. (1995) stated that boar taint compounds, such as androstenone and skatole, may be masked at higher temperatures.

A study done by Myers et al. (2009) consisted of preparing ground beef patties and ground pork patties and cooking them to $66^{\circ} \mathrm{C}$ and $71^{\circ} \mathrm{C}$ to compare degrees of doneness and its effect on flavor. They found that these temperatures did not impart any differences in flavor. Another study done by Moeller et al. (2010) supported this work, where they measured end point temperatures of $62.8^{\circ} \mathrm{C}, 68.3^{\circ} \mathrm{C}, 73.9^{\circ} \mathrm{C}$, and $79.4^{\circ} \mathrm{C}$ for pork loins and found that there were no appreciable effects on flavor as determined by a trained panel. However, other studies that were done previously did not provide the same data (Berry, 1994; Kregel et al., 1986), as their meat was cooked to higher degrees of doneness $\left(71^{\circ} \mathrm{C}\right.$ and $\left.77^{\circ} \mathrm{C}\right)$. Degree of doneness as it relates to flavor may be influenced by the Maillard reaction (Myers et al., 2009).

Mottram (1985) determined cooked pork volatiles through the use of Tenax gas chromatography as effected by cooked temperature (grilled steaks: light $=10 \mathrm{~min} / \mathrm{side}$; medium $=15 \mathrm{~min} / \mathrm{side} ;$ well-done $=30 \mathrm{~min} / \mathrm{side} ;$ roasts: oven set to $180^{\circ} \mathrm{C}$ and cooked until internal temperature reaches $70^{\circ} \mathrm{C}$ ). His study found that highly cooked pork contained 66 different heterocyclic compounds, predominantly pyrazines and others such as thiazoles, thiophenes, furans, pyrroles, and oxazole, whereas pork cooked to lower degrees of doneness contained fewer heterocyclic compounds, such as pentylfuran and acetylthiazole, and contained more oxidative compounds. Compounds that were found in all samples were alcohols, aldehydes and other heterocyclic compounds. Production of alkylpyrazines and thiazoles, as mostly demonstrated in well-done pork, 
were products of the Maillard reactions, whereas acetylthiazole was found in less severe cooking procedures such as boiling or light grilling.

The Maillard reaction occurs on the surface of the meat where free amino acids and the reducing end of a reducing sugar, such as the carbonyl end of a sugar, condense to form a glycosylamine and is favorable in weak basic conditions, with $\mathrm{Aw}=0.4-0.8$, and relatively high temperatures (Mottram, 1998; Calkins and Hodgen, 2007; Shahidi, 1994). This compound is rearranged and dehydrated to form a variety of intermediate compounds, most notably furfurals and furanones (Mottram, 1998) that can react with components in meat (Calkins and Hodgen, 2007) such as reactive compounds that include amino-containing compounds and sulfur-containing compounds (Mottram, 1998). Intermediates from the Amadori rearrangement can participate in Schiff base pathways or Strecker degradation resulting in even more varieties of compounds. As noted, Strecker degradation is of notable importance for creating compounds that contribute to flavor and aroma. The process involves removing the carboxylic acid group and the amine group from the amino acid to create an aldehyde as a dicarbonyl that is transformed into an amino alcohol (Mottram, 1998). Of importance to meat, sulfur compounds created during Strecker degradation and the Maillard reaction are derived from cysteine and ribose (Mottram, 1998). The basic fundamentals of the Maillard reaction are still best illustrated by Hodge (1953). Carbonyls from lipid reactions have the ability to react with Maillard intermediates to create compounds that contribute to the aroma of pork (Shahidi, 1994). 


\section{Measuring Flavor}

Descriptive analysis is used in obtaining specific descriptors for aroma, flavor, and texture and quantifying the values for those descriptors. Additionally, descriptive analysis can be used in quality control, shelf-life studies, research and development, and other areas. The qualitative aspect and the quantitative aspect are the two main components of descriptive analysis. The qualitative aspect encompasses all attributes of a product that provide the big picture of what the product is (Civille and Oftedal, 2012). Examples of these characteristics may include flavor characteristics such as olfactory sensations (vanilla, for example), taste sensations such as salty basic taste, and oral feeling factors such as metallic (Civille and Oftedal, 2012). The quantitative aspect is determined by the intensity or degree with which the characteristic or attribute can be identified on a set scale (Civille and Oftedal, 2012). There are several descriptive analysis methods, ranging in complexity and statistical strength as well as expense and length of time required maintaining and using them. They include the Flavor Profile Method, Texture Profile Method, Quantitative Descriptive Analysis ${ }^{\mathrm{TM}}$, Free Choice Profiling, Spectrum Descriptive Analysis Method ${ }^{\mathrm{TM}}$, and generic descriptive analysis (Murray et al., 2001). Descriptive analysis methods can be used to define the triangular relationship between descriptive sensory, consumer sensory, and instrumental methods (Murray et al., 2001).

Descriptive analysis techniques can be used to develop a lexicon, which is defined as a set of words to describe a product (Drake and Civille, 2002). The lexicon development procedure usually includes selection of panelists, selection of samples, 
developing necessary protocols for running a trained panel, ballot development or generation of attributes and definitions, identifying references, and putting the lexicon to practice through examples and training as well as validation (Lawless and Civille, 2013). Panelists are chosen based on their ability to detect minute differences in flavors between products through the use of acuity tests, discrimination tests, ranking tests, and directional tests (Drake and Civille, 2002). There are a number of other requirements that make a potential candidate an integral part of the panel. Some essential questions to ask the panelists are: availability, health of the potential candidate, lack of allergies, and likeness for food in general (Murray et al., 2001). Sample selection is crucial to the success of lexicon development. For a particular food category, it is important to present samples that accurately represent the availability of that product on the market. Factors to consider for any food product would be variety of brands, geographical regions, gender, breed, cut, etc. depending on the type of product. If the product can be prepared in a variety of ways, then presentation of the product prepared in various ways is necessary to ensure that the researchers encompass all aspects of the product.

Creating and maintaining proper protocols throughout the lexicon development process is crucial to ensure that all samples and conditions are maintained the same way. Sample preparation, procurement, presentation, and evaluation procedures should be consistent (Lawless and Civille, 2013). Additionally, ensuring that panelists are trained prior to term development is crucial for the success of the lexicon. Generation of terms and definitions is initiated by presenting approximately 5-10 samples to panelists per session and they will generate a preliminary list, and once all samples have been 
evaluated and all terms have been determined, definitions for each attribute will be determined (Lawless and Civille, 2013). These definitions will then be used to determine references to accurately represent each attribute determined by the panel. The lexicon can then be validated using a trained panel to ensure that the terms for the attributes that are outlined in the lexicon are accurate for the product. Lexicons have been developed for a wide variety of products such as cheddar cheese (Drake et al., 2001), soymilks (N'Kouka et al., 2004), soy sauce (Cherdchu et al., 2013), and green tea (Lee and Chambers, 2007). Due to the use of standardized references and attributes for lexicons, it is possible to use lexicons across institutions and obtain similar results. Adhikari et al. (2011) developed the beef lexicon as mentioned previously. The lexicon was further validated by Philip (2011). Three universities with highly trained panelists, all of which received the same beef samples and the references that were part of the lexicon, were utilized during this study. The study showed that, when three different highly trained descriptive analysis panelists utilized the beef lexicon across different cuts of beef, panelists from each location were able to identify and rank the intensities of the attributes outlined in the lexicon.

Lexicon development for fresh meat has recently been of interest in the research community. Maughan and Martini (2012) created a lexicon to generally rank attributes for different types of fresh meat (chicken, pork, beef, lamb, and turkey). Some general attributes used included astringent feeling factors, bloody, brothy, browned, gamey, grassy, and oxidized flavor aromatics, and salty, bitter, and sour basic tastes. They found that beef and lamb closely clustered with similar attributes such as roast beef, 
grassy, and livery flavor aromatics, and pork and turkey related to other attributes on the opposite ends of the spectrum such as brothy and juicy flavor aromatics, and sweet and umami basic tastes. Adhikari et al. (2011) worked to develop the beef flavor lexicon that has been a turning point in how beef flavor is evaluated. Several important major notes that were identified were the five basic tastes, beef identity, metallic, liver-like, and green hay-like flavor aromatics. Some minor notes that were identified were: asparagus, cocoa, buttery, dairy, green, and apricot flavor aromatics. Carlucci et al. (1998) performed a sensory study on young goat meat, and developed some flavor and texture definitions. The flavor and aroma attributes that were developed were blood, goat and meaty flavor aromatics.

Several informal fresh pork lexicons have been developed for specific research aims in the area of pork flavor, most with a separate or less prioritized interest in pork flavor. Work outside of the United States has initiated more lexicon development for pork. Meinert et al. (2007a) developed a flavor and odor vocabulary for pan-fried pork. The 6 professional panelists from the Danish Meat Research Institute, who were trained in Quantitative Descriptive Analysis ${ }^{\mathbf{T M}}$, were subjected to 4 training sessions that were used to develop a vocabulary using references. These attributes included fried meat, burnt caramel, boiled meat, piggy, cardboardy, metallic, and heart/liver flavor aromatics, and umami, sweet, and sour basic tastes. Meinert et al. (2007b) developed a similar lexicon for the pork semimembranosus. Attributes that were different were acidic, roasted nut, and burnt flavor aromatics, and salty basic taste. Meinert et al. (2009) studied the flavor development in the longissimus dorsi from different sectors of raw 
meat quality and did not have attribute differences when compared to other Danish Meat Research Institute studies.

Two studies done by Ngapo et al. (2012a, 2012b) looked at the impact of 1) chilled pork on sensory quality, and 2) marbling and aging on sensory quality. The first study on chilled pork utilized 10 panelists trained using the Spectrum Method ${ }^{\mathbf{T M}}$ and attributes were developed using a modified version of Quantitative Descriptive Analysis $^{\text {TM }}$ (Ngapo et al., 2012a). Attributes that were determined were meat (odor and flavor aromatics), pork (odor and flavor aromatics), rancid (flavor aromatics), bread crust (flavor aromatics), the five basic tastes, cardboardy (odor aromatics), linseed oil (odor aromatics), rubber (odor aromatics), sulfur (odor aromatics), vegetable oil (flavor aromatics), fish (flavor aromatics), nut (flavor aromatics), metal (flavor aromatics), caramel (flavor aromatics), pig (flavor aromatics). Ngapo et al. (2012b) developed a vocabulary based upon Byrne et al. (1999a) and Bryhni et al. (2003). Byrne et al. (1999a) developed sensory attributes for warmed-over flavor in pork patties coming from the semimembranosus muscle. The researchers utilized literature for initial ballot development and utilized the trained sensory panel to narrow the terms from 45 terms to 16 terms. These specific terms were anchored with references. Principal component analysis was performed on the data and meat-like flavor aromatics clustered closely together (e.g. boiled meat, pork-like, pork lean flavor aromatics, etc.) and metallic, liverlike and blood-like flavor aromatics, and salt basic tastes, etc., were associated (Byrne et al., 1999a). Works done by Byrne et al. (1999a), Byrne et al. (1999b); and Byrne et al. (2001) were a series of papers aimed at developing a warmed-over flavor vocabulary 
with standards and references for pork. The latter study focused on the RN gene in Hampshire pigs. The final term count was 22 attributes divided into odor aromatics such as roasted-like, caramel-like, fresh cooked pork meat-like, bouillon-like, linseed oil/paint-like, egg/sulfur/rubber-like; basic tastes such as sweet, sour, salt, bitter, and umami; and flavor aromatics such as metallic, fresh cooked chicken meat-like, fresh cooked pork meat-like, rancid-like, lactic/fresh sour-like, vegetable oil-like, bread-like; and aftertastes including metallic and lactic/fresh sour like. Bryhni et al. (2003) developed a 17-attribute vocabulary consisting of meat (odor and flavor aromatics), pig (odor and flavor aromatics), metallic (odor and flavor aromatics), sweet (odor aromatics and basic taste), off (odor aromatics), acidic/sour (odor aromatics and basic taste), warmed-over (odor and flavor aromatics), bitter (basic taste), as well as texture and color attributes with corresponding definitions. This study did not present any references for panel use. A study done by Corino et al. (2002) studied the dietary supplementation (rapeseed oil, corn oil, and corn oil) on heavy pigs and its effects on sensory quality and overall meat quality. They utilized the difference from control method in conjunction with a lexicon that included words such as pig and rancid (odor aromatics), sweet and salty (basic tastes) and pork flavor (flavor aromatics) as well as some descriptors for texture. This lexicon included standards from whole muscle. The results of this study indicated that the supplement type did not influence sensory characteristics. Flores et al. (1999) developed a lexicon using the Quantitative Descriptive Analysis method for determining how post-mortem meat quality and nucleotide content affected sensory characteristics. Aromatics as determined by the panel were serum, browned, pork, 
rancid, and boar taint flavor aromatics, and strange odor aromatics. Basic tastes added to the lexicon included bitter, sour, salty, and sweet. Feeling factors included astringent feeling factors and mouthfilling (as associated with monosodium glutamate).

Instrumental methods are utilized in flavor research and can easily be used in conjunction with sensory methods. Most instrumental methods used to identify flavor and aroma compounds have four distinct steps: collection of volatiles, usually from the headspace of the food matrix, separation of volatiles, identification of each compound, and quantification of each compound (Chambers IV and Koppel, 2013). Common methods for collection and isolation of volatiles for analysis are extraction via supercritical $\mathrm{CO}_{2}$ or the use of a solid phase microextraction (SPME) sampler; (Chambers IV and Koppel, 2013; Maarse, 1991; Di Donfrancesco et al., 2012). The collected volatiles can then be inserted into the gas chromatograph-mass spectrometer (GC-MS) or a gas chromatograph-mass spectrometer with olfactory sniff ports (GC-O), where the gas chromatograph can separate the compounds and the mass spectrometer identifies each compound (Chambers IV and Koppel, 2013). This system has been used to identify flavor compounds starting at approximately 1,500 flavor compounds to more than 7,000 compounds (d'Acampora Zellner et al., 2008). The olfactory port component helps to identify the difference between volatiles that are odor-active and volatiles that are non-odor-active by the ability to incorporate human detection of odor-active compounds (d'Acampora Zellner et al., 2008; Chambers IV and Koppel, 2013). The peaks that are presented and quantified using this process do not always correlate with the intensity of an odor. As such, it makes the utilization of the sniff ports much more 
reasonable since it can be implemented to determine intensity and threshold not based on peak quantity. 


\section{CHAPTER III}

\section{MATERIALS AND METHODS}

\section{Phase I. Lexicon Development}

Pork chops (boneless and bone-in loin chops, shoulder chops, enhanced boneless and bone-in pork chops,), picnic roasts (both enhanced and non-enhanced), shoulders (whole roasts), tenderloins (whole roasts and medallions), bellies, and fresh ham legs were purchased from retail stores in the Bryan/College Station, Texas area to include HEB, Walmart, Village Foods, and Readfield's Meat and Deli. Table 1 outlined all muscle categories and treatments used during lexicon validation. All cuts were refrigerated at approximately $5^{\circ} \mathrm{C}$ until consumed and used within 1 to $3 \mathrm{~d}$ of purchase. These cuts were used to create differences in flavor and were cooked at varying temperatures. Chops and tenderloin medallions were cooked to $57.2^{\circ} \mathrm{C}, 68.3^{\circ} \mathrm{C}$, and $79.4^{\circ} \mathrm{C}$ internal temperature endpoints to create differences in degree of doneness and flavor. Chops and tenderloin medallions were cooked on a Presto Flat Griddle (Model 0702306, National Presto, Inc., Eau Claire, Wisconsin), which was set to $204.4^{\circ} \mathrm{C}$, and cuts were turned at the halfway point for endpoint internal temperature. Whole shoulders, whole tenderloins, bellies, and fresh ham legs were cooked to $62.7^{\circ} \mathrm{C}$ endpoint temperature in a gas conventional oven for roasting and on the stovetop for braising. Picnic shoulders were not braised due to their large size. Braising consisted of the product being seared in 15 grams of vegetable oil in a cast iron Dutch oven over high heat (surface temperature of Dutch oven approximately $173^{\circ} \mathrm{C}$ ) on a gas stove for 2 
minutes per side and then cooked in $500 \mathrm{~mL}$ of double distilled deionized water on medium heat (surface temperature of Dutch oven approximately $149^{\circ} \mathrm{C}$ ) until product internal endpoint temperature was reached as defined in Adhikari et al. (2011). Roasting was defined as product cooked in an aluminum roasting pan on a rack in an oven preheated to $162.7^{\circ} \mathrm{C}$ and cooked until the product reached its internal endpoint temperature as defined in Adhikari et al. (2011). Additionally, approximately 18 boneless, non-enhanced pork chops were packaged using different methods (polyvinyl chloride (PVC) overlay, modified atmosphere packaging (MAP), and vacuumpackaging) to include flavors associated with each packaging technique in the lexicon. These packaged pork chops were kept in the refrigerator at approximately $5^{\circ} \mathrm{C}$. For the PVC overlay, the product was stored on GenPak foam number 2 supermarket trays (product ID number 1002, GenPak, Glens Falls, NY) and wrapped in PVC in the refrigerator for 0 and $3 \mathrm{~d}$. Both the vacuum-packaged product and the MAP products were packaged (MultiVac Chamber Machine C200, Wolfertschweiden, Germany) in Cryovac vacuum-package bags (Model B4173T, Sealed Air Corporation, Simpsonville, SC). The MAP product was back-flushed with $80 \%$ carbon dioxide and $20 \%$ oxygen mixture (Airgas Inc., Radnor, PA). The MAP samples were kept in the refrigerator for 0 and $8 \mathrm{~d}$. The vacuum-packaged products were stored in the refrigerator for 0 and $14 \mathrm{~d}$. Flavors and aromas were also induced for warmed-over flavor, spoiled/putrid, and refrigerator stale flavor aromatics using boneless, non-enhanced pork chops and ground pork ( $20 \%$ fat). Warmed-over flavor aromatics were induced by cooking ground pork (20\% fat) in a Rival electric skillet (Model CKRVSK11, Sunbeam Products, Inc., Boca 
Raton, FL) and storing it in an uncovered glass container in the refrigerator at $5^{\circ} \mathrm{C}$ for approximately 24 hours. Refrigerated ground pork was microwaved for approximately 1 min at $100 \%$ power. Spoiled/putrid flavor aromatics were induced by placing raw ground pork (20\% fat) and a raw boneless pork chop at room temperature for $6 \mathrm{~d}$. The boneless pork chop was cooked on the Presto Electric Griddle and cooked to an internal endpoint temperature of $79.4^{\circ} \mathrm{C}$. The ground pork was cooked in the Rival ${ }^{\mathrm{TM}}$ electric skillet and cooked until browned. Spoiled/putrid flavor aromatics samples were not tasted and were smelled for aroma only. Refrigerator stale flavor aromatics samples were induced by cooking ground pork and storing it as described for warmed-over flavor aromatics samples. Panelists were served this sample at approximately $24^{\circ} \mathrm{C}$. During cooking, internal temperatures were monitored using copper-constantan thermocouples (Omega Engineering, Stanford, CT) and inserted into the chop or roast's geometric center.

Five highly trained panelists, trained in the Spectrum Descriptive Analysis Method $^{\mathrm{TM}}$ were used. The panel had extensive experience in evaluating meat products, and an array of other food products. Trained panelists evaluated the fresh pork products to determine flavor and aroma attributes found in each product. Each panelist tasted the fresh pork products individually, and then the panelists discussed the flavor attributes found in each sample. Once all panelists came to a consensus about attributes, flavor intensity was discussed on a 16-point scale $(0=$ none, $15=$ extremely intense $)$, and discussion of the specific references that would represent each attribute took place. These references were anchored based on the Spectrum Method ${ }^{\mathrm{TM}}$ from which the 
panelists were trained. The intensity of the references would be based on a 16-point anchored scale $(0=$ practically none, $15=$ extremely intense). The panel leader used resources from American Society for Testing and Materials (ASTM, 1996; ASTM, 2011) and Adhikari et al. (2011) for determining attributes, references, and definitions. Panelists participated in $18 \mathrm{~d}$ of ballot development to determine attributes for the pork lexicon.

\section{Phase II. Lexicon Validation}

Once the fresh pork products evaluated during Phase 1 had defined attributes, references, and flavor and aroma intensities with confirmed flavor and aroma differences, trained panelists were asked to evaluate pork samples using the lexicon. Tenderloins $(n=6)$, boneless pork loins $(n=6)$, and bone-in shoulders $(n=6)$ were purchased from Readfield's Meat and Deli in Bryan, TX. Inside hams $(n=6)$ were donated by Farmland Foods (Milan, MO). Each subprimal was cut to $2.54 \mathrm{~cm}$ thickness, vacuum-packaged in Cryovac vacuum-package bags (Model B4173T, Sealed Air Corporation, Simpsonville, SC), and stored at refrigeration temperature for $14 \mathrm{~d}$. The chops were then transferred to the freezer and stored at approximately $-20^{\circ} \mathrm{C}$ and used within four weeks. Once chops were cut from each subprimal, temperature treatments were randomly assigned by location for each replication.

All chops were thawed $24 \mathrm{~h}$ prior to panel evaluation by placing the vacuumpackaged pork samples in the refrigerator at approximately $5^{\circ} \mathrm{C}$. All chops were cooked to $62.7^{\circ} \mathrm{C}, 68.3^{\circ} \mathrm{C}, 73.8^{\circ} \mathrm{C}$, and $79.4^{\circ} \mathrm{C}$ internal temperature to induce differences in flavor on a Presto Flat Griddle (Model 0702306, National Presto, Inc., Eau Claire, 
Wisconsin) set to $204.4^{\circ} \mathrm{C}$. The pork attributes that the panelists measured were quantified using a 16-point anchored scale $(0=$ none and $15=$ extremely intense $)$ based on references in the lexicon. Panelists were placed in individual, breadbox-style booths with red lights to mask color differences between samples. This area was separate from the preparation room. Each panelist received double distilled deionized water, unsalted saltine crackers, and fat-free ricotta cheese for palate cleansing between samples. During cooking, internal temperatures were monitored using copper-constantan thermocouples (Omega Engineering, Stanford, CT) inserted into the chop or roast's geometric center. After cooking, products were either held for no more than $20 \mathrm{~min}$ in an Alto-Shaam Halo Heat (Model No. 750-TH-II, Alto-Shaam, Inc., Milwaukee, WI) holding oven at $48.8^{\circ} \mathrm{C}$ on a Corelle plate covered in aluminum foil or served immediately. Fat and ends were removed from each cut and the remaining portion was cut into approximately $1.27 \mathrm{~cm}$ cubes selected for serving to panelists that did not contain visible connective tissue or intramuscular fat. Panelists received three cubes per sample for evaluation in an odorless, plastic, transparent cup (56.7 g Solo soufflé cup, Dart Container Corporation, Mason, MI). Each sample was assigned a random threedigit code to prevent bias and treatments were served in random order. Panelists were given approximately 3 to $4 \mathrm{~min}$ rest between each sample to reduce sensory fatigue. Each testing day consisted of 8 samples per day randomized by cut and temperature endpoint. The study consisted of $12 \mathrm{~d}$ and 96 samples were evaluated. Between each set of 4 samples, there was a 10-minute break to reduce tastebud fatigue. Before each testing day, panelists were presented with a warm-up sample, where panelists discussed 
the sample orally and came to a consensus about each flavor attribute. The warm up sample was an extra pork chop that came from a boneless loin that was used for validation. This sample was cooked to the same internal endpoint temperature each testing day to ensure that panelists were ranking similarly and to reduce day variation.

Samples used to validate the lexicon, a total of 94 out of 96 samples which differed in flavor attributes, were used for volatile, aromatic compounds analysis using GC-O technology with Aroma-Trax and sniff port technology (MicroAnalyticsAromatrax, Round Rock, TX). Samples were obtained during trained panel validation. This ensured samples evaluated for volatile components were similar to samples evaluated by trained descriptive analysis. Approximately $75 \mathrm{~g}$ of each sample was wrapped in aluminum foil and placed in liquid nitrogen and frozen to $-80^{\circ} \mathrm{C}$. Samples were stored at $-80^{\circ} \mathrm{C}$ until evaluation for up to 2 weeks. Samples were partially thawed in a waterbath at $60^{\circ} \mathrm{C}$ and put into glass jars $(472 \mathrm{~mL})$ with a Teflon septum under a metal screw-top lid heated to $60^{\circ} \mathrm{C}$. The headspace was sampled with a Solid-Phase Micro-Extraction (SPME) Portable Field Sampler (Supelco 504831, $75 \mu \mathrm{m}$ Carboxen/polydimethylsiloxane, Sigma-Aldrich, MO) for $2 \mathrm{~h}$ after the sample reached equilibrated to $60^{\circ} \mathrm{C}$. Alkane standards (C7 to C30; Catalog \#49451-U; Sigma Aldrich, St. Louis, MO, 63103) were run to verify the retention times of sample alkanes and were run prior to and after the experimental samples were run to verify, with retention times, the compounds evaluated by the MS. The SPME was injected into the injection port of the gas chromatograph (GC) (Agilent Technologies 7820A GC System, Santa Clara, CA) where the volatiles were desorbed at $280^{\circ} \mathrm{C}$. The sample was processed by the first 
gas chromatograph (GC) column (30m X 0.53mm ID/ BPX5 (5\% Phenyl

Polysilphenylene-siloxane) X 0.5 $\mu \mathrm{m}$, SGE Analytical Sciences, Austin, TX) and separated compounds based on the boiling point. Through the first column, the temperature started at $40{ }^{\circ} \mathrm{C}$ and increased at a rate of $7^{\circ} /$ minute until reaching $260{ }^{\circ} \mathrm{C}$. The first column had a program that was designed to leave the heart-cut and cryo-trap open to move compounds to the second column $\{(30 \mathrm{~m} X 0.53 \mathrm{~mm}$ ID)(BP20Polyethylene Glycol) X $0.50 \mu \mathrm{m}$, SGE Analytical Sciences, Austin, TX $\}$, which separated compounds by polarity. The GC column then partitioned the sample volatiles into three different columns. One column went to the mass spectrometer (MS) (Agilent Technologies 5975 Series MSD, Santa Clara, CA) to determine compounds and the other columns went to two humidified sniff ports heated to $115^{\circ} \mathrm{C}$. Two panelists sat at each glass sniff port to determine aromas events as the compounds were separated. Aroma events were defined when trained panelists identified an odor at the sniff port as compounds were eluted off the GC column. Specific attributes and intensities associated with aroma events were not determined. From this AromaTrax information, aromaactive compounds were determined. The sniff ports, as well as the software for determining aromas, were part of the AromaTrax program (MicroAnalytics-AromaTrax, Round Rock, TX). The panelists that participated in the sniff port portion were part of the development training and testing for the intact muscle fresh pork flavor lexicon. Statistical Analyses

Data were analyzed using SAS (v9.3, SAS Institute, Cary, NC) using an $\alpha<$ 0.05. Means and simple correlation coefficients were calculated using PROC MEANS 
and PROC CORR. Stepwise regression was conducted using PROC REG. Independent variables were significant at $\mathrm{P}<0.15$. For Phase II, main effects were defined as cut and internal temperature endpoints and their interaction. Analysis of variance was conducted using PROC GLM. The first analysis tested the effect of panelists and panelists by treatment interactions to assure that panelists evaluated cuts and internal temperature effects similarly. As differences were not reported, sensory data were averaged across panelists within an experimental unit. Data were analyzed with sensory day as a block, with cut, internal cook temperature endpoint, and cut by internal cook temperature endpoint interaction as main effects. When main effects were significant $(\mathrm{P}<0.05)$, least squares means were calculated and differences between least squares means were determined using the pdiff function of SAS by performing T-tests. Partial least squares regression was conducted using XLSTAT (2009, Addinsoft, Accresco Software, Inc., New York, NY) where the flavor attributes of pork identity, brown/roasted, fat-like, bloody/serumy, metallic, cardboardy, and liver-like flavor aromatics, and astringent feeling factors, and sweet, sour, salty, bitter and umami basic tastes were defined as dependent variables and volatile aromatic compounds were used as independent variables. Data were presented in a bi-plot with treatments defined to understand relationships between major flavor attributes from the Pork Flavor Lexicon attributes, volatile aromatic compounds, and treatments. 


\section{CHAPTER IV}

\section{RESULTS AND DISCUSSION}

\section{Lexicon Attributes}

Twenty-four flavor and aroma attributes including the 5 basic tastes were determined to be components of the pork flavor lexicon (Table 2). Pork identity, brown/roasted, fat-like, bloody/serumy, and metallic flavor aromatics, and astringent feeling factors, and sweet, sour, salty, and bitter basic tastes were major notes found in most samples. It was expected that attributes such as bloody/serumy, metallic, and fatlike flavor aromatics, and salty and sweet basic tastes were present in pork cuts since these were shown to be present in raw pork (Gorbatov and Lyaskovskaya, 1980; Imafidon et al., 1994). The basic tastes have also been shown to be taste attributes in cooked pork in a number of studies (Flores et al., 1999; Ngapo et al., 2012a; Ngapo et al., 2012b).

Other attributes were found in some samples but not as frequently. Interestingly, all panelists found vinegary flavor aromatics in the roasted enhanced picnic and the boneless loin roast. Shahidi et al. (2013) found acetic acid to be present in pork. However, that study did not relate chemical aromatic compounds to lexicons or published aromas. Lexicon studies on pork, as found during this research, have not previously found any flavor or aroma terms related to vinegary flavor aromatic. When panelists in the present study discussed vinegary flavor aromatics, it was defined as separate from citric acid that is usually associated with sour basic taste. Flavor aromatic 
attributes associated with oxidation, such as cardboard (Maughan and Martini, 2012; Rhee et al., 2005; Johnson and Civille, 1986), heated oil, warmed-over flavor (Byrne et al., 2001), refrigerator stale, and floral (Calkins and Hodgen, 2007) flavor aromatics were expected as some lipid oxidation was induced to create flavor differences for panelists to evaluate and determine appropriate levels. However, oxidation can occur upon cooking, yielding some flavors derived from lipid oxidation (Mottram, 1998). Thus, some of these flavors were present in non-induced lipid oxidation samples.

Warmed-over flavor aromatics are generally associated with oxidation products that are formed from polyunsaturated fatty acids (Byrne et al., 2001). Warmed-over flavor aromatics that may be associated with lipid oxidation were induced by cooking, refrigerating overnight, and reheating for panelists to evaluate for the lexicon; however, panelists found warmed-over flavor aromatics to be present in a few samples that were not induced with prior preparation. According to Byrne et al. (2001), warmed-over flavor aromatics were determined to be complex with many facets. The original work on warmed-over flavor done by Johnson and Civille (1986) reported similar attributes. The researchers used ground patties of pork, turkey, chicken, and beef and whole roasts of beef. These attributes included cardboard, cooked beef lean, cooked beef fat, and serum/bloody flavor aromatics, and 4 of the 5 basic tastes. Byrne et al. (2001) determined that a warmed-over flavor vocabulary included 15 flavor, aroma, taste, and aftertaste attributes. This vocabulary consisted of similar terms to the present lexicon, including the 5 basic tastes, metallic, nut-like, vegetable oil-like, rancid, and cardboardlike flavor aromatics, and astringent feeling factors. The similarities in these findings 
may indicate that descriptors for overall pork flavor aromatics may be present in all pork samples regardless of preparation such as inducing warmed-over flavor aromatics.

Additionally, some attributes that contribute to overall pork flavor aromatics may carry over to warmed-over flavor aromatics attributes and vice versa.

The soapy flavor aromatic was an attribute determined by the panelists to be due to the enhancement of some of the intact muscle pork products. Studies done by Prestat et al. (2002) and Sutton et al. (1997) included a soapy flavor aromatics descriptor in the terminology used for trained panelists when evaluating pumped pork loins, indicating that soapy flavor aromatics may play a role in the evaluation of enhanced pork products.

Burnt flavor aromatics were determined by panelists to be in braised products such as pork bellies and pork chops cooked to higher degrees of doneness on the Presto flat griddle. The braised samples had full surface contact with the Dutch oven on the stove for 2 minutes on each side, which may explain the detection of this attribute by panelists. Additionally, loin chops cooked to a higher degree of doneness had exposure to the surface of the griddle for a longer time than chops cooked to a lower degree of doneness, which may have influenced the amount of burnt flavor aromatics present on the surface of the pork chops.

Many attributes were similarly found in the beef flavor lexicon developed by Adhikari et al. (2011). These included: the five basic tastes, bloody/serumy, brown/roasted, burnt, chemical, fat-like, liver-like, warmed-over, refrigerator stale, soapy, heated oil, and floral flavor aromatics. It was not surprising to find similarities between the two lexicons since many of the same terms may be attributed to innate basic 
tastes, storage conditions, and attributes that are representative in raw animal meat. The differences in other attributes could be attributed to the difference in species, as well as differences in cook methods and endpoint temperatures. Adhikari et al. (2011) used 3 basic cook methods for all samples and 5 different endpoint temperatures. Additionally, a wider range of categories was used. The pork lexicon study did not include quality grade differences, aging differences, or animal maturity differences.

Astringent feeling factors were found in several studies that used or developed lexicons for pork (Flores et al., 1999; Maughan and Martini, 2012; Jeremiah et al., 1990). It was interesting to see that some studies, such as Byrne et al. (1999a) and Jeremiah et al. (1990), described astringent feeling factors as aftertastes and Flores et al. (1999) specifically determined astringent feeling factors as feeling factors. Astringent feeling factors were found by all panelists to be present in most pork samples presented during lexicon development.

Panelists did not find any off-flavors or oxidative flavors when evaluating products packaged in different packaging systems. When considering pork products that were packaged using modified atmosphere, the mixture that was used was $80 \%$ carbon dioxide and $20 \%$ oxygen. Because modifying the atmosphere for meat products can have both positive and negative consequences (color stability and organoleptic quality via microbial growth, respectively), it was imperative to include this packaging technique for lexicon development. High oxygen ratios tend to catalyze lipid oxidation, yielding off-flavors derived from this reaction, and carbon dioxide has been shown to inhibit microbial growth (Zhao et al., 1993). Because the ratio of oxygen to carbon 
dioxide was not high, it may explain why panelists did not detect oxidative flavors or aromas. Panelists only found pork identity, brown/roasted, fat-like, bloody/serumy, and metallic flavor aromatics and astringent feeling factors, and sweet, sour, salty, and bitter basic tastes.

Adhikari et al. (2011) found other attributes in beef that were indicative of oxidative rancidity, which included liver-like, rancid, warmed-over, and spoiled flavor aromatics. However, in the present study, long frozen pork chops were shown to have cardboardy flavor aromatics as determined by the trained panelists. Cardboardy flavor aromatics have been shown in a number of studies to be present in oxidative samples (Johnson and Civille, 1986; Rhee et al., 2005; Byrne et al., 2001). Floral, chemical, and heated oil flavor aromatics were present in some samples. These minor attributes may be off-flavors that could be expected since long frozen pork chops were frozen for over 2 years. It was interesting to see that the panelists found only cardboardy flavor aromatics to be a result of lipid oxidation, when compared to rancid flavor aromatics. Other studies have determined rancid flavor aromatics to be a flavor attribute to describe meat flavor aromatics (Byrne et al., 1999a; Ngapo et al., 2012a). Heated oil flavor aromatics were also shown to be present in pork bellies that were braised and roasted. Upon visual inspection, most fat on the pork bellies that melted in the pan or dutch oven was cooked until the product reached its internal endpoint temperature and could explain the heated oil flavor aromatics attribute. Other studies may have used similar terms to describe heated oil flavor aromatics, including vegetable oil-like flavor aromatics (Byrne et al., 2001) and vegetable oil flavor aromatics (Ngapo et al., 2012a, Ngapo et al., 2012b). 
Several studies were found to have similarities in lexicon terms when compared to the present study. Meinert et al. (2007a) used cuts from the semimembranosus cooked to $70^{\circ} \mathrm{C}$ and pan heat temperatures of $150^{\circ} \mathrm{C}$ and $250^{\circ} \mathrm{C}$. The internal endpoint temperature was approximately $1.7^{\circ} \mathrm{C}$ different from the middle temperature used in the lexicon development for pork chops. The surface temperature of the griddle in the current study used was approximately $204.4^{\circ} \mathrm{C}$ that was roughly the median for the pan temperatures used in Meinert et al. (2007a). Thus, there were similarities in some attributes such as sweet basic tastes, and acidic, roasted nut, fried meat, and piggy flavor aromatics. Additionally, Ngapo et al. (2012a, 2012b) outlined attributes for all five basic tastes and pork odor and flavor aromatics that coincide with the basic tastes and pork identity flavor aromatics outlined in the pork lexicon (Table 2). The pork loin chops that were used by Ngapo et al. (2012a, 2012b) were cooked to $72^{\circ} \mathrm{C}$ on a panini grill that reached $160^{\circ} \mathrm{C}$. Pork loin roasts were also roasted to a final core temperature of $72^{\circ} \mathrm{C}$. Caramel, bread crust, and sulfur flavor aromatics were attributes associated with increased internal endpoint temperature. Caramel and bread crust flavor aromatics may be similar to the term brown/roasted flavor aromatics defined in this lexicon as bread crust typically has a browned surface from the Maillard reaction since the Maillard reaction tends to occur on the surface of the meat or other food product.

The all-meats lexicon developed by Maughan and Martini (2012) included similar terms to this pork lexicon including astringent feeling factors, and bloody, browned, grassy, fatty, livery, metallic and brothy flavor aromatics, and the five basic tastes. Across all studies, it can be concluded that the basic tastes, meat/pig/pork flavor 
and aroma attributes as determined by trained panelists are important for pork flavor. However, the pork studies with terms were developed or used only for each researcher's individual purposes and not necessarily to be used across studies. Additionally, these lexicons provided only qualitative references, and instructions for preparation of references may or may not have been present. Furthermore, these studies did not provide any magnitude or scaling for each reference. The references with defined levels in the present lexicon are a major key to applying the lexicon across studies.

\section{Lexicon Validation}

Flavor aromatic attributes and basic tastes were affected $(\mathrm{P}<0.05)$ by cut $($ Table 3). The interaction between cut and internal endpoint temperature was evaluated but was not reported $(\mathrm{P}>0.05)$. Pork identity, brown/roasted, fat-like, bloody/serumy, liverlike, metallic, and nutty flavor aromatics, and astringent feeling factors, and sweet, sour, salty, and umami basic tastes differed across cuts $(\mathrm{P}<0.05)$; (Table 3). Bitter basic taste did not differ across cuts $(\mathrm{P}>0.05)$. Heated oil, cardboardy, soapy, chemical, burnt, floral, warmed-over, refrigerator stale, vinegary, boar taint, spoiled/putrid, medicinal, grassy, bell pepper, dirt, and musty flavor aromatics were not detected. Pork samples had moderate levels of pork identity flavor aromatics. Attributes that were barely detectable in samples were umami basic taste, and liver-like, nutty, and fat-like flavor aromatics. Shoulder roasts cut into pork chops were ranked slightly higher in pork identity and fat-like flavor aromatics and lower in umami basic taste $(\mathrm{P}<0.05)$. During cooking, shoulder chops had more visible fat when compared to the other cuts. Bloody/serumy flavor aromatics were slightly higher $(\mathrm{P}<0.05)$ in shoulder chops and 
inside ham chops when compared to tenderloin medallions and loin chops. Loin chops and shoulder chops were slightly higher $(\mathrm{P}<0.05)$ in brown/roasted flavor aromatics when compared to tenderloin medallions and inside ham chops. Loin chops and inside ham chops were slightly higher $(\mathrm{P}<0.05)$ in sour basic taste when compared to shoulder chops and tenderloin medallions. Inside ham chops were slightly higher $(\mathrm{P}<0.05)$ in metallic flavor aromatics and astringent feeling factors, and sour basic taste than tenderloin medallions and loin chops. This was expected since other studies have indicated similar results. For example, semimembranosus muscles cooked in a pan heated to $150^{\circ} \mathrm{C}$ had higher metallic flavor aromatics and sour basic taste when compared to those muscles cooked in a pan heated to $250^{\circ} \mathrm{C}$ (Meinert et al., 2007a). Nutty flavor aromatics were not found during lexicon development but were found during lexicon validation; thus, it was included as part of the lexicon. Interestingly, Meinert et al. (2007b) determined roasted nut flavor aromatics to be an attribute in pork and roasted nut flavor aromatics were higher in grilled pork when compared to pan-fried pork chops cooked to the same internal endpoint temperature. However, intensities of the attribute as determined by trained panelists were low, which coincided with the data from this study.

Internal endpoint temperatures $\left(62.7^{\circ} \mathrm{C}, 68.3^{\circ} \mathrm{C}, 73.8^{\circ} \mathrm{C}\right.$, and $\left.79.4^{\circ} \mathrm{C}\right)$ used for lexicon validation created differences in attributes (Table 3). Brown/roasted, bloody/serumy, and metallic flavor aromatics, and astringent feeling factors, and sour and bitter basic tastes differed across internal endpoint temperatures $(\mathrm{P}<0.05)$. Pork identity, fat-like, liver-like, and nutty flavor aromatics, and sweet, salty, and umami 
basic tastes did not differ $(\mathrm{P}>0.05)$. As internal endpoint temperatures increased, brown/roasted flavor aromatics increased, while bloody/serumy flavor aromatics and astringent feeling factors, and sour and bitter basic tastes decreased $(\mathrm{P}<0.05)$. The increase in brown/roasted flavor aromatics was expected as chops that were cooked to a higher degree of doneness were exposed to heat for a longer time. Burnt caramel and fried meat flavor aromatics from Meinert et al. (2007a) may represent or be a component of the attribute brown/roasted flavor aromatics as these attributes increased when pan temperature was increased from $150^{\circ} \mathrm{C}$ to $250^{\circ} \mathrm{C}$. This study also showed that sour basic taste and metallic flavor aromatics decreased with increased pan temperature. Furthermore, a decrease in bloody/serumy flavor aromatics and astringent feeling factors, and sour basic taste was expected as Miller et al. (2014) showed that increasing the degree of doneness of beef resulted in the same trends indicated in this study.

The pork flavor lexicon was successfully developed to find differences in pork cuts that were treated with different methods to induce differences in pork flavor and aroma. All pork cuts had flavor or aroma attributes that seem to be fundamental to pork flavor including pork identity, brown/roasted, bloody/serumy, fat-like, and metallic flavor aromatics, and astringent feeling factors, and the 5 basic tastes. Additionally, the validation of the lexicon showed that cut and internal temperature endpoints that were chosen to create differences in flavor and aroma differed. 


\section{Volatile Aromatic Compounds}

One hundred and fifty-seven aromatic compounds were defined by the GC/MS and presented in Table 4. These aroma compounds were components of aroma events. Aroma events were defined when trained panelists identified an odor at the sniff port as compounds were eluted off the GC column. Table 4 also included the mean total ion area counts under the curve and the standard deviation for each compound. Some key classes of compounds found were sulfur-containing compounds, nitrogen-containing compounds, aldehydes, alcohols, ketones, acids, alkanes, alkenes, furans, pyrazines, and benzenes (Table 5). Shahidi (1994) reported that common chemical compound categories that have been identified to describe pork flavor aromatics were alcohols, carbonyls, carboxylic acids, sulfur-containing compounds, esters, ethers, lactones, and some heterocyclic compound categories including pyridines, oxazoles, thiazoles, thiophenes, and pyrazines. Mottram (1985) found a total of 66 compounds, which consisted mostly of pyrazines, pyridines, thiazoles, thiopenes, furans, pyrroles, and oxazoles in roasted pork legs cooked to $70^{\circ} \mathrm{C}$ and grilled chops cooked for 10 min per side for grilled light, 15 min per side for grilled medium, and $30 \mathrm{~min}$ per side for grilled well-done. The present study included pork cuts cooked to different internal endpoint temperatures that would expectantly explain the differences in quantities and types of compounds. In the present study, lipid-derived volatiles such as aldehydes, hydrocarbons, ketones, and alcohols were present in treatments as all treatments were cooked below $100^{\circ} \mathrm{C}$ (Shahidi, 1994). Shahidi (1994) suggested that below this temperature, lipid-derived volatiles were the major components in pork flavor. 
Additionally, Elmore et al. (2000) determined 96 volatile compounds to be present in cooked pork. These included Alkanes, aldehydes, alcohols, ketones, furans, nitrogencontaining compounds, sulfur-containing compounds, and acids.

Flavor aromatic compound categories were affected by cut (Table 5). Sulfurcontaining compounds, nitrogen-containing compounds, aldehydes, alcohols, ketones, pyrazines, and benzenes differed across cuts $(\mathrm{P}<0.05)$. Acids, alkanes, alkenes, and furans did not differ across cuts $(\mathrm{P}>0.05)$. Sulfur-containing compounds were present in all cuts except for inside ham chops. Research has shown that sulfur-containing compounds have a large impact on overall "meaty" flavor (Shahidi, 1994). When compared to other species, beef was reported to have the most overall compounds as well as sulfur compounds, whereas pork was reported to have a third of the amount of sulfur compounds when compared to beef (Shahidi, 1994). Nitrogen-containing compounds were highest $(\mathrm{P}<0.05)$ in loin chops and inside ham chops when compared to shoulder chops and tenderloin medallions. Nitrogen-containing compounds could have originated from peptides, free amino acids, proteins, thiazoles, pyrroles, or others. Some nitrogen-containing compounds have the ability to react in the Maillard reaction to form new compounds. It was not surprising to see that pyrazines, also a class nitrogencontaining compounds, were lower in pork cuts. Additionally, some nitrogen-containing compounds provide umami basic tastes (Shahidi, 1994). A large number of heterocyclic compounds, such as benzenes, have been shown to be derived from the Maillard reaction (Shahidi, 1994). A wide variety of compounds fall under the benzene umbrella to include pyrazine compounds. Benzenes and pyrazines were present at lower levels in 
shoulder chops. Aldehyde levels were the highest value for chemical categories. Similarly, Shahidi (1994) stated that aldehydes represent a large portion of compounds present in pork.

Aldehydes and acids differed across internal endpoint temperatures $(\mathrm{P}<0.05)$ (Table 5). Sulfur-containing compounds, nitrogen-containing compounds, alcohols, ketones, alkanes, alkenes, furans, pyrazines, and benzenes did not differ across internal endpoint temperatures $(\mathrm{P}>0.05)$. Alkenes were present at higher levels $(\mathrm{P}>0.05)$ in chops cooked to $62.7^{\circ} \mathrm{C}$ when compared to other internal endpoint temperatures. Benzenes, ketones, and nitrogen-containing compounds had similar levels $(\mathrm{P}>0.05)$ across all degrees of doneness. The lowest internal endpoint temperature had the highest levels $(\mathrm{P}<0.05)$ of acids. "Sour" flavors or basic tastes have been shown to be present in raw pork or pork cooked to lower degrees of doneness since organic acids have been shown to elicit sour basic taste (Shahidi, 1994). Chops cooked to $79.4^{\circ} \mathrm{C}$ had the highest levels of pyrazines since pyrazines tend to be present in meat cooked to higher degrees of doneness. Meinert et al. (2007a) showed that the semimembranosus muscle cooked in a pan that was heated to either $150^{\circ} \mathrm{C}$ or $250^{\circ} \mathrm{C}$ temperature and cooked to an internal temperature of $70^{\circ} \mathrm{C}$ resulted in increased levels of aldehydes and ketones. The present study did not find this relationship, however, surface temperature of the grill was approximately the same when cooking all chops. Aldehydes were present at higher levels in cuts cooked to $62.7^{\circ} \mathrm{C}$ and ketones were present at higher levels in cuts cooked to $73.8^{\circ} \mathrm{C}$. 
The interaction of pork cut by internal temperature endpoint was reported for compound classifications (Figure 1). Nitrogen-containing compounds, aldehydes, and benzenes differed across treatments and internal temperature endpoint $(\mathrm{P}<0.05)$. Sulfur-containing compounds, alcohols, ketones, acids, alkanes, alkenes, furans, and pyrazines did not differ $(\mathrm{P}>0.05)$. Quantitatively, aldehydes were more prevalent in all treatments; however, no clear trend was observed for amount of aldehydes present. As internal endpoint temperatures increased, aldehyde levels tended to increase for tenderloin medallions and decrease $(\mathrm{P}<0.05)$ for loin chops cooked to $62.7^{\circ} \mathrm{C}, 68.3^{\circ} \mathrm{C}$, and $73.8^{\circ} \mathrm{C}$. As internal endpoint temperatures increased, benzene levels in loin chops decreased $(\mathrm{P}<0.05)$. Benzene levels were lowest $(\mathrm{P}<0.05)$ in tenderloin medallions cooked to $62.7^{\circ} \mathrm{C}$ and were higher $(\mathrm{P}<0.05)$ for all other internal endpoint temperatures. Benzene levels in inside ham chops tended to increase $(\mathrm{P}<0.05)$ as internal endpoint temperatures increased, with the exception of inside ham chops cooked to $79.4^{\circ} \mathrm{C}$. However, as internal endpoint temperatures for $68.3^{\circ} \mathrm{C}, 73.8^{\circ} \mathrm{C}$, and $79.4^{\circ} \mathrm{C}$ increased for shoulder chops, benzene levels increased $(\mathrm{P}<0.05)$. Across all treatments, pork cuts were lowest $(\mathrm{P}<0.05)$ in nitrogen compounds. For pork loin chops, as internal endpoint temperatures increased, nitrogen compounds tended to decrease $(\mathrm{P}<0.05)$. This was not the case for other cuts. Nitrogen levels tended to increase slightly $(\mathrm{P}<0.05)$ for inside ham chops across all internal endpoint temperatures. These trends showed that cuts cooked to the same internal endpoint temperature had differences in compound category levels and trends that occurred as internal endpoint temperature increased, indicating that each cut may have varied levels of compounds that may play a role in pork flavor. 
Cornet and Bousset (1999) showed that across three different pork muscle fiber types, amino acid content varied in quality and quantity, indicating that flavor differences could be present. This information may correlate to differences across cut and internal endpoint temperature in nitrogen-containing compounds and possibly benzene compounds. These results imply that differences in classes of compounds were not appreciably impacted as internal cook temperature increased for specific pork cuts, however, individual compounds may have been affected.

\section{Simple Correlation Coefficients}

In order to better understand the relationship between trained descriptive attributes and aromatic compounds, simple correlation coefficients were reported in Table 6. Pork identity flavor aromatics were moderately related $(\mathrm{P}<0.05)$ to $2,4-$ decadienal, 1-pentanol, 4-dodecene, (E)-, and butanoic acid. Carboxylic acids, such as butanoic acid, have been identified as contributors to pork flavor (Shahidi, 1994). Czerny et al. (2008) stated that butanoic acid has an odor quality of sweaty. The compound 2,4-decadienal, a lipid oxidation product and an aldehyde, has been shown to be associated with deep fat flavor (Calkins and Hodgen, 2007) and/or green, roasted aroma (Xie et al., 2008). 1-pentanol, also a lipid oxidation product and alcohol, has been shown to have a balsamic, fruit flavor or odor (Calkins and Hodgen, 2007). These results indicate that these aromatic compounds and their published aromas may play a role in describing the flavor and aroma of pork identity flavor aromatics.

Fat-like flavor aromatics were moderately correlated $(\mathrm{P}<0.05)$ to $2,3-$

dimethylbenzaldehyde. 2,3-dimethylbenzaldehyde was expected to have an impact on 
fat-like flavor aromatics as Calkins and Hodgen (2007) showed that benzaldehyde tends to have a volatile almond oil or bitter, burning aromatic. 2-decen-1-ol was moderately associated $(\mathrm{P}<0.05)$ with bloody/serumy flavor aromatics. 2,4-decadienal and tetradecanal were negatively and moderately correlated to metallic flavor aromatics. As the concentration of 2,4-decadienal increased, metallic flavor aromatics decreased and pork identity flavor aromatics increased. Tetradecanal is an aldehyde lipid oxidation product that has been identified in cooked pork (Shahidi, 1994) and has been identified as having a roasted, fried meat aroma (Xie et al., 2008). As tetradecanal and 2,4decadienal decreased, metallic flavor aromatics increased. As mentioned earlier, 2,4decadienal was positively related $(\mathrm{P}<0.05)$ to pork identity flavor aromatics, which may indicate that as pork identity flavor aromatics increased, metallic flavor aromatics decreased. 1,2-dimethylpyrrolidine was negatively and moderately related $(\mathrm{P}<0.05)$ to astringent feeling factors. As 1,2-dimethylpyrrolidine increased, astringent feeling factors decreased. Because pyrrole derivatives are formed from the Maillard reaction and proteins are denaturing as the product is heated, there could be a decrease in proteins available to precipitate that could cause an astringent feeling factors perception.

Decanal, a lipid oxidation product, has been associated with powerful, waxy, citrus peel flavor and aroma (Calkins and Hodgen, 2007) that was negatively and moderately associated $(\mathrm{P}<0.05)$ to sweet basic taste. Decanal, 2,4-nonadienal, and nonanal were all negatively and moderately correlated $(\mathrm{P}<0.05)$ to umami basic taste. 2,4-nonadienal has been shown to have fatty, green, floral, grassy, and waxy odors (Czerny et al., 2008; Calkins and Hodgen, 2007), and nonanal has been shown to have 
citrus-like or soapy aromatics (Czerny et al., 2008). 2,3-dimethylbenzaldehyde and octadecanal were highly related $(\mathrm{P}<0.05)$ to umami basic taste. As decanal increased, sweet and umami basic tastes decreased, whereas octadecanal increased as umami basic taste increased. Octadecanal has an oil flavor or aroma (Calkins and Hodgen, 2007) and is a lipid oxidation aldehyde (Shahidi, 1994). These results indicate that aldehydes, such as decanal, may play a role in masking or reducing umami and sweet basic tastes, and that octadecanal may be a factor in determining umami basic taste. The compound 2,3dimethylbenzaldehyde was also moderately correlated $(\mathrm{P}<0.05)$ with fat-like flavor aromatics, indicating that as 2,3-dimethylbenzaldehyde increased, both umami basic taste and fat-like flavor aromatics increased.

Simple correlation coefficients for classes of compounds as they relate to trained descriptive attributes are reported in Table 7. Nitrogen-containing compounds were negatively and weakly correlated $(\mathrm{P}<0.05)$ with fat-like flavor aromatics and bloody/serumy flavor aromatics. Pork identity flavor aromatics were negatively correlated $(\mathrm{P}<0.05)$ to alcohols and ketones. Pyrazines were negatively and weakly related $(\mathrm{P}<0.05)$ to fat-like flavor aromatics and positively related $(\mathrm{P}<0.05)$ to bloody/serumy flavor aromatics. It was not expected that, as pyrazines increased, bloody/serumy flavor aromatics increased since pyrazines are usually indicative of increased internal degrees of doneness and high heat treatments. Brown/roasted flavor aromatics were moderately correlated $(\mathrm{P}<0.05)$ to nitrogen-containing compounds and pyrazines. This was not surprising, as pyrazines tend to provide browned or roasted flavors from the Maillard reaction. Benzenes were negatively and weakly related $(\mathrm{P}<$ 
$0.05)$ to fat-like flavor aromatics. Sweet basic taste was negatively and weakly associated $(\mathrm{P}<0.05)$ with nitrogen-containing compounds, alcohols, and ketones. Sour basic taste was negatively associated $(\mathrm{P}<0.05)$ with aldehydes and acids. This was not surprising since some acids have been described as sour basic taste (Shahidi, 1994). Additionally, umami basic taste was negatively correlated to alcohols and ketones.

\section{Stepwise Linear Regression Equations}

Stepwise linear regression equations to predict descriptive flavor attributes for pork identity, brown/roasted, fat-like, bloody/serumy, and metallic flavor aromatics, and astringent feeling factors, and sour, salty, and bitter basic tastes were calculated (Tables 8-16, respectively). These equations used 50, 42, 43, 58, 33, 37, 75, 53, and 42 volatile aromatic compounds to account for $93,91,83,94,77,87,96,88$, and $83 \%$ of pork identity, brown/roasted, fat-like, bloody/serumy, and metallic flavor aromatics, and astringent basic tastes, and sour, salty, and bitter basic taste descriptive attributes, respectively $(\mathrm{P}<0.05)$.

Six compounds, butanoic acid, 2,4-decadienal, ethylidene cycloheptane, N,N'dimethylcyclobutane-1,1-bis (methylamine), and 1-heptanol, accounted $(\mathrm{P}<0.05)$ for $41 \%$ of variation in pork identity flavor aromatics when used in a stepwise linear regression equation (Table 8). Step two in the stepwise linear regression for pork identity flavor aromatics was the addition of 2,4-decadienal. 2,4-decadienal was moderately related $(\mathrm{P}<0.05)$ to pork identity flavor aromatics $(\mathrm{r}=0.29)$. Additionally, butanoic acid entered the stepwise linear regression equation for pork identity flavor aromatics at step 1 and was moderately related $(\mathrm{P}<0.05)$ to pork identity flavor 
aromatics $(\mathrm{r}=0.33)$. These data indicated that there might be a moderate relationship between pork identity flavor aromatics and butanoic acid and 2,4-decadienal. 1heptanol, a lipid oxidation alcohol (Shahidi, 1994), has been shown to have flavor and aroma characteristics of woody, oily, green, herb, and winey (Calkins and Hodgen, 2007) and as pork identity flavor aromatics increased, 1-heptanol decreased. The same trend was shown in the simple correlation coefficients for classes of compounds as pork identity flavor aromatics increased, alcohols decreased $(r=-0.22 ; \mathrm{P}<0.05)$. Other classes of compounds that were present were benzaldehyde derivatives, alkanes, and aldehydes.

Six aromatic compounds, 2,3-dimethylbenzaldehyde, 4-ethyl-benzaldehyde, 2,4nonadienal, 2-heptanone, nonanal, and trans-2-undecen-1-ol accounted $(\mathrm{P}<0.05)$ for $38 \%$ of the variation in fat-like flavor aromatics (Table 9). Interestingly, two of those were benzaldehyde derivatives. These were the only class of compounds to be moderately related to fat-like flavor aromatics $(\mathrm{r}=0.38 ; \mathrm{P}<0.05)$. A large number of aldehyde compounds entered the equation as well such as nonanal, undecanal, and hexadecanal, indicating that lipid oxidation products play a major role in fat-like flavor aromatics. The flavor aromatics associated with brown/roasted had a large number of compounds that entered the stepwise linear regression equation (Table 10). 3-ethyl-2,5dimethyl-pyrazine entered the stepwise equation at step 1, followed by aldehydes and benzaldehydes. This was expected since the Maillard reaction products such as pyrazines, yield flavors that contribute to roasted flavors. Benzaldehydes were also 
associated with fat-like flavor aromatics, which may indicate a positive relationship between brown/roasted flavor aromatics and fat-like flavor aromatics.

Pyrazine compounds entered the stepwise equation for bloody/serumy flavor aromatics (trimethyl pyrazine at step 6, 2,3,5-trimethylpyrazine at step 18, 2-ethyl-3,5dimethyl-pyrazine at step 19, and 2,5-dimethylpyrazine at step 33) and they are usually associated with Maillard browning and increased temperatures $(\mathrm{P}<0.05$; Table 11). However, $\beta$ values for these compounds indicated that as bloody/serumy flavor aromatics increased, pyrazine compounds decreased $(\mathrm{P}<0.05$; Table 11). The simple correlation coefficients also showed that bloody/serumy flavor aromatics were negatively associated with pyrazine derivatives. Additionally, 2-decen-1-ol entered the stepwise linear regression equation at step 1 as well as other alcohol compounds including 1-heptanol, 1-pentanol, and 1-octen-3-ol. 1-octen-3-ol has been associated with mushroom or smoke flavor aromatics (Bueno et al., 2011). Other classes of compounds included alkanes, aldehydes, and ketones, indicating lipid oxidation played a role in bloody/serumy flavor aromatics.

One single aromatic compound, N,N'-dimethylcyclobutane-1,1bis(methylamine) accounted $(\mathrm{P}<0.05)$ for $17 \%$ of the variation in metallic flavor aromatics and was the first compound to enter the stepwise regression equation (Table 12). As metallic flavor aromatics increased, N,N'-dimethylcyclobutane-1,1bis(methylamine) decreased, which was also shown in the simple correlation coefficients. Other compounds, specifically those identified as lipid oxidation products, namely aldehydes and ketones, entered the stepwise equation for metallic flavor 
aromatics such as heptenal (step 4), 2,4-nonadienal (step 7) 2,4-decadienal (step 8), and 2-heptanone (step 10) and 1-phenyl-ethanone (step 17). 2,4 nonadienal, a compound derived from fatty acid autoxidation to hydroperoxides (Calkins and Hodgen, 2007), was negatively and moderately correlated $(\mathrm{P}<0.05)$ to both metallic flavor aromatics and umami basic taste. 2,4-nonadienal was shown to be related to fat, wax, and pungent flavors/aromas (Calkins and Hodgen, 2007). Metallic flavor aromatics had other compounds enter the stepwise equation as well, including 3-ethyl-2,5-dimethyl-pyrazine (step 5) and benzothiazole (step 23).

Astringent feeling factors were negatively associated with 1,2dimethylpyrrolidine $(\mathrm{r}=-0.29 ; \mathrm{P}<0.05)$ and entered the stepwise equation for astringent feeling factors at step 1, and as astringent feeling factors increased, 1,2dimethylpyrrolidine decreased (Table 13). This compound is a heterocyclic nitrogencontaining compound. Eight out of 37 compounds that entered the equation were aldehydes that have been shown to be largely present in pork (Shahidi, 1994).

The stepwise linear regression for sour basic taste showed that a variety of compounds could be used to predict sour basic taste (Table 14). A total of 75 compounds were used in the stepwise regression equation for sour basic taste. The compound 1-heptanol entered the stepwise equation for sour basic taste at step 1 and entered the stepwise linear regression equation at step 2 for astringent feeling factors. Maughan and Martini (2012) showed that astringent feeling factors and sour basic taste were clustered in the same quadrant. These compounds may provide the link to astringent feeling factors and sour basic taste. A sulfur-containing compound, 2-acetyl 
thiazole, entered the stepwise equation for sour basic taste at step 2. Methyl-pyrazine also entered the stepwise equation at step 8 , and indicated that as sour basic taste increased, methyl-pyrazine decreased. Thiazoles and pyrazines are usually associated with roasted meat odor (Bueno et al., 2011) and may indicate that the sour basic taste may be a component of roasted meat odor.

Heneicosane entered the stepwise linear regression equation for salty basic taste at step 1 and 3-(1,1-dimethylethyl)-2,2,4,4-tetramethyl-3-pentanol entered the equation at step 2 (Table 15). Other compounds that were predictive of the salty basic taste were 2,3-dimethylbenzaldehyde (step 3), and ethyl-benzene (step 4). Nine out of the 53 compounds in the final equation were aldehydes.

The stepwise linear regression equation for bitter basic taste included compounds used in prediction equations for other attributes (Table 16). For example, 1,2dimethylpyrrolidine entered the stepwise regression equation for bitter basic taste at step 10 and entered the stepwise linear regression equation for astringent feeling factors at step 1. Additionally, trimethyl-pyrazine was predictive for bitter basic taste at step 7 and was included in the stepwise regression equation for bloody/serumy flavor aromatics (step 6). At high concentrations and when treatments have been cooked for long periods of time over high heat, Maillard reaction products may provide a wide range of flavors, some unpleasant or pleasant, depending on the food matrix.

\section{Partial Least Squares Regression}

To better understand the relationship between trained sensory attributes and aromatic categories of compounds as well as the relationship between these variables 
and treatments, partial least square regression was performed (Figure 2). Ketones, benzenes, pyrazines, and nitrogen-containing compounds were clustered together in the same quadrant as alkanes, sulfur-containing compounds, and tenderloin medallions cooked to $79.4^{\circ} \mathrm{C}$ and loin chops cooked to $62.7^{\circ} \mathrm{C}$ and $68.3^{\circ} \mathrm{C}$. Alcohols, aldehydes, furans, and alkenes were clustered in the same quadrant with acids, as well as inside ham chops cooked to $73.8^{\circ} \mathrm{C}$ and $62.7^{\circ} \mathrm{C}$, and loin chops cooked to $79.4^{\circ} \mathrm{C}$. Sour basic taste and metallic flavor aromatics and astringent feeling factors were also present in this quadrant. Although the majority of classifications of compounds did not cluster closely with specific treatments or flavor aromatic attributes, Maillard-derived categories, such as nitrogen-containing compounds, pyrazines, and benzenes were clustered together. Tenderloin medallions and inside ham chops cooked to $79.4^{\circ} \mathrm{C}$ were present in the same quadrant as these classifications since this is the highest degree of doneness that was measured in this study and was exposed to the griddle for a longer time to achieve the internal endpoint temperature. Additionally, in another quadrant, lipid-derived classifications, such as alcohols and aldehydes, clustered together. Metallic flavor aromatics and astringent feeling factors were clustered near inside ham chops cooked to $62.7^{\circ} \mathrm{C}$ and acids. Sour basic taste and acids were present in the same quadrant as most sour basic tastes are derived from the acids classification (Damodaran et al., 2008). Maughan and Martini (2012) also showed that sour basic taste and metallic flavor aromatics were clustered together.

The relationship between trained sensory attributes and specific aromatic compounds as well as the relationship between these variables and treatments was 
determined using the partial least square regression (Figure 3). Some attributes and treatments were related. Pork identity and brown/roasted flavor aromatics were clustered in the same positive quadrant, indicating that brown/roasted flavor aromatics may play a role in pork identity flavor aromatics. Salty, umami, and sweet basic taste, and fat-like flavor aromatics were clustered loosely together in a different quadrant with cardboardy flavor aromatics. It was interesting to see that cardboardy flavor aromatics were present in the same quadrant as basic tastes and fat-like flavor aromatics, since cardboardy flavor aromatics has sometimes been described as an oxidation flavor attribute (Johnson and Civille, 1986; Rhee et al., 2005). Johnson and Civille (1986) determined that cardboardy flavor aromatics were an attribute used to describe warmedover flavor aromatics. Maughan and Martini (2012) found that, using principal component analysis, brothy and fatty flavor aromatics, and salty basic taste were clustered with pork. However, brothy flavor aromatics were determined to be a separate attribute from umami basic taste and were clustered in a different quadrant. Astringent feeling factors, metallic, bloody/serumy, and liver-like flavor aromatics as well as bitter and sour basic tastes were present in the same quadrant as inside ham chops and tenderloin medallions cooked to $73.8^{\circ} \mathrm{C}$, inside ham chops and tenderloin medallions cooked to $62.7^{\circ} \mathrm{C}$, and tenderloin medallions and inside ham chops cooked to $68.3^{\circ} \mathrm{C}$ but opposite the other attributes in a different quadrant. Therefore, as astringent feeling factors, metallic, and bloody/serumy flavor aromatics, and bitter basic taste increased, fat-like and pork identity flavor aromatics decreased. Metallic and bloody/serumy flavor aromatics have been shown to be related (Miller et al., 2014). Maughan and Martini 
(2012) showed that bloody and metallic flavor aromatics, and bitter basic taste clustered in the same quadrant, also indicating a negative relationship; however, astringent feeling factors and sour basic taste were clustered in a different quadrant in our study. Glascock (2014) showed that bloody/serumy flavor aromatics were related to cuts that were cooked to lower degrees of doneness. Both inside ham and tenderloin treatments cooked to lower internal endpoint temperatures were located in the same quadrant as sour and bitter basic tastes and astringent feeling factors, metallic, and bloody/serumy flavor aromatics. Additionally, the two lower degrees of doneness for both tenderloin medallions and inside ham chops indicated that there might be a connection between lower internal endpoint cook temperature and these attributes in these treatments. Means separations for the four temperatures showed this trend for these attributes.

Most compounds did not cluster with any treatments or attributes, but some attributes and treatments were related to compounds. Pork identity flavor aromatics and shoulder chops cooked to $73.8^{\circ} \mathrm{C}$ were clustered with a large number of compounds including butanoic acid, 2,3-dimethylbenzaldehyde, trans, trans-2,4-octadienal, 2,4 heptadienal, (E,E)-2,4-heptadienal, 4-ethyl-benzaldehyde, octadecanal, 2-butylfuran, octane, 2-dodecen-1-ol, 1,1'-oxybis-heptane. Butanoic acid was also related to pork identity flavor aromatics and entered the stepwise regression for pork identity flavor aormatics at step 1. 2,4-heptadienal has been shown to be associated with nut and fat flavors and aromas (Calkins and Hodgen, 2007). Aldehydes have been shown to be flavor potentiators due to their low odor threshold and prevalence as oxidized flavors (Shahidi et al., 2013). Benzaldehyde compounds have been associated with almond oil, 
bitter, and burning aromatics (Calkins and Hodgen, 2007) and aldehydes with six to ten carbons are major compounds that play a large role in meat aroma (Mottram, 1998). Mottram (1985) found benzaldehyde in all treatments that were studied with the highest levels being in roasted and lightly grilled treatments. This data may indicate a link between benzaldehyde, pork identity flavor aromatics, and cuts cooked to a higher internal endpoint temperature across all pork products used in Mottram (1985) and the present study. Because of the prevalence of multiple benzaldehyde derivatives as shown across all data, it could partially explain pork identity flavor aromatics and the flavors associated with it. 2,3-dimethylbenzaldehyde was also highly related to umami basic taste $(\mathrm{r}=0.54)$ and entered the stepwise regression equation for pork identity flavor aromatics at step 16, for brown/roasted flavor aromatics at step 9, and fat-like flavor aromatics at step 1. Benzaldehyde derivatives may explain the effect that umami basic taste could have on pork identity flavor aromatics as the umami basic taste likely provides "meaty" and "brothy" flavor aromatics to a food matrix (Kawamura and Kare, 1987; Adhikari et al., 2011). It was not surprising that many chemical compounds and even other flavor aromatics could be related to pork identity flavor aromatics since pork flavor is complex.

Cardboardy flavor aromatics were loosely clustered with 4-hydroxy-benzoic acid, pentanal, and (1-methylethyl)-benzene. Pentanal has been associated with flavor aromatics such as burnt, green (Shahidi et al., 2013) and almond, malt, pungent, and acrid (Calkins and Hodgen, 2007). Brown/roasted flavor aromatics were loosely clustered with 2,4-decadienal. Aldehydes such as 2,4-decadienal have been found in 
pork fat and may play a role in brown/roasted flavor aromatics (Shahidi et al., 2013).

Pork identity flavor aromatics were related to 2,4-decadienal in both the simple correlation coefficients and stepwise linear regression equations analyses, which further indicated that brown/roasted and this compound influenced pork identity flavor aromatics and that brown/roasted flavor aromatics may influence the pork identity flavor aromatics. Calkins and Hodgen (2007) stated that this compound was associated with a deep fat flavor and came from the autoxidation of fatty acids such as linoleic and arachidonic acid. They also discussed that 2,4-decadienal had a positive effect on beef flavor, but that there were unknown effects on pork flavor. Maughan and Martini (2012) found that pork was clustered with fatty and browned flavor aromatics in the same quadrant. The partial least square regression did not show the same relationship. The relationship of this compound to these aforementioned attributes in the stepwise regression may explain why they clustered together in Maughan and Martini (2012). Bitter basic taste was loosely clustered with 4-methyl-phenol, which has been shown to be present in pork flavor as well as mutton flavor (Shahidi et al., 2013). This compound also entered the stepwise linear regression equation for metallic flavor aromatics at step 21.

Shoulder chops cooked to $79.4^{\circ} \mathrm{C}$ were clustered with 2,4-nonadienal, octadecane, and (E)-2-hexenal. 2,4-nonadienal entered the stepwise linear regression equation for astringent feeling factors at step 6 and fat-like flavor aromatics in step 3. Interestingly, trained panelists ranked shoulder chops higher in fat-like flavor aromatics during lexicon validation. Xie et al. (2008) described that 2-hexenal may have green, 
rancid or roasted flavor aromatics, which may indicate that, at higher internal endpoint temperatures, 2-hexenal may play a role in roast flavor aromatics. Additionally, 2hexenal was predictive for bitter basic taste at step 2. Shoulder chops cooked to $62.7^{\circ} \mathrm{C}$ were closely clustered with 2-decen-1-ol, which entered the stepwise equation for bloody/serumy flavor aromatics at step 1 . This was expected since bloody/serumy flavor aromatics have been associated with cuts cooked to lower degrees of doneness (Glascock, 2014). Shoulder treatments, regardless of temperature, were shown to be influenced by lipid oxidation products. Inside ham chops cooked to $62.7^{\circ} \mathrm{C}$ were closely clustered with 2,5-dimethyl-heptane, which entered the stepwise linear regression equation for bloody/serumy flavor aromatics at step 3. Loin chops cooked to $79.4^{\circ} \mathrm{C}$ were closely clustered with pentadecane, hexanal, 1-decanol, 1-pentanol, heptanal, and cyclooctane. Heptanal has been shown to have oily, fatty, and rancid flavor aromatics, hexanal has been shown to have fatty-green, grassy, and fat flavor aromatics, and 1pentanol has been shown to have fusel oil, fruit, and balsamic flavor aromatics (Calkins and Hodgen, 2007). 1-pentanol was found by Mottram (1985) in all samples that were studied, but was slightly higher in lightly grilled and roasted products. Aldehydes and alcohols were shown to be in the same quadrant as this particular treatment, further strengthening the relationship (Figure 2). Inside ham chops cooked to $79.4^{\circ} \mathrm{C}$ were closely clustered with 2-decanone. Ketones were shown to be in the same quadrant as this treatment (Figure 2). Tenderloin medallions cooked to $79.4^{\circ} \mathrm{C}$ were closely clustered with several compounds including 4-oxononanal, octenal, dodecanal, 3dodecen-1-al, (E)-4-dodecene, benzothiazole, N,N'-Dimethylcyclobutane-1,1- 
bis(methylamine), 1-tetradecanol, 3-isopropyl-piperidine, (Z)-2-dodecene, formic acid, heptyl ester, and tetradecane. N,N'-Dimethylcyclobutane-1,1-bis(methylamine) was predictive for astringent feeling factors at step 3 and sour basic taste at step 5 .

Benzothiazole was present in this particular treatment since thiazole quantities have been shown to increase with increasing internal temperature and cook method (Mottram, 1998). Mottram (1985) also found thiazole derivatives in well-done pork samples. 


\section{CHAPTER V}

\section{CONCLUSIONS}

Data from this study indicated that an intact muscle lexicon for pork flavor and aroma was successfully developed and validated as panelists found differences between treatments. Trained panelists determined a total of 24 flavor and aroma attributes that have been defined as the pork flavor lexicon. Pork identity, brown/roasted, bloody/serumy, fat-like, and metallic flavor aromatics, and astringent feeling factors, sweet, sour, salty, and bitter basic tastes were attributes that trained panelists determined to be present in pork most frequently.

Lexicon validation showed that, overall, all pork samples had moderate levels of pork identity flavor aromatics and umami basic taste. Liver-like, nutty, and fat-like flavor aromatics were not present at high levels. Some of the attributes were not detected during lexicon validation. Shoulder chops were ranked higher in pork identity and fat-like flavor aromatics and lower in umami basic taste. Loin chops and shoulder chops were slightly higher in brown/roasted flavor aromatics. Loin chops and inside ham chops were slightly higher in sour basic taste, and inside ham chops were slightly higher in astringent feeling factors and metallic flavor aromatics, and sour basic taste. As internal endpoint temperatures increased, brown/roasted flavor aromatics increased, while bloody/serumy flavor aromatics and astringent feeling factors, and sour and bitter basic tastes decreased.

Compound classes that contributed to pork flavor were sulfur-containing 
compounds, nitrogen-containing compounds, aldehydes, ketones, acids, alkanes, alkenes, furans, pyrazines, and benzenes. Aldehydes influenced many attributes, as their levels were quantitatively much higher than other compound classes. Treatments also varied widely in the number and type of aromatic compounds clustering with treatments. Cuts that were shown to be higher in attributes that were indicative of lower internal endpoint temperatures, such as inside ham chops, clustered with alkanes and alcohols. Shoulder chops cooked to a higher internal endpoint temperature clustered with aldehydes and benzaldehydes. Regardless of internal endpoint temperature across cuts, aldehydes and alcohols clustered with treatments, indicating that lipid oxidation products may play a large role in pork flavor research.

Additional research and lexicon validation needs to be done using the pork lexicon to ensure consistency within the meat research community. This would allow researchers to better communicate about pork flavor since all meat scientists would be using the same language and ranking scale. Further studies comparing flavor aromatic compounds of various retail pork cuts by examining the differences in muscle myology as well as the effects of fatty acid level, myoglobin content, non-heme iron levels, and fat and moisture levels may be needed to further understand what drives pork flavor. Looking more closely at specific compounds that were most predictive and supported by other data may help researchers to understand the specific compounds that influence specific flavor and aroma attributes. Aromatic compounds clearly influenced specific flavor aromatic attributes as defined by the trained panelists from lexicon development and validation. Utilization of the GC-O and the Aroma-Trax program could be helpful 
in specifically identifying odor-active compounds that are responsible for each attribute by using the intensity and attribute functions within the program. 


\section{REFERENCES}

Aberle, J., Forrest, J., Gerrard, D., Mills, E. 2012. Principles of Meat Science $5^{\text {th }}$ Edition. Dubuque: Kendall/Hunt Publishing Company. 264-265.

Adhikari, K., Chambers IV, E., Miller, R., Vasquez-Araujo, L., Bhumiratana, N., Philip, C. 2011. Development of a lexicon for beef flavor in intact muscle. Journal of Sensory Studies 26: 413-420.

AMSA. 1995. Research Guidelines for Cookery, Sensory Evaluation and Instrumental Tenderness Measurements of Fresh Meat. Chicago: American Meat Science Association Press. 16-28.

AMSA. 2014. Research Guidelines for Cookery, Sensory Evaluation and Instrumental Tenderness Measurements of Fresh Meat. Chicago: American Meat Science Association Press. 16-28.

ASTM. 1996. Civille, G., Lyon, B. 1996. Aroma and Flavor Lexicon for Sensory Evaluation: Terms, Definitions, References, and Examples. West Conshohocken: American Society for Testing and Materials. 57-151.

ASTM. 2011. "Lexicon for Sensory Evaluation: Aroma, Flavor, Texture, and Appearance." American Society for Testing and Materials. CD-ROM. Version 1.0. West Conshohocken: American Society for Testing and Materials.

Babol J., Squires, J. 1995. Quality of meat from entire male pigs. Food Research International 28: 201-212. 
Bennett, M., Bramblett, V., Aberle, E., Harrington, R. 1973. Muscle quality, cooking method and aging vs. palatability of pork loin chops. Journal of Food Science 38: 536-538.

Berry, B. 1994. Fat level, high temperature cooking and degree of doneness affect sensory, chemical, and physical properties of beef patties. Journal of Food Science 59: 10-14.

Breer, H. 2008. The sense of smell: reception of flavors. Annals of the New York Academy of Sciences 1126: 1-6.

Brewer, M., McKeith, F., Sprouls, G. 1993. Sodium lactate effects on microbial, sensory, and physical characteristics of vacuum-packaged pork sausage. Journal of Muscle Foods 4: 179-192.

Brooke, M., Kaiser, K. 1970. Muscle fiber types: how many and what kind? Archives of Neurology 23: 269-379.

Bryhni, E., Byrne, D., Rodbotten, M., Claudi-Magnussen, C., Agerhem, H., Johansson, M., Lea, P., Martens, M. 2003. Consumer perceptions of pork in Denmark, Norway, and Sweden. Food Quality and Preference 13: 257-266.

Bueno, M., Resconi, V., Campo, M., Cacho, J., Ferreira, V., Escudero, A. 2011. Gas chromatographic-olfactometric characterization of headspace and mouthspace key aroma compounds in fresh and frozen lamb meat. Food Chemistry 129: 1909-1918. 
Byrne, D., Bak, L., Bredie, W., Bertelsen, G., Martens, M. 1999a. Development of a sensory vocabulary for warmed-over flavor: part I. in porcine meat. Journal of Sensory Studies 14: 47-65.

Byrne, D., Bredie, W., Martens, M. 1999b. Development of a sensory vocabulary for warmed-over flavour II: in chicken meat. Journal of Sensory Studies 14: 67-78.

Byrne, D., O’Sullivan, M., Dijksterhuis, G., Bredie, W., Martens, W. 2001. Sensory panel consistency during development of a vocabulary for warmed-over flavor. Food Quality and Preference 12: 171-187.

Calkins, C., Hodgen, J. 2007. A fresh look at meat flavor. Meat Science 77: 63-80.

Carlucci, A., Girolami, A., Napolitano, F., Monteleone, E. 1998. Sensory evaluation of young goat meat. Meat Science 50: 131-136.

Chambers IV, E., Koppel, K. 2013. Associations of volatile compounds with sensory aroma and flavor: the complex nature of flavor. Molecules 18: 4887-4905.

Cherdchu, P., Chambers IV, E., Suwonsichon, T. 2013. Sensory lexicon development using trained panelists in Thailand and the U.S.A.: soy sauce. Journal of Sensory Studies 28: 248-255.

Civille, G., Oftedal, Katherine. 2012. Sensory evaluation techniques-make "good for you" taste "good". Physiology and Behavior 107: 598-605.

Corino, C., Magni, S., Pagliarini, E., Rossi, R., Pastorelli, G., Chiesa, L. 2002. Effects of dietary fats on meat quality and sensory characteristics of heavy pig loins. Meat Science 60: 1-8. 
Cornet, M., Bousset, J. 1999. Free amino acids and dipeptides in porcine muscles: differences between 'red' and 'white' muscles. Meat Science 51: 215-219.

Czerny, M., Christlbauer M., Christlbauer, M., Fischer, A., Granvogl, M., Hammer, M., Hartl, C., Hernandez, N., Schieberle, P. 2008. Re-investigation on odour thresholds of key food aroma compounds and development of an aroma language based on odour qualities of defined aqueous odorant solutions. European Food Research and Technology 228: 265-273.

d'Acampora Zellner, B., Dugo, P., Dugo, G., Mondello, L. 2008. Gas chromatographyolfactometry in food flavour analysis. Journal of Chromatography 1186: 123 143.

Damodaran, S. (ed.), Parkin, K. (ed.), Fennema, O (ed.)., McClements, D., Decker, E., Lindsay, R. 2008. Lipids and Flavors in: Fennema's Food Chemistry $4^{\text {th }}$ Edition. Boca Raton: CRC Press. 187-190; 656-657.

Deethardt, D., Tuma, H. 1971. Effect of cooking methods on various qualities of pork loin. Journal of Food Science 36: 626-628.

Di Donfrancesco, B., Koppel, K., Chambers, E., IV. 2012. An initial lexicon for sensory properties of dry dog food. Journal of Sensory Studies 27: 498-510.

Drake, M., Civille, G. 2002. Flavor lexicons. Comprehensive Reviews in Food Science and Food Safety 2: 33-40.

Drake, M., McIngvale, S., Gerard, P., Cadwallader, K., Civille, G. 2001. Development of a descriptive language for cheddar cheese. Sensory and Nutritive Qualities of Food 66: 1422-1427. 
Drumm, T., Spanier, A. 1991. Changes in the content of lipid autoxidation and sulfurcontaining compounds in cooked beef during storage. Journal of Agriculture and Food Chemistry 39: 336-343.

Elmore, J., Mottram, D., Hierro, E. 2000. Two-fibre solid-phase microextraction combined with gas chromatography—mass spectrometry for the analysis of volatile aroma compounds in cooked pork. Journal of Chromatography 905: $233-240$.

Enser, M., Hallett, K., Hewitt, B., Fursey, G., Wood, J. 1996. Fatty acid content and composition of English beef, lamb, and pork at retail. Meat Science 42: 443-456.

Flores, M., Amero, E., Aristoy, M., Toldra, F. 1999. Sensory characteristics of cooked pork loin as affected by nucleotide content and post-mortem meat quality. Meat Science 51: 53-59.

Glascock, R. 2014. Beef Flavor and Consumer Perception [Msc thesis]. College Station, TX: Texas A\&M University. 133 p. Available electronically from: Oak Trust at Texas A\&M University Library

Gorbatov, V., Lyaskovskaya, Y. 1980. Review of the flavor-contributing volatiles and water-soluble non-volatiles in pork meat and derived products. Meat Science 4: 209-225.

Guinard, J., Mazzucchelli, R. 1996. The sensory perception of texture and mouthfeel. Trends in Food Science and Technology 7: 213-219. 
Heymann, H., Hedrick, H., Karrasch, M., Eggeman, M., Ellersieck, M. 1990. Sensory and chemical characteristics of fresh pork roasts cooked to different endpoint temperatures. Journal of Food Science 55 613-617.

Ho, C., Chen, Q. 1994. Lipids in food flavors: an overview. American Chemical Society ACS Symposium Series: 2-14.

Hodge, J. 1953. Chemistry of browning reactions in model systems. Agricultural and Food Chemistry 1: 928-943.

Hornstein, I., Crowe, P. 1960. Flavor studies on beef and pork. Agricultural and Food Chemistry 8: 494-498.

Huff-Lonergan, E., Baas, T., Malek, M., Dekkers, J., Prusa, K., Rothschild, M. 2002. Correlations among selected pork quality traits. Journal of Animal Science 80: $617-627$.

Imafidon, G., Spanier, A. 1994. Unraveling the secret of meat flavor. Trends in Food Science and Technology 5: 315-321.

Jeremiah, L., Gibson, L. 1997. The influence of controlled atmosphere storage on the flavor and texture profiles of display-ready pork cuts. Food Research International 30: 117-129.

Jeremiah, L., Murray, A., Gibson, L. 1990. The effects of differences in inherent muscle quality and frozen storage on the flavor and texture profiles of pork loin roasts. Meat Science 27: 305-327.

Johnson, P., Civille, G. 1986. A standardized lexicon of meat WOF descriptors. Journal of Sensory Studies 1: 99-104. 
Judge, M., Mills, E., Orcutt, M., Forrest, J., Diekman, M., Harmon, B., Lin, R., Nicholls, L. 1990. Utilization of boar meat: composition, quality, and odor incidence in relation to androstenone and skatole. Journal of Animal Science 68: 1030-1033.

Kawamura, U., Kare, M. 1987. Umami: A Basic Taste: Physiology, Biochemistry, Nutrition, Food Science. New York: Marcel Dekker. 1-649.

Kregel, K., Prusa, K., Hughes, K. 1986. Cholesterol content and sensory analysis of ground beef as influenced by fat level, heating, and storage. Journal of Food Science 51: 1162-1165.

Larick, D., Turner, B., Shoenberr, W., Coffey, M., Pilkinton, D. 1992. Volatile compound content and fatty acid composition of pork as influenced by linoleic acid content of diet. Journal of Animal Science 70: 1397-1403.

Lawless, L., Civille, G. 2013. Developing lexicons: a review. Journal of Sensory Studies 28: 270-281.

Lee, J., Chambers, D. 2007. A lexicon for flavor descriptive analysis of green tea. Journal of Sensory Studies 22: 256-272.

Lefaucheur, L., Hoffman, R., Gerrard, D., Okamura, C., Rubinstein, N., Kelly, A. 1998. Evidence for three adult fast myosin heavy chain isoforms in type II skeletal muscle fibers in pigs. $76:$ 1584-1593.

Lim, J., Johnson, M. 2011. Potential mechanisms of retronasal odor referral to the mouth. Chemical Senses 36: 283-389. 
Lu, P., Li, D., Yin, J., Zhang, L., Wang, Z. 2008. Flavour differences of cooked longissimus muscle from Chinese indigenous pig breeds and hybrid pig breed (Duroc x Landrace x Large White). Food Chemistry 107: 1529-1537.

Maarse, H. 1991. Introduction in: Volatile Compounds in Foods and Beverages, $1^{\text {st }} \mathrm{Ed}$. New York: Marcel Dekker Inc. 1-39.

Maughan, C., Martini, S. 2012. Identification and quantification of flavor attributes present in chicken, lamb, pork, beef, and turkey. Journal of Food Science 77: S115-S121.

Meinert, L., Andersen, L., Bredie, W., Bjergegaard, C., Aaslyng, M. 2007a. Chemical and sensory characterization of pan-fried pork flavor: interactions between raw meat quality, ageing, and frying temperature. Meat Science 75: 229-242.

Meinert, L., Tikk, K., Brockhoff, P., Bejerholm, C., Aaslyng, M. 2007b. Flavor formation in pork semimembranosus: combination of pan-temperature and raw meat quality. Meat Science 80: 249-258.

Meinert, L., Tikk, K., Tikk, M., Brockhoff, P., Bredie, W., Bjergegaard, C., Aaslyng, M. 2009. Flavour development in pork. Influence of flavour precursor concentrations in longissimus dorsi from pigs with different raw meat qualities. Meat Science 81: 255-262.

Meisinger, D. 2002. A system for assuring pork quality. National Pork Board, Des Moines.

Melton, S. 1990. Effects of feeds on flavor of red meat: a review. Journal of Animal Science 68: 4421-4435. 
Miller, M., Shackelford, S., Haydon, K., Reagan, J. 1990. Determination of the alteration in fatty acid profiles, sensory characteristics and carcass traits of swine fed elevated levels of monounsaturated fats in the diet. Journal of Animal Science 68: 1624-1631.

Miller, R., Luckemeyer, T., Kerth, C. 2014. Beef Flavor Attributes and Consumer Perception II. Final Report. National Cattlemen's Beef Association, Centennial, $\mathrm{CO}$.

Min, D., Smouse, T. 1989. Flavor Chemistry of Lipid Foods. Arizona: American Oil Chemists' Society. 167-189.

Moeller, S., Miller, R., Aldredge, T. Logan, K., Edwards, K., Zerby, H., Boggess, M., Box-Steffensmeier, J., Stahl, C. 2010. Trained sensory perception of pork eating quality as affected by fresh and cooked pork quality attributes and end-point cooked temperatures. Meat Science 85: 96-103.

Mottram, D. 1998. Flavour formation in meat and meat products: a review. Food Chemistry 62: 415-424.

Mottram, D. 1985. The effect of cooking conditions on the formation of volatile heterocyclic compounds in pork. Journal of the Science of Food and Agriculture 36: $377-382$.

Murray, J., Delahunty, C., Baxter, I. 2001. Descriptive sensory analysis: past, present, and future. Food Research International 34: 461-471. 
Myers, A., Scramlin, S., Dilger, A., Souza, C., McKeith, F., Killefer, J. 2009.

Contribution of lean, fat, muscle color and degree of doneness to pork and beef species flavor. Meat Science 82: 59-63.

Newell, J., Bowland, J. 1972. Performance, carcass composition, and fat composition of boars, gilts, and barrows fed two levels of protein. Canadian Journal of Animal Science 52: 543-551.

Ngapo, T., Gariepy, C. 2008. Factors affecting the eating quality of pork. Critical Reviews in Food Science and Nutrition 48: 599-633.

Ngapo, T., Riendeau, L., Laberge, C., Fortin, J. 2012a. Marbling and ageing-part 1. Sensory quality of pork. Food Research International 49: 396-405.

Ngapo, T., Riendeau, L., Laberge, C., Leblanc, D., Fortin, J. 2012b. “Chilled” porkpart I: sensory and physico-chemical quality. Meat Science 92: 330-337.

Nishimura, T. 2010. The role of intramuscular connective tissue in meat texture. Animal Science Journal 81: 21-27.

N'Kouka, K., Klein, B., Lee, S. 2004. Developing a lexicon for descriptive analysis of soymilks. Sensory and Nutritive Qualities of Food 69: S259-S263.

Papadopoulos, L., Miller, R., Acuff, G., Vanderzant, C., Cross, H. 1991. Effects of sodium lactate on microbial and chemical composition of cooked beef during storage. Journal of Food Science 56: 341-347.

Pearson, A., Wolzak, A., Gray, J. 1983. Possible role of muscle proteins in flavor and tenderness of meat. Journal of Food Biochemistry 7: 189-210. 
Philip, C. 2011. Differentiation of Beef Flavor Across Muscles and Quality Grades [Msc thesis]. College Station, TX: Texas A\&M University. 120 p. Available electronically from: Oak Trust at Texas A\&M University Library.

Prestat, C., Jensen, J., McKeith, F., Brewer, M. 2002. Cooking method and endpoint temperature effects on sensory and color characteristics of pumped pork loin chops. Meat Science 60: 396-400.

Prusa, K., Nederveld, H., Runnels, P., Li, R., King, V., Crane, J. 2011. Prevalence and relationships of sensory taint, $5 \alpha$-androstenone and skatole in fat and lean tissue from the loin (longissimus dorsi) of barrows, gilts, sows, and boars from selected abattoirs in the United States. Meat Science 88: 96-101.

Rhee, K., Anderson, L., Sams, A. 2005. Comparison of flavor changes in cookedrefrigerated beef, pork, and chicken meat patties. Meat Science 71: 392-396.

Shahidi, F. (ed)., Chen, J., Ho, C. 1994. The Flavor of Pork in: Flavor of Meat, Meat Products, and Seafoods, $2^{\text {nd }}$ Edition. Weinheim: Blackie Academic and Professional. 61-83.

Shahidi, F., Rubin, L., D’Souza, L., Teranishi, R., Buttery, R. 2013. Meat flavor volatiles: a review of the composition, techniques of analysis, and sensory evaluation. Critical Reviews in Food Science and Nutrition 24: 141-243.

Shallenberger, R. 1996. The AH,B glycophore and general taste chemistry. Food Chemistry 56: 209-214.

Sink, J. 1979. Symposium on meat flavor: factors influencing the flavor of muscle foods. Journal of Food Science 44: 1-11. 
Solms, J.(ed.), Hall, R. (ed.), Birch, G. 1981. Basic Tastes of Sugar Molecules in: Criteria of Food Acceptance. Forster Verlag: Zurich. 282-291.

Spanier, A., Shahidi, F., Parliament, T., Ho, C., Tratras, E., Contis, E. 2001. Food Flavors and Chemistry. Cambridge: Athenaeum Press: 34-45.

Straadt, I., Aaslyng, M., Bertram, H. 2013. Sensory and consumer evaluation of pork loins from crossbreeds between Danish Landrace, Yorkshire, Duroc, Iberian, and Mangalitza. Meat Science 95: 27-35.

Sutton, D., Brewer, M., McKeith, F. 1997. Effects of sodium lactate and sodium phosphate on the physical and sensory characteristics of pumped pork loins. Journal of Muscle Foods 8: 95-104.

Tikk, K., Tikk, M., Aaslyng, M., Karlsson, A., Lindahl, G., Andersen, H. 2007. Significance of fat supplemented diets on pork quality—connections between specific fatty acids and sensory attributes of pork. Meat Science 77: 275-286.

Voilley, A., Etievant, P. 2006. Flavour In Food. Boca Raton: CRC Press. 3-12.

Walstra, P. 1974. Fattening of young boars: quantification of negative and positive aspects. Livestock Production Science 1: 187-196.

Wasserman, A., Spinelli, A. 1972. Effect of some water-soluble components on aroma of heated adipose tissue. Journal of Agricultural and Food Chemistry 20: 171174.

Wasserman, A. 1972. Thermally produced flavor components in the aroma of meat and poultry. Journal of Agricultural and Food Chemistry 20: 737-741.

Winstanley, M. 1979. The colour of meat. Nutrition and Food Science 79: 5-8. 
Wood, J., Enser, M., Fisher, A., Nute, G., Sheard, P., Richardson, R., Hughees, S., Whittington, F. 2008. Fatty deposition, fatty acid composition and meat quality: a review. Meat Science 78: 343-358.

Wood, J., Nute, G., Fursey, A., Cuthbertson, A. 1995. The effect of cooking conditions on the eating quality of pork. Meat Science 40: 127-135.

Wood, J., Nute, G., Richardson, R., Whittington, F., Southwood, O., Plastow, G., Mansbridge, R., da Costa, N., Chang, K. 2004. Effects of breed, diet, and muscle on fat deposition and eating quality. Meat Science 67: 651-667.

Wood, J., Richardson, R., Nute, G., Fisher, A., Campo, M., Kasapidou, E., Sheard, P., Enser, M. 2003. Effects of fatty acids on meat quality: a review. Meat Science 66: 21-32.

Wright, L., Scanga, J., Belk, K., Engle, T., Tatum, J., Person, R., McKenna, D., Griffin, D., McKeith, F., Savell, J., Smith, J. 2005. Benchmarking value in the pork supply chain: characterization of US pork in the retail marketplace. Meat Science 71: 451-463.

Xie, J., Sun, B., Zheng, F., Wang, S. 2008. Volatile flavor constituents in roasted pork of mini-pig. Food Chemistry 109: 506-514.

Zhao, Y., Wells, J., McMillin, K. 1993. Applications of dynamic modified atmosphere packaging systems for fresh red meats: review. Journal of Muscle Foods 5: 299328. 


\section{APPENDIX A}

\section{TABLES}

Table 1. Sample descriptions, muscle categories, cooking methods and endpoint temperatures used in the lexicon development.

\begin{tabular}{|c|c|c|}
\hline Treatment & Cut & Samples (n) \\
\hline \multicolumn{3}{|l|}{ Cook Methods } \\
\hline Braising & Roasts & 7 \\
\hline Roasting & Roasts & 12 \\
\hline Grilling & Chops/Medallions & 48 \\
\hline \multicolumn{3}{|l|}{ Endpoint Temperatures } \\
\hline $62.7^{\circ} \mathrm{C}$ & Roasts & 19 \\
\hline $57.2^{\circ} \mathrm{C}$ & Chops/Medallions & 18 \\
\hline $68.3^{\circ} \mathrm{C}$ & Chops/Medallions & 19 \\
\hline $79.4^{\circ} \mathrm{C}$ & Chops/Medallions & 16 \\
\hline \multicolumn{3}{|l|}{ Muscle categories } \\
\hline \multirow[t]{2}{*}{ Shoulder } & Chops & 4 \\
\hline & Roasts & 3 \\
\hline Picnic & Roasts & 1 \\
\hline \multirow[t]{2}{*}{ Tenderloin } & Medallions & 8 \\
\hline & Roasts & 4 \\
\hline Bellies & Roasts & 7 \\
\hline Fresh Ham Leg & Roasts & 2 \\
\hline \multirow[t]{2}{*}{ Loin } & Chops & 22 \\
\hline & Roasts & 2 \\
\hline \multicolumn{3}{|l|}{ Conditions } \\
\hline \multirow[t]{2}{*}{ Boar Taint } & Chops & 3 \\
\hline & Ground & 2 \\
\hline Sow & Ground & 2 \\
\hline \multirow[t]{2}{*}{ Enhanced } & Chops & 7 \\
\hline & Roasts & 1 \\
\hline Packaging & Chops & 18 \\
\hline \multicolumn{3}{|l|}{ PVC } \\
\hline \multicolumn{3}{|l|}{ MAP } \\
\hline \multicolumn{3}{|l|}{ Vacuum } \\
\hline \multirow[t]{2}{*}{ Spoiled/Putrid } & Chops & 1 \\
\hline & Ground & 1 \\
\hline \multirow[t]{2}{*}{ Warmed-Over } & Ground & 3 \\
\hline & Chops & 3 \\
\hline \multirow[t]{2}{*}{ Refrigerator Stale } & Chops & 5 \\
\hline & Ground & 4 \\
\hline Long Frozen & Chops & 8 \\
\hline
\end{tabular}


Table 2. Definitions and references for pork flavor attributes, where $0=$ none and $15=$ extremely intense.

Attribute Definition Reference

\begin{tabular}{|c|c|c|}
\hline \multicolumn{3}{|l|}{ Basic Tastes } \\
\hline Bitter & The fundamental taste factor associated with a caffeine solution & $\begin{array}{l}0.05 \% \text { caffeine in } 1000 \mathrm{~mL} \text { water }=2.0(\mathrm{~F}) \\
0.08 \% \text { caffeine in } 1000 \mathrm{~mL} \text { water }=5.0(\mathrm{~F})\end{array}$ \\
\hline Salty & The fundamental taste factor of which sodium chloride is typical & $\begin{array}{l}0.2 \% \text { Salt in } 1000 \mathrm{~mL} \text { water }=2.5(\mathrm{~F}) \\
0.35 \% \text { Salt in } 1000 \mathrm{~mL} \text { water }=5.0(\mathrm{~F})\end{array}$ \\
\hline Sour & The fundamental taste factor associated with citric acid solution & $\begin{array}{l}0.05 \% \text { Citric Acid in } 1000 \mathrm{~mL} \text { water }=2.0(\mathrm{~F}) \\
0.08 \% \text { Citric Acid in } 1000 \mathrm{~mL} \text { water }=5.0(\mathrm{~F})\end{array}$ \\
\hline Sweet & The fundamental taste factor associated with a sucrose solution & $\begin{array}{l}0.05 \% \text { Sugar in } 1000 \mathrm{~mL} \text { water }=2.0(\mathrm{~F}) \\
0.08 \% \text { Sugar in } 1000 \mathrm{~mL} \text { water }=5.0(\mathrm{~F})\end{array}$ \\
\hline Umami & $\begin{array}{l}\text { Flat, salty, somewhat brothy. The taste of glutamate, salts of amino acids } \\
\text { and other molecules called nucleotides. }\end{array}$ & $0.035 \%$ Accent flavoring in $1000 \mathrm{~mL}$ water $=7.5(\mathrm{~F})$ \\
\hline \multicolumn{3}{|c|}{ Flavor Aromatics } \\
\hline Boar Taint & Aromatic associated with boar taint; hormone-like; sweat, animal urine & $\begin{array}{l}0.1 \mathrm{~g} 3 \text {-methylindole, sniffed }=13.0(\mathrm{~A}) \\
\text { Androstenone wafted directly from bottle }=15.0(\mathrm{~A})\end{array}$ \\
\hline $\begin{array}{l}\text { Bloody/ } \\
\text { Serumy }\end{array}$ & $\begin{array}{l}\text { An aromatic associated with blood on cooked meat products; closely } \\
\text { related to metallic aromatic }\end{array}$ & Boneless Pork Chop, $135^{\circ} \mathrm{F}=2.0(\mathrm{~F} \& \mathrm{~A})$ \\
\hline $\begin{array}{l}\text { Brown/ } \\
\text { Roasted }\end{array}$ & $\begin{array}{l}\text { A round, full aromatic generally associated with pork suet that has been } \\
\text { broiled }\end{array}$ & Pork Fat, cooked and browned $=3.0(\mathrm{~F}), 4.0(\mathrm{~A})$ \\
\hline Burnt & $\begin{array}{l}\text { The sharp/acrid flavor note associated with over roasted pork muscle, } \\
\text { something over baked or excessively browned in oil }\end{array}$ & Arrowhead Barley Cereal, 7-10 puffs $=3.0(\mathrm{~F} \& \mathrm{~A})$ \\
\hline Cardboardy & $\begin{array}{l}\text { Aromatic associated with slightly oxidized fats and oils, reminiscent of } \\
\text { wet cardboard packaging }\end{array}$ & $\begin{array}{l}\text { Dry cardboard, } 1 \text { in square }=5.0(\mathrm{~F}), 3.0(\mathrm{~A}) \\
\text { Wet cardboard, } 1 \text { in square steeped in } 1 \text { cup water for } \\
30 \mathrm{~min}=7.0(\mathrm{~F}), 6.0(\mathrm{~A})\end{array}$ \\
\hline Chemical & $\begin{array}{l}\text { Aromatic associated with garden hose, hot Teflon pan, plastic packaging } \\
\text { and petroleum-based products such as charcoal lighter fluid }\end{array}$ & $\begin{array}{l}1 \text { drop Clorox in } 200 \mathrm{~mL} \text { water }=6.5(\mathrm{~F}) \\
\text { Ziploc Bag in snifter }=13.0(\mathrm{~A})\end{array}$ \\
\hline Fat-Like & Aromatics associated with cooked animal fat & Pork Fat, cooked and browned= $10.0(\mathrm{~F}) ; 7.0(\mathrm{~A})$ \\
\hline Floral & Sweet, light, slightly perfume impression associated with flowers & $\begin{array}{l}0.12 \mathrm{oz} \text { Clorox Wipe Liquid in } 4 \mathrm{oz} \text { water }=8.0(\mathrm{~A}) \\
\text { Geraniol, } 2 \text { drops on cotton ball in snifter }=7.5(\mathrm{~A}) \\
1: 1 \text { White Grape Juice to Water }=5.0(\mathrm{~F} \& \mathrm{~A})\end{array}$ \\
\hline Heated Oil & The aromatics associated with oil heated to a high temperature & $\begin{array}{l}\text { Wesson Oil, microwaved } 3 \mathrm{~min}=7.0(\mathrm{~F} \& \mathrm{~A}) \\
\text { Lay's Potato Chips }=4.0(\mathrm{~A})\end{array}$ \\
\hline
\end{tabular}


Table 2 (Continued).

\begin{tabular}{|c|c|c|}
\hline Attribute & Definition & Reference \\
\hline Liver-Like & Aromatics associated with cooked organ meat/liver & Pork Liver, $71^{\circ} \mathrm{C}=15.0(\mathrm{~F}) ; 12.0(\mathrm{~A})$ \\
\hline Metallic & $\begin{array}{l}\text { The impression of slightly oxidized metal, such as iron, copper, } \\
\text { and silver spoons }\end{array}$ & $\begin{array}{l}\text { Dole Pineapple Juice }=6.0(\mathrm{~A} \& \mathrm{~F}) \\
0.10 \% \mathrm{KCl} \text { in } 1 \mathrm{~L} \text { water }=1.5(\mathrm{~A} \& \mathrm{~F})\end{array}$ \\
\hline Nutty & $\begin{array}{l}\text { Nutty characteristics are: sweet, oily, light brown, slightly musty and/or } \\
\text { buttery, earthy, woody, astringent, bitter, etc. }\end{array}$ & Diamond Shelled Walnut, ground for $1 \mathrm{~min}=6.5(\mathrm{~F})$ \\
\hline Pork Identity & Amount of pork flavor identity in the sample & $\begin{array}{l}\text { Boneless Pork Chop, } 175^{\circ} \mathrm{F}=7.0(\mathrm{~F}), 5.0(\mathrm{~A}) \\
80 / 20 \text { Ground Pork, } 71^{\circ} \mathrm{C}=6.0(\mathrm{~F}) ; 5.0(\mathrm{~A})\end{array}$ \\
\hline $\begin{array}{l}\text { Refrigerator } \\
\text { Stale }\end{array}$ & $\begin{array}{l}\text { Aromatics associated with products left in the refrigerator for an extended } \\
\text { period time and absorbing a combination of odors (lack of freshness/flat) }\end{array}$ & $\begin{array}{l}80 / 20 \text { Ground Pork, } 71^{\circ} \mathrm{C} \text {, left chilled } \\
\text { overnight, served room temperature }=6.0(\mathrm{~F}), 8.0(\mathrm{~A})\end{array}$ \\
\hline Soapy & An aromatic commonly found in unscented hand soap & $\begin{array}{l}0.12 \mathrm{oz} \text { Clorox Wipe Liquid in } 4 \mathrm{oz} \text { water }=3.0(\mathrm{~A}) \\
0.5 \mathrm{~g} \text { Ivory Bar Soap in } 100 \mathrm{~mL} \text { water }=6.5(\mathrm{~A})\end{array}$ \\
\hline $\begin{array}{l}\text { Spoiled/Putrid } \\
\text { hours, }\end{array}$ & $\begin{array}{l}\text { The presence of inappropriate aromatics and flavors that is commonly } \\
\text { associated with the products. It is a foul taste and/or smell that indicates } \\
\text { product is starting to decay and putrefy. }\end{array}$ & $\begin{array}{l}\text { Boneless Pork Chop room temperature raw for } 24 \\
\text { refrigerate for } 6 \text { days, } 175^{\circ} \mathrm{F} \text {, smelled only }=3.0 \text { (A) } \\
80 / 20 \text { Ground Pork, same as above, } 71^{\circ} \mathrm{C}=5.0 \text { (A) }\end{array}$ \\
\hline Vinegary & Aroma notes associated with vinegar & $1.1 \mathrm{~g}$ Vinegar in $200 \mathrm{~g}$ water $=6.0(\mathrm{~F}) ; 4.0(\mathrm{~A})$ \\
\hline Warmed-Over & Perception of a product that has been previously cooked and reheated & $\begin{array}{l}80 / 20 \text { Ground Pork, cooked to } 71^{\circ} \mathrm{C} \text {, left chilled } \\
\text { overnight and microwaved for } 1 \mathrm{~min}=5.0(\mathrm{~F} \& \mathrm{~A})\end{array}$ \\
\hline \multicolumn{3}{|l|}{ Mouthfeels } \\
\hline Astringent & $\begin{array}{l}\text { The chemical feeling factor on the tongue or other skin surfaces of the oral } \\
\text { cavity described as a puckering/dry and associated with tannins or alum }\end{array}$ & $\begin{array}{l}\text { Lipton Tea, } 1 \text { bag in } 1 \text { cup boiling water and steeped } \\
\text { for } 3 \text { min }=6.0(\mathrm{~F}) \\
\text { Lipton Tea, } 3 \text { bags in } 1 \text { cup boiling water and steeped } \\
\text { for } 3 \min =12.0(\mathrm{~F})\end{array}$ \\
\hline
\end{tabular}


Table 3. Pork flavor attribute $(0=$ none; $15=$ extremely intense $)$ least squares means for pork cuts and degrees of doneness using the Pork Lexicon.

\begin{tabular}{|c|c|c|c|c|c|c|c|c|c|c|c|c|c|}
\hline \multirow[b]{2}{*}{ Effects } & \multirow{2}{*}{$\begin{array}{l}\text { Pork } \\
\text { Identity }\end{array}$} & \multirow{2}{*}{$\begin{array}{l}\text { Brown/ } \\
\text { Roasted }\end{array}$} & \multirow{2}{*}{$\begin{array}{l}\text { Fat- } \\
\text { Like }\end{array}$} & \multirow{2}{*}{$\begin{array}{l}\text { Bloody/ } \\
\text { Serumy }\end{array}$} & \multirow{2}{*}{\multicolumn{2}{|c|}{$\begin{array}{l}\text { Atrin- } \\
\text { Metallic gent }\end{array}$}} & \multirow[b]{2}{*}{ Sweet } & \multirow[b]{2}{*}{ Sour } & \multicolumn{2}{|c|}{ Basic Tastes } & \multicolumn{3}{|c|}{ Liver- } \\
\hline & & & & & & & & & Salty & Bitter & Umami & Like & Nutty \\
\hline$P-$ value $^{\mathrm{d}}$ & $<0.0001$ & 0.002 & $<0.0001$ & 0.02 & 0.004 & 0.02 & $<0.0001$ & 0.001 & $<0.0001$ & 0.08 & $<0.0001$ & 0.01 & 0.02 \\
\hline \multicolumn{14}{|l|}{ Cuts } \\
\hline Tenderloin & $5.5^{\mathrm{a}}$ & $0.6^{\mathrm{a}}$ & $0.4^{\mathrm{b}}$ & $1.1^{\mathrm{ab}}$ & $1.9^{\mathrm{a}}$ & $1.8^{\mathrm{ab}}$ & $0.3^{\mathrm{b}}$ & $1.8^{\mathrm{ab}}$ & $1.1^{\mathrm{a}}$ & 1.9 & $0.1^{\mathrm{a}}$ & $0.1^{\mathrm{c}}$ & $0.0^{\mathrm{a}}$ \\
\hline Loin & $5.6^{\mathrm{a}}$ & $1.1^{\mathrm{b}}$ & $0.3^{\mathrm{a}}$ & $0.9^{\mathrm{a}}$ & $2.0^{\mathrm{a}}$ & $1.7^{\mathrm{a}}$ & $0.2^{\mathrm{a}}$ & $2.0^{\mathrm{bc}}$ & $1.1^{\mathrm{a}}$ & 1.8 & $0.1^{\mathrm{a}}$ & $0.0^{\mathrm{a}}$ & $0.0^{\mathrm{a}}$ \\
\hline Ham & $5.6^{\mathrm{a}}$ & $0.8^{\mathrm{ab}}$ & $0.5^{\mathrm{b}}$ & $1.4^{\mathrm{b}}$ & $2.2^{\mathrm{b}}$ & $1.9^{\mathrm{b}}$ & $0.3^{\mathrm{ab}}$ & $2.1^{\mathrm{c}}$ & $1.2^{\mathrm{a}}$ & 2.0 & $0.1^{\mathrm{a}}$ & $0.1^{\mathrm{bc}}$ & $0.1^{\mathrm{ab}}$ \\
\hline Shoulder & $6.0^{\mathrm{b}}$ & $1.0^{\mathrm{b}}$ & $1.2^{\mathrm{c}}$ & $1.3^{\mathrm{ab}}$ & $2.0^{\mathrm{a}}$ & $1.7^{\mathrm{a}}$ & $0.7^{\mathrm{c}}$ & $1.6^{\mathrm{a}}$ & $1.4^{\mathrm{b}}$ & 1.9 & $0.4^{\mathrm{b}}$ & $0.0^{\mathrm{ab}}$ & $0.1^{\mathrm{b}}$ \\
\hline \multicolumn{14}{|c|}{ Cooked Internal Temperature Endpoint } \\
\hline$P-$ value $^{\mathrm{d}}$ & 0.19 & 0.007 & 0.60 & $<0.0001$ & 0.001 & 0.01 & 0.88 & 0.009 & 0.11 & 0.007 & 0.09 & 0.08 & 0.97 \\
\hline $62.7^{\circ} \mathrm{C}$ & 5.6 & $0.6^{\mathrm{a}}$ & 0.6 & $1.7^{\mathrm{b}}$ & $2.2^{\mathrm{b}}$ & $1.9^{\mathrm{b}}$ & 0.3 & $2.1^{\mathrm{c}}$ & 1.1 & $2.0^{\mathrm{b}}$ & 0.1 & 0.1 & 0.1 \\
\hline $68.3^{\circ} \mathrm{C}$ & 5.7 & $0.8^{\mathrm{ab}}$ & 0.5 & $1.5^{\mathrm{b}}$ & $2.1^{\mathrm{b}}$ & $1.8^{\mathrm{b}}$ & 0.4 & $2.0^{b c}$ & 1.2 & $2.0^{\mathrm{b}}$ & 0.2 & 0.1 & 0.1 \\
\hline $73.8^{\circ} \mathrm{C}$ & 5.7 & $1.0^{\mathrm{b}}$ & 0.6 & $0.9^{\mathrm{a}}$ & $2.0^{\mathrm{b}}$ & $1.8^{\mathrm{ab}}$ & 0.4 & $1.8^{\mathrm{ab}}$ & 1.3 & $1.9^{\mathrm{ab}}$ & 0.3 & 0.1 & 0.1 \\
\hline $79.4^{\circ} \mathrm{C}$ & 5.7 & $1.1^{\mathrm{b}}$ & 0.6 & $0.8^{\mathrm{a}}$ & $1.9^{\mathrm{a}}$ & $1.6^{\mathrm{a}}$ & 0.4 & $1.7^{\mathrm{a}}$ & 1.2 & $1.8^{\mathrm{a}}$ & 0.2 & 0.0 & 0.1 \\
\hline RMSE $^{\mathrm{e}}$ & 0.31 & 0.48 & 0.31 & 0.49 & 0.26 & 0.24 & 0.20 & 0.39 & 0.20 & 0.26 & 0.18 & 0.11 & 0.14 \\
\hline
\end{tabular}

${ }^{\mathrm{abc}}$ Mean values within a column followed by the same letter are not significantly different $(\mathrm{P}>0.05)$

${ }^{\mathrm{d}} P$ - value from analysis of variance tables.

${ }^{\mathrm{e}}$ Root Mean Square Error 
Table 4. Overall means and standard deviation values for volatile, aromatic chemicals identified by the GC/MS.

\begin{tabular}{|c|c|c|c|c|c|c|}
\hline \multirow{2}{*}{\multicolumn{2}{|c|}{ Code: Volatile, Aromatic Chemical }} & \multicolumn{3}{|c|}{ Retention } & \multicolumn{2}{|l|}{ Standard } \\
\hline & & Time & $\mathrm{n}$ & Mean & Deviation & Classification \\
\hline c1: & 2-Octenal & 17.05 & 94 & 109265 & 145707 & Aldehyde \\
\hline $\mathrm{c} 2:$ & 2,4-Nonadienal & 21.46 & 94 & 21800 & 34401 & Aldehyde \\
\hline c3: & 3-Octanone & 14.83 & 94 & 10531 & 101156 & Ketone \\
\hline c4: & 5-Pentyl-2(5H)-furanone & 25.84 & 94 & 2325 & 10591 & Ketone; Furan \\
\hline c6: & Acetophenone & 18.98 & 94 & 1768 & 8484 & Ketone; Benzene \\
\hline c7: & Benzaldehyde & 16.31 & 94 & 443717 & 573934 & Aldehyde; Benzene \\
\hline c8: & 3-Ethyl-benzaldehyde & 20.86 & 94 & 11947 & 25394 & Aldehyde; Benzene \\
\hline c9: & Decanal & 20.19 & 94 & 43786 & 47202 & Aldehyde \\
\hline c10: & Dodecane & 19.28 & 94 & 84600 & 210648 & Alkane \\
\hline c11: & 2-Pentyl-furan & 14.35 & 94 & 276989 & 427206 & Furan \\
\hline c12: & Hexanoic acid & 20.21 & 94 & 39400 & 52999 & Acid \\
\hline c13: & N-heptanal & 12.22 & 94 & 283511 & 480526 & Aldehyde \\
\hline c14: & Nonanal & 17.65 & 94 & 1740909 & 1315541 & Aldehyde \\
\hline c15: & Nonenal & 19.45 & 94 & 48843 & 58981 & Aldehyde \\
\hline c16: & Octanal & 15.13 & 94 & 1052276 & 1023654 & Aldehyde \\
\hline c17: & Phenol & 22.55 & 94 & 16309 & 31885 & Alcohol; Benzene \\
\hline c18: & Phenyl acetaldehyde & 18.54 & 94 & 17830 & 23341 & Aldehyde; Benzene \\
\hline c19: & Styrene & 12.53 & 94 & 21701 & 24503 & Alkene; Benzene \\
\hline c20: & 1-Heptanol & 15.39 & 94 & 87992 & 109241 & Alcohol \\
\hline c21: & (E)-2-decenal & 22.01 & 94 & 86144 & 108868 & Aldehyde \\
\hline c22: & 2,3-Octanedione & 14.73 & 94 & 200898 & 18884430 & Ketone \\
\hline c23: & 2,4-Decadienal & 23.00 & 94 & 32790 & 106359 & Aldehyde \\
\hline c24: & Hexanal & 9.40 & 94 & 2941517 & 3072000 & Aldehyde \\
\hline c25: & 3-Isopropyl-piperidine & 18.25 & 94 & 532.8 & 4232 & Nitrogen \\
\hline
\end{tabular}


Table 4 (Continued).

\begin{tabular}{|c|c|c|c|c|c|c|}
\hline & & Retention & & & Standard & \\
\hline Code & Volatile, Aromatic Chemical & Time & $\mathrm{n}$ & Mean & Deviation & Classification \\
\hline c26: & Tridecanal & 24.51 & 94 & 3745 & 13541 & Aldehyde \\
\hline c27: & Undecenal & 24.21 & 94 & 16643 & 45508 & Aldehyde \\
\hline c29: & 1-Octanol & 17.78 & 94 & 59376 & 153121 & Alcohol \\
\hline c30: & 1-Octen-3-ol & 15.47 & 94 & 111734 & 288139 & Alcohol \\
\hline c32: & 2-Docecen-1-al & 22.30 & 94 & 9146 & 29409 & Aldehyde \\
\hline c33: & (E)-2-nonenal & 19.56 & 94 & 21073 & 50326 & Aldehyde \\
\hline c34: & 1,3-Bis (1,1-dimethylethyl)-benzene & 20.76 & 94 & 41972 & 70681 & Benzene \\
\hline c35: & Benzothiazole & 23.83 & 94 & 5300 & 16038 & Benzene; Nitrogen; \\
\hline Sulfi & & & & & & \\
\hline c37: & Dl-limonene & 15.22 & 94 & 8853 & 31428 & Alkene \\
\hline c38: & Heptanal & 12.31 & 94 & 300203 & 606609 & Aldehyde \\
\hline c40: & 4-Methyl-phenol & 23.83 & 94 & 8536 & 23315 & Alcohol; Benzene \\
\hline c41: & 2,5-Dimethyl-pyrazine & 13.55 & 94 & 36419 & 66333 & Pyrazine; Nitrogen \\
\hline c42: & 3-Ethyl-2,5-dimethyl-pyrazine & 17.45 & 94 & 11658 & 24209 & Pyrazine; Nitrogen \\
\hline c43: & Tridecane & 21.16 & 94 & 5532 & 21641 & Alkane \\
\hline c44: & 1-Octen-3-ol & 15.46 & 94 & 233775 & 414964 & Alcohol \\
\hline c45: & 1-Octen-3-one & 14.49 & 94 & 22976 & 51396 & Ketone \\
\hline c46: & 1-Pentanol & 10.22 & 94 & 55901 & 111844 & Alcohol \\
\hline c47: & 2-Methylene cyclopentanol & 21.81 & 94 & 1518 & 10519 & Alcohol; Alkene \\
\hline c48: & 3-Dodecen-1-al & 23.80 & 94 & 28286 & 82120 & Aldehyde \\
\hline c50: & Benzene acetaldehyde & 18.56 & 94 & 6728 & 21122 & Aldehyde; Benzene \\
\hline c51: & 1-(1H-pyrrol-2-yl)-ethanone & 22.43 & 94 & 1725 & 9439 & Ketone; Nitrogen \\
\hline c52: & N-caproic acid, vinyl ester & 15.39 & 94 & 60120 & 206785 & Acid \\
\hline c54: & Nonanoic acid & 20.38 & 94 & 1103 & 7542 & Acid \\
\hline c55: & 2-Ethyl-5-methyl-pyrazine & 15.69 & 94 & 3496 & 11183 & Pyrazine; Nitrogen \\
\hline
\end{tabular}


Table 4 (Continued).

\begin{tabular}{|c|c|c|c|c|c|c|}
\hline Code: & Volatile, Aromatic Chemical & $\begin{array}{l}\text { Retention } \\
\text { Time } \\
\text { (min) }\end{array}$ & $\mathrm{n}$ & Mean & $\begin{array}{l}\text { Standard } \\
\text { Deviation }\end{array}$ & Classification \\
\hline c57: & 2-Ethyl-6-methyl-pyrazine & 15.65 & 94 & 625.1 & 3823 & Pyrazine; Nitrogen \\
\hline c58: & Trimethyl-pyrazine & 15.80 & 94 & 27520 & 53188 & Pyrazine: Nitrogen \\
\hline c60: & 1-Hexanol & 12.82 & 94 & 16690 & 1568866 & Alcohol \\
\hline c61: & 1-Pyrrolidine carboxaldehyde & 18.83 & 94 & 905.4 & 4007 & Aldehyde; Nitrogen \\
\hline c63: & (E)-2-octen-1-ol & 18.23 & 94 & 13602 & 44767 & Alcohol \\
\hline c64: & 2,4 Decadienal & 23.74 & 94 & 4285 & 17851 & Aldehyde \\
\hline c65: & 2,4 Heptadienal & 16.70 & 94 & 2278 & 14852 & Aldehyde \\
\hline c66: & Octanoic acid & 21.41 & 94 & 4125 & 28769 & Acid \\
\hline c67: & Pentanal & 8.32 & 94 & 18559 & 60489 & Aldehyde \\
\hline c69: & 2-Ethyl-3,5-dimethyl-pyrazine & 17.55 & 94 & 1351 & 5252 & Pyrazine; Nitrogen \\
\hline c72: & 2-Acetyl thiazole & 18.28 & 94 & 2771 & 10139 & Nitrogen; Sulfur \\
\hline c73: & 2-Butylfuran & 11.73 & 94 & 2141 & 14605 & Furan \\
\hline c74: & 2-Heptanone & 12.00 & 94 & 16528 & 42887 & Ketone \\
\hline c75: & (E)-2-heptenal & 14.40 & 94 & 40494 & 115477 & Aldehyde \\
\hline c77: & 1-Methyl-4-(1-methylethyl)-benzene & 15.64 & 94 & 1630 & 11938 & Benzene \\
\hline c79: & 2-Ethyl-1-hexanol & 16.61 & 94 & 1232 & 8698 & Alcohol \\
\hline c80: & (E)-2-hexenal & 12.28 & 94 & 7618 & 24899 & Aldehyde \\
\hline c82: & (E)-2-octenal & 17.01 & 94 & 68215 & 145413 & Aldehyde \\
\hline c83: & 1-Propoxy-2-propanol & 11.30 & 94 & 2134 & 11617 & Alcohol \\
\hline c84: & 2,5-Octanedione & 14.80 & 94 & 264184 & 103573 & Ketone \\
\hline c86: & Ethyl-benzene & 8.41 & 94 & 1080 & 6150 & Benzene \\
\hline c87: & Hexadecane & 19.89 & 94 & 1508 & 7500 & Alkane \\
\hline c90: & Methyl-pyrazine & 11.43 & 94 & 2133 & 15453 & Pyrazine; Nitrogen \\
\hline c91: & 6-Methyl-2-heptanone & 14.42 & 94 & 1743 & 7552 & Ketone \\
\hline
\end{tabular}


Table 4 (Continued).

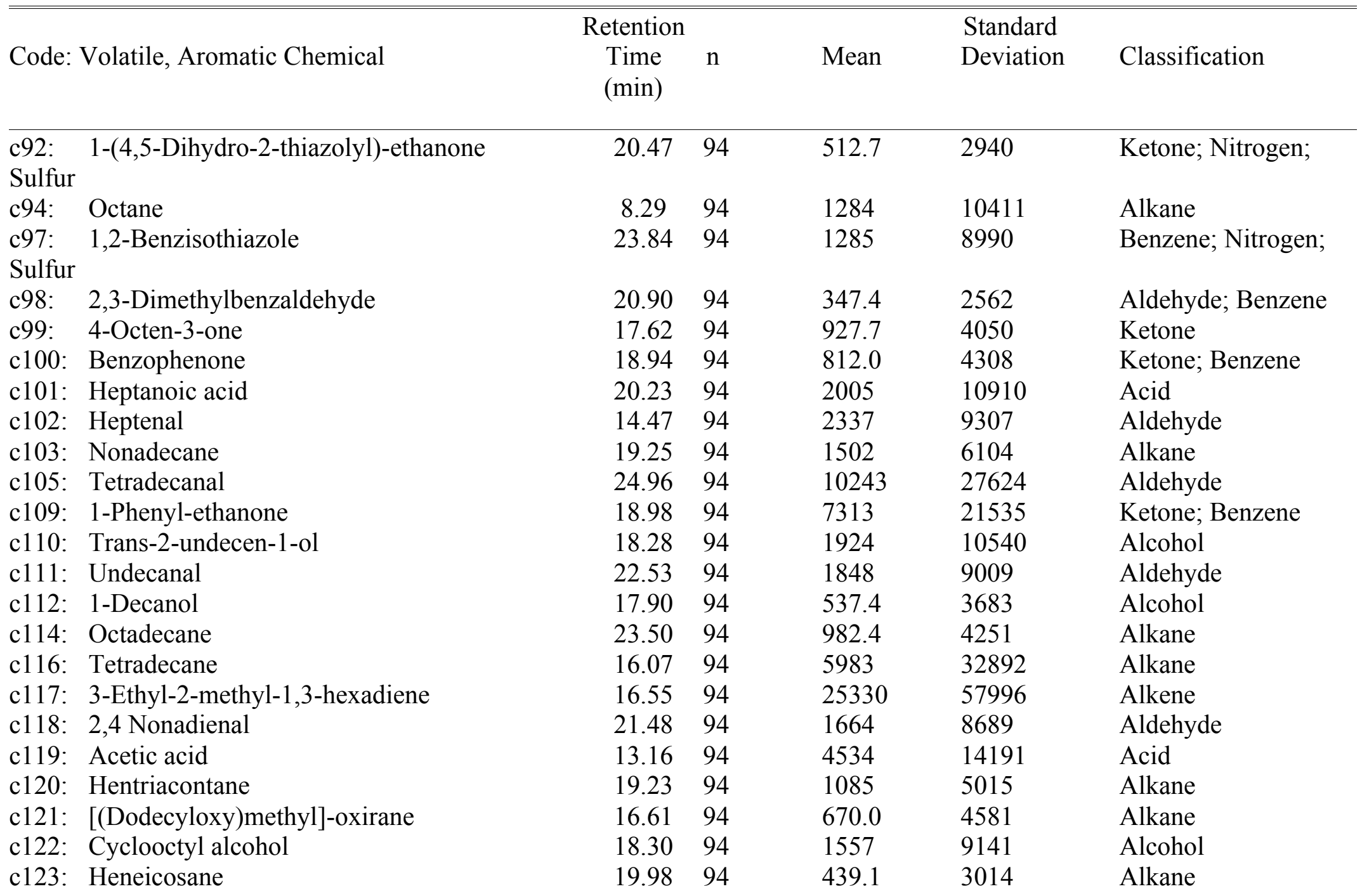


Table 4 (Continued).

\begin{tabular}{lcccc}
\hline \hline & Retention & & Standard \\
Code: Volatile, Aromatic Chemical & $\begin{array}{c}\text { Time } \\
(\min )\end{array}$ & $\mathrm{n}$
\end{tabular}$\quad$ Mean $\quad \begin{aligned} & \text { Deviation } \\
& \text { Classification }\end{aligned}$

c124: 2,5-Dimethyl-heptane

c128: Trans, trans-2,4-octadienal

c129: 2-Dodecen-1-ol

c131: 1-[2-(2-Methylbutyl)phenyl]ethanone

$14.91 \quad 94$

14.9194

2091

19.6494

2091

$18.34 \quad 94$

1644

15502

8601

Alkane

$20.84 \quad 94$

685.7

$16.55 \quad 94$

5004

4957

c132: (E,E)-2,4-heptadienal

c133: 4-Ethyl-benzaldehyde

20.8294

3208

27058

$15.44 \quad 94$

1852

12116

c134: 1,1'-Oxybis-heptane

c135: 1-Tetradecanol

$16.81 \quad 94$

6138

12721

46636

c138: 1,2-Dimethylpyrrolidine

$25.83 \quad 94$

433.5

862.1

c139: 2-butyl-2-octenal

$23.71 \quad 94$

608.8

c140: N,N'-bis (3-aminopropyl)-1,3-propanediamine

17.1494

440.6

$16.64 \quad 94$

1399

c144: Heptanol

c145: (1-Methylbutyl)-oxirane

$15.27 \quad 94$

2863

$12.83 \quad 94$

1370

$22.77 \quad 94$

357.8

c150: Pentadecane

c151: Trans-2-tridecenal

c152: Dodecanal

c154: Octadecanal

c155: 2,3,5-Trimethyl pyrazine

c158: (Z)-2-dodecene

c159: (E)-4-dodecene

c160: Nonacosane

c161: Hexadecanal

c162: 1,1-Bis(dodecyloxy)-hexadecane

$22.57 \quad 94$

1707

$\begin{array}{lll}22.71 & 94 & 3389\end{array}$

$22.57 \quad 94$

10905

$25.07 \quad 94$

1305

3217

5883

4161

2610

9549

16081

8207

2520

6575

20960

48985

15.8294

7151

8954

$19.55 \quad 94$

771.7

29537

$19.15 \quad 94$

1055

5758

$20.70 \quad 94$

186.7

8748

$20.70 \quad 94$

325.6

1279

$22.54 \quad 94$

2228

$339.7 \quad 2514$

Aldehyde

Alcohol

Ketone; Benzene

Aldehyde

Aldehyde; Benzene

Alkane

Alcohol

Nitrogen

Aldehyde

Alkane; Nitrogen

Alkane

Alcohol

Alkane

Aldehyde

Alkane

Aldehyde

Aldehyde

Aldehyde

Pyrazine; Nitrogen

Alkene

Alkene

Alkane

Aldehyde

Alkane 
Table 4 (Continued).

\begin{tabular}{|c|c|c|c|c|c|}
\hline \multirow{2}{*}{ Code: Volatile, Aromatic Chemical } & \multirow{2}{*}{$\begin{array}{l}\text { Retention } \\
\text { Time } \\
\text { (min) }\end{array}$} & \multirow[b]{2}{*}{$\mathrm{n}$} & \multirow[b]{2}{*}{ Mean } & \multicolumn{2}{|l|}{ Standard } \\
\hline & & & & Deviation & Classification \\
\hline Cyclooctane & 17.74 & 94 & 19517 & 84798 & Alkane \\
\hline c164: 2-Decanone & 19.01 & 94 & 773.4 & 4815 & Ketone \\
\hline c166: Cycloheptane & 16.49 & 94 & 2663 & 18550 & Alkane \\
\hline c167: 2-Nonanone & 17.75 & 94 & 941.9 & 6638 & Ketone \\
\hline \multicolumn{6}{|l|}{ c170: 3-(1,1-Dimethylethyl)- } \\
\hline 2,2,4,4-tetramethyl-3-pentanol & 14.82 & 94 & 3015 & 24167 & Alcohol \\
\hline c171: Butanoic acid & 16.60 & 94 & 3955 & 22509 & Acid \\
\hline c172: Octenal & 16.91 & 94 & 4984 & 34138 & Aldehyde \\
\hline c173: 1,3,5,7-Cyclooctatetraene & 12.58 & 94 & 848.7 & 5792 & Alkene \\
\hline c174: 4-(2-Propenyl)-1H-imidazole & 21.34 & 94 & 1688 & 8734 & Nitrogen \\
\hline c175: Chavicol & 20.87 & 94 & 466.4 & 3000 & Alcohol; Benzene \\
\hline c177: Formic acid, heptyl ester & 15.35 & 94 & 757.6 & 6468 & Acid \\
\hline c182: 6,7-Dodecanedione & 14.63 & 94 & 7190 & 53584 & Ketone \\
\hline c183: Cyclooctanol & 18.23 & 94 & 2321 & 13066 & Alcohol \\
\hline c184: 3-(Methylthio)-propanal & 14.76 & 94 & 1025 & 6344 & Aldehyde; Sulfur \\
\hline c185: 2-Methyl-3-octanone & 14.81 & 94 & 8308 & 76339 & Ketone \\
\hline c186: 2-Dodecenal & 24.24 & 94 & 999.2 & 6899 & Aldehyde \\
\hline Dihydro-2(3H)-furanone & 17.20 & 94 & 4073 & 31030 & Ketone; Furan \\
\hline c189: 2-Ethyl-cyclobutanone & 10.21 & 94 & 590.7 & 4297 & Ketone \\
\hline c190: Nitro-L-arginine & 20.94 & 94 & 470.1 & 3241 & Nitrogen \\
\hline c192: 3-(1,1-Dimethylethyl)-2,2,4,4- & & & & & \\
\hline tetramethyl-3-pentanol, & 14.94 & 94 & 3141 & 24889 & Alcohol \\
\hline c194: Decane & 17.88 & 94 & 506.7 & 3473 & Alkane \\
\hline c196: 3-Methyl-butanal & 11.33 & 94 & 1959 & 13433 & Aldehyde \\
\hline c197: (E,E)-2,4-Octadienal & 19.02 & 94 & 1316 & 7460 & Aldehyde \\
\hline
\end{tabular}


Table 4 (Continued).

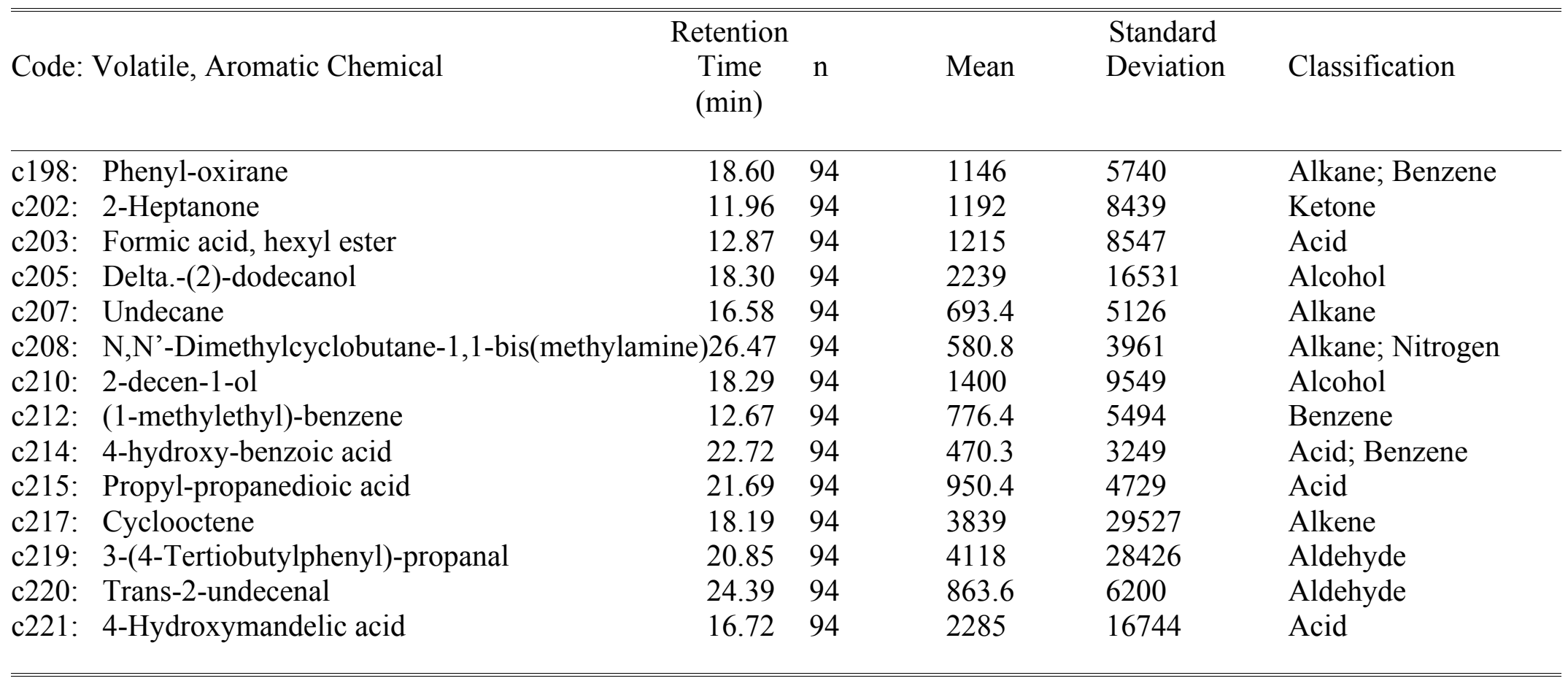


Table 5. Flavor aromatic compound categories least squares means for pork cuts and degrees of doneness.

\begin{tabular}{|c|c|c|c|c|c|c|c|}
\hline Effects & $\begin{array}{l}\text { Sulfur- } \\
\text { Containing }\end{array}$ & $\begin{array}{l}\text { Nitrogen- } \\
\text { Containing }\end{array}$ & Aldehydes & Alcohols & Ketones & Acids & Alkanes \\
\hline \multicolumn{8}{|l|}{ Cut } \\
\hline$P-$ value $^{\mathrm{d}}$ & 0.004 & $<0.0001$ & 0.02 & 0.04 & 0.01 & 0.50 & 0.07 \\
\hline Tenderloin & $18551.8^{\mathrm{b}}$ & $49558.6^{\mathrm{a}}$ & $6712898.8^{\mathrm{a}}$ & $589989.3^{\mathrm{ab}}$ & $286166.4^{\mathrm{ab}}$ & 134313.7 & 276597.1 \\
\hline Loin & $20493.9^{b}$ & $237873.3^{\mathrm{c}}$ & $8319270.2^{\mathrm{ab}}$ & $835753.7^{\mathrm{b}}$ & $451037.7^{\mathrm{b}}$ & 138311.3 & 111458.9 \\
\hline Ham & $-1626.4^{a}$ & $125690.5^{\mathrm{b}}$ & $9888075.3^{\mathrm{b}}$ & $861914.6^{\mathrm{b}}$ & $424764.6^{\mathrm{b}}$ & 177232.6 & 79794.4 \\
\hline Shoulder & $8637.3^{\mathrm{ab}}$ & $30932.8^{\mathrm{a}}$ & $5643161.4^{\mathrm{a}}$ & $315316.9^{\mathrm{a}}$ & $159087.1^{\mathrm{a}}$ & 75904.5 & 78776.7 \\
\hline \multicolumn{8}{|c|}{ Cooked Internal temperature Endpoint } \\
\hline$P-$ value $^{\mathrm{d}}$ & 0.90 & 0.62 & 0.03 & 0.15 & 0.21 & 0.03 & 0.47 \\
\hline $62.7^{\circ} \mathrm{C}$ & 11078.6 & 101941.2 & $9516677.0^{\mathrm{b}}$ & 973698.8 & 367622.4 & $268133.5^{\mathrm{b}}$ & 171382.3 \\
\hline $68.3^{\circ} \mathrm{C}$ & 11832.1 & 112014.7 & $4928411.9^{\mathrm{a}}$ & 465215.5 & 196914.0 & $62127.1^{\mathrm{a}}$ & 58525.5 \\
\hline $73.8^{\circ} \mathrm{C}$ & 9188.0 & 93643.0 & $8038629.2^{\mathrm{b}}$ & 551017.1 & 389716.8 & $96872.7^{\mathrm{a}}$ & 130978.8 \\
\hline $79.4^{\circ} \mathrm{C}$ & 13957.9 & 136456.3 & $8079687.6^{\mathrm{b}}$ & 613043.2 & 366802.7 & $98628.7^{\mathrm{a}}$ & 185740.4 \\
\hline $\mathrm{RMSE}^{\mathrm{e}}$ & 20548.64 & 112421.6 & 4656991 & 687462.9 & 3165831.7 & 216975.8 & 270249.0 \\
\hline
\end{tabular}

${ }^{\mathrm{abc}}$ Mean values within a column followed by the same letter are not significantly different $(\mathrm{P}>0.05)$

${ }^{\mathrm{d}} P$ - value from analysis of variance tables.

${ }^{\mathrm{e}}$ Root Mean Square Error 
Table 5 (Continued).

\begin{tabular}{|c|c|c|c|c|}
\hline Effects & Alkenes & Furans & Pyrazines & Benzenes \\
\hline$P-$ value $^{\mathrm{d}}$ & \multirow{2}{*}{0.24} & 0.22 & $<0.0001$ & 0.02 \\
\hline \multicolumn{4}{|l|}{ Cuts } & \\
\hline$\overline{\text { Tenderloin }}$ & 65669.5 & 231076.7 & $20778.4^{\mathrm{a}}$ & $716338.0^{\mathrm{b}}$ \\
\hline Loin & 89294.3 & 309351.6 & $213443.2^{\mathrm{c}}$ & $764880.0^{\mathrm{b}}$ \\
\hline Ham & 71958.9 & 441924.9 & $121999.6^{\mathrm{b}}$ & $678713.8^{\mathrm{b}}$ \\
\hline Shoulder & 30001.3 & 205040.7 & $15666.3^{\mathrm{a}}$ & $270997.8^{\mathrm{a}}$ \\
\hline \multicolumn{5}{|c|}{ Cooked Internal Temperature Endpoint } \\
\hline$P-$ value $^{\mathrm{d}}$ & 0.05 & 0.13 & 0.94 & 0.96 \\
\hline $62.7^{\circ} \mathrm{C}$ & 117384.1 & 462800.4 & 88900.0 & 618075.2 \\
\hline $68.3^{\circ} \mathrm{C}$ & 32379.4 & 143045.9 & 95458.7 & 635373.4 \\
\hline $73.8^{\circ} \mathrm{C}$ & 45399.0 & 299105.8 & 83520.0 & 627516.9 \\
\hline $79.4^{\circ} \mathrm{C}$ & 61761.6 & 282441.9 & 104008.9 & 549964.1 \\
\hline $\mathrm{RMSE}^{\mathrm{e}}$ & 94674.56 & 399453.8 & 113301.7 & 545616.4 \\
\hline
\end{tabular}

$\begin{array}{lllll}\text { RMSE }^{\mathrm{e}} & 94674.56 & 399453.8 & 113301.7 & 545616.4\end{array}$

${ }^{\mathrm{abc}}$ Mean values within a column followed by the same letter are not significantly different $(\mathrm{P}>0.05)$

${ }^{\mathrm{d}} P$ - value from analysis of variance tables.

${ }^{\mathrm{e}}$ Root Mean Square Error 
Table 6. Simple correlation coefficients ${ }^{\mathrm{a}}$ between trained descriptive sensory attributes and volatiles.

\begin{tabular}{|c|c|c|c|c|c|c|}
\hline Effect & $\begin{array}{c}\text { Pork } \\
\text { Identity }\end{array}$ & $\begin{array}{l}\text { Brown/ } \\
\text { Roasted }\end{array}$ & $\begin{array}{l}\text { Fat- } \\
\text { Like }\end{array}$ & $\begin{array}{l}\text { Bloody/ } \\
\text { Serumy }\end{array}$ & Metallic & Astringent \\
\hline c1 2-Octenal & -0.18 & -0.18 & 0.07 & 0.10 & 0.05 & 0.09 \\
\hline c2 2,4-Nonadienal & 0.11 & -0.06 & 0.22 & -0.03 & -0.30 & -0.15 \\
\hline c3 3-Octanone & -0.13 & -0.05 & -0.04 & 0.00 & -0.02 & -0.06 \\
\hline c4 5-Pentyl-2(5H)- & & & & & & \\
\hline furanone & 0.19 & 0.19 & 0.02 & -0.13 & -0.09 & -0.16 \\
\hline c6 Acetophenone & 0.02 & -0.08 & -0.11 & 0.00 & 0.11 & 0.08 \\
\hline c7 Benzaldehyde & -0.19 & -0.08 & -0.22 & -0.04 & 0.01 & 0.05 \\
\hline c8 3-Ethyl-benzaldehyd & de 0.06 & -0.10 & -0.02 & -0.03 & -0.10 & -0.01 \\
\hline c9 Decanal & -0.09 & 0.03 & -0.21 & -0.13 & 0.02 & 0.03 \\
\hline c10 Dodecane & -0.10 & -0.11 & -0.16 & -0.09 & 0.07 & 0.06 \\
\hline c11 2-Pentyl-furan & -0.17 & -0.06 & -0.19 & -0.01 & 0.12 & 0.08 \\
\hline c12 Hexanoic acid & -0.02 & -0.03 & -0.02 & 0.09 & 0.19 & 0.14 \\
\hline c13 N-heptanal & 0.05 & -0.01 & 0.06 & 0.10 & 0.17 & 0.18 \\
\hline c14 Nonanal & -0.25 & -0.22 & -0.19 & 0.09 & 0.19 & 0.19 \\
\hline c15 Nonenal & -0.02 & -0.04 & -0.04 & 0.03 & -0.05 & 0.06 \\
\hline c16 Octanal & -0.22 & -0.19 & -0.06 & 0.11 & 0.18 & 0.19 \\
\hline c17 Phenol & 0.11 & 0.15 & -0.03 & -0.13 & -0.17 & -0.22 \\
\hline c18 Phenyl acetaldehyd & de 0.01 & 0.27 & -0.04 & -0.05 & -0.03 & -0.05 \\
\hline c19 Styrene & -0.02 & 0.11 & -0.17 & -0.05 & -0.04 & -0.01 \\
\hline c20 1-Heptanol & -0.26 & -0.26 & -0.03 & 0.26 & 0.22 & 0.25 \\
\hline c21 (E)-2-decenal & 0.09 & -0.04 & 0.16 & -0.05 & -0.22 & -0.14 \\
\hline c22 2,3-Octanedione & -0.22 & -0.14 & -0.05 & 0.06 & 0.08 & 0.09 \\
\hline c23 2,4-Decadienal & 0.29 & 0.17 & 0.19 & -0.16 & -0.36 & -0.27 \\
\hline c24 Hexanal & -0.02 & 0.02 & -0.15 & -0.01 & 0.16 & 0.06 \\
\hline
\end{tabular}


Table 6 (Continued).

\begin{tabular}{|c|c|c|c|c|c|c|}
\hline Effect & $\begin{array}{c}\text { Pork } \\
\text { Identity }\end{array}$ & $\begin{array}{l}\text { Brown/ } \\
\text { Roasted }\end{array}$ & $\begin{array}{l}\text { Fat- } \\
\text { Like }\end{array}$ & $\begin{array}{l}\text { Bloody/ } \\
\text { Serumy }\end{array}$ & Metallic & Astringent \\
\hline \multicolumn{7}{|l|}{ c25 3-Isopropyl- } \\
\hline $\begin{array}{l}\text { piperidine } \\
\text { c26 Tridecanal }\end{array}$ & $\begin{array}{r}-0.00 \\
0.10\end{array}$ & $\begin{array}{r}-0.05 \\
0.21\end{array}$ & $\begin{array}{r}-0.03 \\
0.00\end{array}$ & $\begin{array}{l}-0.03 \\
-0.05\end{array}$ & $\begin{array}{l}-0.10 \\
-0.01\end{array}$ & $\begin{array}{l}-0.13 \\
-0.02\end{array}$ \\
\hline c27 Undecenal & 0.14 & 0.09 & 0.04 & 0.06 & -0.08 & -0.07 \\
\hline c29 1-Octanol & -0.00 & 0.04 & -0.00 & -0.05 & 0.04 & -0.00 \\
\hline c30 1-Octen-3-ol & -0.09 & -0.09 & -0.07 & -0.02 & 0.03 & 0.04 \\
\hline c32 2-Docecen-1-al & -0.04 & -0.02 & -0.10 & -0.02 & 0.07 & 0.10 \\
\hline c33 (E)-2-nonenal & -0.02 & -0.07 & 0.09 & 0.02 & 0.06 & -0.02 \\
\hline \multicolumn{7}{|l|}{ c34 1,3-Bis $(1,1-$ di- } \\
\hline methylethyl)-benzene & -0.11 & -0.08 & -0.25 & -0.07 & 0.02 & 0.06 \\
\hline c35 Benzothiazole & -0.16 & 0.04 & -0.08 & -0.15 & -0.23 & -0.11 \\
\hline c37 Dl-limonene & -0.05 & 0.10 & -0.04 & -0.00 & 0.12 & 0.04 \\
\hline c38 Heptanal & -0.20 & -0.11 & -0.09 & 0.06 & 0.13 & 0.05 \\
\hline c40 4-Methyl-phenol & -0.05 & -0.09 & -0.00 & 0.20 & 0.07 & 0.10 \\
\hline \multicolumn{7}{|l|}{ c41 2,5-Dimethyl- } \\
\hline pyrazine & 0.18 & 0.24 & -0.17 & -0.19 & -0.03 & -0.05 \\
\hline \multicolumn{7}{|l|}{ c42 3-Ethyl-2,5- } \\
\hline dimethyl-pyrazine & 0.19 & 0.30 & -0.19 & -0.23 & -0.08 & -0.10 \\
\hline c43 Tridecane & 0.03 & -0.04 & 0.01 & -0.12 & 0.02 & 0.01 \\
\hline c44 1 Octen 3 ol & -0.23 & -0.12 & -0.13 & 0.00 & 0.07 & 0.08 \\
\hline c45 1-Octen-3-one & -0.03 & 0.05 & -0.15 & -0.02 & 0.10 & 0.05 \\
\hline c46 1-Pentanol & 0.32 & -0.07 & -0.11 & -0.08 & 0.04 & -0.06 \\
\hline \multicolumn{7}{|l|}{ c47 2-Methylene cyclo- } \\
\hline pentanol & 0.07 & 0.02 & -0.08 & -0.11 & -0.06 & -0.07 \\
\hline c48 3-Dodecen-1-al & 0.10 & -0.02 & 0.09 & -0.11 & -0.27 & -0.20 \\
\hline
\end{tabular}


Table 6 (Continued).

\begin{tabular}{|c|c|c|c|c|c|c|}
\hline Effect & $\begin{array}{c}\text { Pork } \\
\text { Identity }\end{array}$ & $\begin{array}{l}\text { Brown/ } \\
\text { Roasted }\end{array}$ & $\begin{array}{l}\text { Fat- } \\
\text { Like }\end{array}$ & $\begin{array}{l}\text { Bloody/ } \\
\text { Serumy }\end{array}$ & Metallic & Astringent \\
\hline \multicolumn{7}{|l|}{ c50 Benzene } \\
\hline c51 1-(1H-pyrrol-2-yl)- & -0.00 & 0.18 & -006 & -0.00 & 015 & 007 \\
\hline \multicolumn{7}{|c|}{ c52 N-caproic acid vinyl } \\
\hline ester & -0.12 & -0.15 & -0.12 & 0.03 & 0.08 & 0.08 \\
\hline c54 Nonanoic acid & 0.08 & 0.03 & -0.06 & -0.06 & -0.02 & 0.07 \\
\hline \multicolumn{7}{|l|}{ c55 2-Ethyl-5-methyl- } \\
\hline \multicolumn{7}{|l|}{ c57 2-Ethyl-6-methyl- } \\
\hline pyrazine & 0.13 & 0.17 & -0.11 & -0.07 & -0.02 & -0.01 \\
\hline c58 Trimethyl-pyrazine & 0.11 & 0.25 & -0.19 & -0.22 & -0.09 & -0.10 \\
\hline c60 1-Hexanol & -0.13 & -0.04 & -0.04 & 0.02 & 0.08 & 0.05 \\
\hline \multicolumn{7}{|c|}{ c61 1-Pyrrolidine carbox- } \\
\hline aldehyde & -0.06 & -0.17 & 0.17 & -0.01 & -0.16 & -0.13 \\
\hline c63 (E)-2-octen-1-ol & -0.18 & -0.09 & -0.12 & 0.02 & 0.07 & 0.01 \\
\hline c64 2,4 Decadienal & -0.04 & -0.16 & -0.07 & 0.04 & 0.06 & -0.03 \\
\hline c65 2,4 Heptadienal & 0.02 & -0.03 & 0.21 & 0.03 & 0.01 & -0.10 \\
\hline c66 Octanoic acid & -0.12 & -0.05 & -0.02 & -0.02 & -0.01 & -0.06 \\
\hline c67 Pentanal & 0.03 & 0.00 & 0.09 & -0.01 & -0.03 & -0.09 \\
\hline \multicolumn{7}{|l|}{ c69 2-Ethyl-3,5-di- } \\
\hline methyl-pyrazine & -0.13 & -0.07 & -0.06 & 0.09 & 0.00 & 0.03 \\
\hline c72 2-Acetyl thiazole & -0.09 & 0.01 & -0.14 & 0.18 & 0.11 & 0.16 \\
\hline c73 2-Butylfuran & -0.07 & -0.06 & 0.12 & 0.06 & 0.09 & -0.04 \\
\hline c74 2-Heptanone & -0.07 & 0.08 & -0.16 & -0.06 & 0.10 & 0.12 \\
\hline
\end{tabular}


Table 6 (Continued).

\begin{tabular}{|c|c|c|c|c|c|c|}
\hline Effect & $\begin{array}{c}\text { Pork } \\
\text { Identity }\end{array}$ & $\begin{array}{l}\text { Brown/ } \\
\text { Roasted }\end{array}$ & $\begin{array}{l}\text { Fat- } \\
\text { Like }\end{array}$ & $\begin{array}{l}\text { Bloody/ } \\
\text { Serumy }\end{array}$ & Metallic & Astringent \\
\hline c75 (E)-2-heptenal & -0.08 & -0.08 & 0.22 & 0.06 & 0.04 & -0.09 \\
\hline \multicolumn{7}{|l|}{ c77 1-Methyl-4-(1- } \\
\hline c79 2-Ethyl-1-hexanol & $\begin{array}{r}0.21 \\
-0.09\end{array}$ & 0.00 & -0.08 & 0.07 & 0.08 & $\begin{array}{l}0.01 \\
0.15\end{array}$ \\
\hline c80 (E)-2-hexenal & -0.08 & -0.09 & 0.08 & -0.00 & 0.09 & -0.00 \\
\hline c82 (E)-2-octenal & 0.07 & 0.05 & -0.07 & -0.07 & -0.02 & -0.05 \\
\hline \multicolumn{7}{|l|}{ c83 1-Propoxy-2- } \\
\hline propanol & 0.07 & 0.15 & 0.01 & -0.02 & 0.07 & 0.08 \\
\hline c84 2,5-Octanedione & 0.04 & 0.18 & -0.08 & -0.05 & -0.05 & 0.04 \\
\hline c86 Ethyl-benzene & 0.08 & 0.15 & 0.01 & -0.01 & 0.06 & 0.05 \\
\hline c87 Hexadecane & -0.01 & -0.09 & -0.04 & 0.07 & 0.10 & 0.01 \\
\hline c90 Methyl-pyrazine & 0.02 & 0.05 & -0.09 & -0.06 & -0.07 & -0.10 \\
\hline c91 6-Methyl-2- & & & & & & \\
\hline heptanone & -0.25 & -0.26 & -0.05 & 0.08 & 0.09 & 0.06 \\
\hline \multicolumn{7}{|l|}{ c92 1-(4,5-Dihydro-2- } \\
\hline thiazolyl)-ethanone & -0.27 & -0.01 & -0.03 & 0.12 & -0.05 & 0.06 \\
\hline c94 Octane & 0.22 & 0.11 & 0.04 & -0.10 & -0.10 & -0.06 \\
\hline c97 1,2-Benzisothiazole & 0.14 & 0.08 & 0.19 & -0.09 & -0.05 & -0.07 \\
\hline \multicolumn{7}{|l|}{ c98 2,3-Dimethylbenz- } \\
\hline aldehyde & 0.19 & 0.19 & 0.38 & -0.13 & -0.05 & -0.11 \\
\hline c99 4-Octen-3-one & 0.26 & 0.22 & 0.08 & -0.05 & -0.08 & -0.03 \\
\hline c100 Benzophenone & 0.03 & 0.14 & -0.03 & -0.02 & 0.03 & -0.05 \\
\hline c101 Heptanoic acid & -0.15 & -0.06 & -0.06 & -0.09 & -0.07 & -0.08 \\
\hline c102 Heptenal & 0.10 & 0.08 & 0.06 & -0.11 & -0.18 & -0.08 \\
\hline c103 Nonadecane & -0.03 & 0.12 & -0.03 & -0.09 & -0.14 & -0.01 \\
\hline
\end{tabular}


Table 6 (Continued).

\begin{tabular}{|c|c|c|c|c|c|c|}
\hline Effect & $\begin{array}{l}\text { Pork } \\
\text { Identity }\end{array}$ & $\begin{array}{l}\text { Brown/ } \\
\text { Roasted }\end{array}$ & $\begin{array}{l}\text { Fat- } \\
\text { Like }\end{array}$ & $\begin{array}{l}\text { Bloody/ } \\
\text { Serumy }\end{array}$ & Metallic & Astringent \\
\hline c105 Tetradecanal & -0.11 & 0.07 & 0.03 & -0.07 & -0.35 & -0.19 \\
\hline \multicolumn{7}{|c|}{ c110 Trans-2-undecen- } \\
\hline$-1-\mathrm{ol}$ & -0.11 & -0.07 & -0.21 & -0.15 & 0.00 & 0.10 \\
\hline c111 Undecanal & -0.01 & 0.00 & -0.03 & -0.09 & -0.11 & -0.10 \\
\hline c112 1-Decanol & 0.12 & 0.22 & -0.09 & -0.04 & -0.01 & 0.01 \\
\hline c114 Octadecane & 0.00 & 0.13 & 0.06 & -0.06 & -0.01 & -0.03 \\
\hline c116 Tetradecane & -0.01 & -0.09 & -0.09 & -0.04 & 0.07 & 0.07 \\
\hline \multicolumn{7}{|c|}{ c117 3-Ethyl-2-methyl- } \\
\hline 1,3-hexadiene & -0.20 & -0.17 & -0.11 & -0.09 & 0.02 & -0.03 \\
\hline c118 2,4 Nonadienal & -0.05 & -0.01 & -0.07 & -0.15 & -0.14 & -0.18 \\
\hline c119 Acetic acid & -0.06 & -0.09 & -0.17 & 0.00 & 0.16 & 0.03 \\
\hline $\begin{array}{l}\text { c120 Hentriacontane } \\
\text { c121 [(Dodecyloxy) }\end{array}$ & -0.18 & 0.14 & -0.12 & 0.03 & 0.07 & 0.00 \\
\hline methyl]-oxirane & -0.11 & 0.08 & -0.03 & -0.13 & -0.02 & -0.04 \\
\hline c122 Cyclooctyl alcohol & 10.04 & -0.20 & -0.01 & 0.21 & 0.07 & 0.07 \\
\hline $\begin{array}{l}\text { c123 Heneicosane } \\
\text { c124 2,5-Dimethyl- }\end{array}$ & -0.05 & -0.20 & -0.08 & 0.03 & 0.03 & -0.06 \\
\hline $\begin{array}{l}\text { heptane } \\
\text { c128 Trans trans-24- }\end{array}$ & -0.01 & -0.11 & -0.04 & 0.24 & 0.16 & 0.14 \\
\hline octadienal & -0.01 & -0.03 & 0.24 & 0.02 & -0.05 & -0.17 \\
\hline c129 2-Dodecen-1-ol & 0.24 & 0.20 & 0.11 & -0.11 & -0.05 & -0.09 \\
\hline ethanone & -0.11 & -0.13 & -0.06 & 0.01 & 0.08 & 0.04 \\
\hline
\end{tabular}


Table 6 (Continued).

\begin{tabular}{|c|c|c|c|c|c|c|}
\hline Effect & $\begin{array}{l}\text { Pork } \\
\text { Identity }\end{array}$ & $\begin{array}{l}\text { Brown/ } \\
\text { Roasted }\end{array}$ & $\begin{array}{l}\text { Fat- } \\
\text { Like }\end{array}$ & $\begin{array}{l}\text { Bloody/ } \\
\text { Serumy }\end{array}$ & Metallic & Astringent \\
\hline \multicolumn{6}{|l|}{ c132 (E,E)-2,4-hepta- } & -0.11 \\
\hline $\begin{array}{l}\text { c133 4-Ethyl-benzalde- } \\
\text { hyde }\end{array}$ & 0.00 & 0.05 & 0.25 & -0.07 & -0.14 & -0.27 \\
\hline c134 1,1'-Oxybis-heptan & ne0.02 & 0.07 & 0.12 & 0.00 & 0.04 & -0.06 \\
\hline c135 1-Tetradecanol & -0.09 & -0.09 & -0.07 & -0.02 & -0.06 & -0.06 \\
\hline \multicolumn{7}{|c|}{ c138 1,2-Dimethylpyrro- } \\
\hline lidine & 0.00 & 0.03 & 0.12 & -0.15 & -0.26 & -0.29 \\
\hline c139 2-butyl-2-octenal & -0.05 & -0.15 & -0.04 & -0.01 & 0.04 & 0.00 \\
\hline $\begin{array}{l}\text { c140 N,N'-bis (3- } \\
\text { aminopropyl)-1,3-prop- }\end{array}$ & & & & & & \\
\hline $\begin{array}{l}\text { anediamine } \\
\text { c141 Ethylidene }\end{array}$ & 0.02 & 0.04 & -0.02 & -0.09 & -0.03 & 0.10 \\
\hline cycloheptane & 0.28 & 0.14 & 0.09 & -0.02 & 0.03 & -0.04 \\
\hline $\begin{array}{l}\text { c144 Heptanol } \\
\text { c145 (1-Methylbutyl)- }\end{array}$ & 0.22 & 0.03 & 0.13 & -0.13 & -0.02 & -0.05 \\
\hline oxirane & 0.11 & 0.16 & 0.00 & -0.17 & -0.11 & -0.09 \\
\hline c147 4-Oxononanal & 0.12 & 0.04 & 0.08 & -0.08 & -0.26 & -0.08 \\
\hline c150 Pentadecane & -0.14 & 0.17 & -0.14 & 0.06 & 0.17 & 0.07 \\
\hline c151 Trans-2-tridecenal & 0.01 & 0.21 & 0.02 & -0.06 & -0.15 & -0.03 \\
\hline c152 Dodecanal & -0.20 & 0.11 & 0.01 & -0.11 & -0.21 & -0.16 \\
\hline $\begin{array}{l}\text { c154 Octadecanal } \\
\text { c155 2,3,5-Trimethyl }\end{array}$ & 0.12 & 0.08 & 0.27 & -0.12 & -0.01 & -0.05 \\
\hline pyrazine & 0.09 & 0.15 & -0.15 & -0.01 & 0.03 & -0.02 \\
\hline c158 (Z)-2-dodecene & 0.00 & -0.07 & -0.11 & -0.13 & 0.07 & 0.08 \\
\hline
\end{tabular}


Table 6 (Continued).

\begin{tabular}{|c|c|c|c|c|c|c|}
\hline Effect & $\begin{array}{c}\text { Pork } \\
\text { Identity }\end{array}$ & $\begin{array}{l}\text { Brown/ } \\
\text { Roasted }\end{array}$ & $\begin{array}{l}\text { Fat- } \\
\text { Like }\end{array}$ & $\begin{array}{l}\text { Bloody/ } \\
\text { Serumy }\end{array}$ & Metallic & Astringent \\
\hline c159(E)-4-dodecene & 0.37 & -0.07 & -0.07 & -0.13 & 0.03 & 0.07 \\
\hline c160 Nonacosane & 0.12 & 0.04 & -0.15 & -0.19 & -0.08 & -0.06 \\
\hline c161 Hexadecanal & -0.05 & -0.11 & 0.10 & 0.08 & 0.08 & 0.06 \\
\hline $\begin{array}{l}\text { c162 1,1-Bis(dode- } \\
\text { cyloxy)-hexadecane }\end{array}$ & 0.01 & 0.01 & -0.13 & -0.07 & -0.05 & -0.10 \\
\hline c163 Cyclooctane & -0.06 & -0.08 & -0.15 & 0.02 & 0.09 & 0.05 \\
\hline c164 2-Decanone & 0.17 & 0.24 & 0.02 & -0.10 & -0.06 & -0.02 \\
\hline c166 Cycloheptane & 0.12 & 0.10 & 0.10 & -0.06 & -0.08 & -0.11 \\
\hline c167 2-Nonanone & 0.11 & 0.15 & -0.03 & -0.05 & 0.01 & 0.08 \\
\hline \multicolumn{7}{|c|}{$\begin{array}{l}\text { c170 3-(1,1-Dimethylethyl)- } \\
\text { 2,2,4,4-tetramethyl-3- }\end{array}$} \\
\hline pentanol & 0.14 & 0.23 & -0.06 & -0.11 & -0.02 & 0.03 \\
\hline c171 Butanoic acid & 0.33 & 0.27 & 0.08 & -0.11 & 0.02 & -0.01 \\
\hline c172 Octenal & 0.03 & 0.12 & -0.09 & -0.11 & -0.08 & -0.10 \\
\hline \multicolumn{7}{|c|}{ c173 1,3,5,7-Cyclooctate- } \\
\hline $\begin{array}{l}\text { traene } \\
\text { c174 4-(2-Propenyl)- }\end{array}$ & 0.05 & -0.07 & 0.04 & 0.06 & -0.13 & 0.00 \\
\hline $1 \mathrm{H}$-imidazole & -0.02 & -0.12 & 0.22 & -0.02 & -0.24 & -0.12 \\
\hline c175 Chavicol & 0.06 & 0.16 & -0.09 & -0.12 & 0.06 & -0.01 \\
\hline $\begin{array}{l}\text { c177 Formic acid, } \\
\text { heptyl ester }\end{array}$ & -0.07 & -0.06 & -0.08 & -0.05 & -0.10 & -0.14 \\
\hline c182 6,7-Dodecanedion & e- 0.04 & 0.12 & -0.15 & -0.08 & 0.07 & 0.01 \\
\hline $\begin{array}{l}\text { c183 Cyclooctanol } \\
\text { c184 3-(Methylthio)- }\end{array}$ & 0.04 & 0.26 & -0.12 & -0.15 & 0.10 & 0.01 \\
\hline propanal & -0.07 & 0.09 & -0.08 & -0.02 & 0.05 & 0.10 \\
\hline
\end{tabular}


Table 6 (Continued).

\begin{tabular}{|c|c|c|c|c|c|c|}
\hline Effect & $\begin{array}{c}\text { Pork } \\
\text { Identity }\end{array}$ & $\begin{array}{l}\text { Brown/ } \\
\text { Roasted }\end{array}$ & $\begin{array}{l}\text { Fat- } \\
\text { Like }\end{array}$ & $\begin{array}{l}\text { Bloody/ } \\
\text { Serumy }\end{array}$ & Metallic & Astringent \\
\hline $\begin{array}{l}\text { c185 2-Methyl-3- } \\
\text { octanone }\end{array}$ & 0.09 & 0.17 & -0.09 & -0.06 & 0.12 & 0.01 \\
\hline $\begin{array}{l}\text { c186 2-Dodecenal } \\
\text { c188 Dihydro-2(3H)- }\end{array}$ & -0.06 & -0.09 & -0.03 & -0.05 & 0.01 & 0.07 \\
\hline $\begin{array}{l}\text { furanone } \\
\text { c189 2-Ethyl-cyclo- }\end{array}$ & -0.07 & -0.03 & -0.07 & -0.10 & -0.02 & 0.08 \\
\hline butanone & -0.10 & -0.12 & -0.03 & 0.03 & 0.03 & 0.11 \\
\hline $\begin{array}{l}\text { c190 Nitro-L-arginine } \\
\text { c192 3-(1,1-Dimethyl- } \\
\text { ethyl)-2,2,4,4- }\end{array}$ & -0.02 & 0.02 & -0.15 & -0.07 & 0.04 & 0.04 \\
\hline tetramethyl-3-pentanol, & -0.04 & -0.08 & -0.05 & -0.03 & 0.04 & 0.06 \\
\hline c194 Decane & 0.02 & -0.15 & 0.09 & 0.10 & 0.02 & 0.02 \\
\hline $\begin{array}{l}\text { c196 3-Methyl-butanal } \\
\text { c197 (E,E)-2,4- }\end{array}$ & 0.07 & 0.07 & -0.08 & -0.09 & 0.04 & -0.07 \\
\hline Octadienal & -0.12 & -0.16 & -0.05 & -0.00 & -0.02 & 0.05 \\
\hline c198 Phenyl-oxirane & 0.10 & -0.05 & -0.14 & -0.10 & -0.08 & -0.03 \\
\hline c202 2-Heptanone & -0.20 & -0.19 & 0.19 & 0.20 & 0.13 & 0.16 \\
\hline $\begin{array}{l}\text { c203 Formic acid, } \\
\text { hexyl ester } \\
\text { c205 Delta.-(2)-do- }\end{array}$ & -0.06 & -0.06 & 0.04 & 0.00 & 0.01 & 0.04 \\
\hline decanol & -0.12 & -0.11 & -0.11 & -0.11 & -0.02 & -0.03 \\
\hline c207 Undecane & -0.08 & -0.06 & -0.06 & 0.04 & 0.01 & -0.02 \\
\hline $\begin{array}{l}\text { c208 N,N'-Dimethyl- } \\
\text { cyclobutane-1,1- } \\
\text { bis(methylamine) }\end{array}$ & -0.07 & 0.03 & 0.10 & -0.16 & -0.41 & -0.24 \\
\hline
\end{tabular}


Table 6 (Continued).

\begin{tabular}{|c|c|c|c|c|c|c|}
\hline Effect & $\begin{array}{c}\text { Pork } \\
\text { Identity }\end{array}$ & $\begin{array}{l}\text { Brown/ } \\
\text { Roasted }\end{array}$ & $\begin{array}{l}\text { Fat- } \\
\text { Like }\end{array}$ & $\begin{array}{l}\text { Bloody/ } \\
\text { Serumy }\end{array}$ & Metallic & Astringent \\
\hline $\begin{array}{l}\text { c210 2-decen-1-ol } \\
\text { c212 (1-methylethyl)- }\end{array}$ & -0.11 & -0.15 & 0.10 & 0.32 & 0.17 & 0.16 \\
\hline $\begin{array}{l}\text { benzene } \\
\text { c214 4-hydroxy-benzoic }\end{array}$ & $c^{0.15}$ & 0.09 & -0.00 & -0.06 & -0.05 & -0.05 \\
\hline $\begin{array}{l}\text { acid } \\
\text { c215 Propyl-propane- }\end{array}$ & 0.13 & 0.07 & 0.03 & -0.02 & -0.06 & 0.03 \\
\hline dioic acid & -0.07 & 0.07 & -0.04 & -0.24 & -0.19 & -0.14 \\
\hline $\begin{array}{l}\text { c217 Cyclooctene } \\
\text { c219 3-(4-Tertiobutyl- }\end{array}$ & -0.01 & -0.03 & -0.06 & 0.00 & 0.06 & 0.01 \\
\hline phenyl)-propanal & -0.23 & -0.16 & 0.06 & 0.24 & 0.13 & 0.19 \\
\hline $\begin{array}{l}\text { c220 Trans-2-undecenal } \\
\text { c221 4-Hydroxymandeli }\end{array}$ & $\begin{array}{l}10.09 \\
\text { lic }\end{array}$ & 0.08 & 0.08 & 0.02 & 0.01 & 0.04 \\
\hline acid & -0.04 & 0.06 & -0.01 & 0.16 & 0.12 & 0.07 \\
\hline
\end{tabular}

${ }^{\mathrm{a}}$ Simple correlation coefficients $>0.20$ are significant $(\mathrm{P}<0.05)$. 
Table 6 (Continued).

\begin{tabular}{|c|c|c|c|c|c|}
\hline Effect & Sweet & Sour & Salty & Bitter & Umami \\
\hline c1 2-Octenal & 0.06 & 0.05 & -0.02 & 0.09 & 0.05 \\
\hline c2,4-Nonadienal & 0.17 & -0.06 & 0.02 & -0.07 & -0.30 \\
\hline c3 3-Octanone & -0.12 & -0.02 & -0.09 & 0.09 & -0.02 \\
\hline c4 5-Pentyl-2(5H)-furanone & 0.05 & -0.11 & 0.08 & -0.27 & -0.07 \\
\hline c6 Acetophenone & -0.07 & 0.09 & 0.00 & 0.01 & 0.05 \\
\hline c7 Benzaldehyde & -0.06 & 0.08 & -0.03 & -0.01 & -0.11 \\
\hline c8 3-Ethyl-benzaldehyde & -0.01 & 0.13 & -0.10 & -0.03 & -0.05 \\
\hline c9 Decanal & -0.35 & 0.09 & -0.12 & -0.09 & -0.29 \\
\hline c10 Dodecane & -0.07 & -0.05 & -0.14 & 0.06 & -0.18 \\
\hline c11 2-Pentyl-furan & -0.16 & 0.11 & -0.05 & -0.18 & -0.16 \\
\hline c12 Hexanoic acid & 0.01 & 0.18 & 0.12 & 0.12 & -0.09 \\
\hline c13 N-heptanal & 0.08 & 0.16 & -0.10 & 0.18 & -0.05 \\
\hline c14 Nonanal & -0.26 & 0.24 & -0.15 & 0.09 & -0.30 \\
\hline c15 Nonenal & -0.10 & 0.04 & -0.09 & 0.04 & -0.15 \\
\hline c16 Octanal & -0.15 & 0.25 & -0.12 & 0.15 & -0.27 \\
\hline c17 Phenol & -0.04 & -0.02 & 0.09 & -0.18 & 0.05 \\
\hline c18 Phenyl acetaldehyde & -0.10 & 0.09 & 0.17 & 0.03 & -0.11 \\
\hline c19 Styrene & -0.27 & 0.06 & -0.05 & 0.05 & -0.17 \\
\hline c20 1-Heptanol & -0.10 & 0.25 & -0.12 & 0.13 & -0.17 \\
\hline c21 (E)-2-decenal & 0.07 & -0.09 & -0.02 & -0.14 & 0.10 \\
\hline c22 2,3-Octanedione & -0.05 & 0.07 & -0.06 & -0.07 & -0.19 \\
\hline c23 2,4-Decadienal & 0.16 & -0.17 & 0.06 & -0.20 & 0.28 \\
\hline c24 Hexanal & -0.15 & 0.17 & 0.10 & 0.09 & -0.07 \\
\hline c25 3-Isopropyl-piperidine & 0.07 & -0.09 & 0.08 & -0.13 & 0.04 \\
\hline c26 Tridecanal & -0.13 & 0.02 & -0.01 & -0.02 & -0.12 \\
\hline
\end{tabular}


Table 6 (Continued).

\begin{tabular}{|c|c|c|c|c|c|}
\hline Effect & Sweet & Sour & Salty & Bitter & Umami \\
\hline c27 Undecenal & 0.13 & -0.08 & 0.05 & -0.17 & 0.02 \\
\hline c29 1-Octanol & -0.16 & 0.14 & -0.03 & -0.00 & -0.17 \\
\hline c30 1-Octen-3-ol & -0.16 & 0.10 & -0.07 & 0.15 & -0.11 \\
\hline c32 2-Docecen-1-al & -0.22 & 0.19 & -0.17 & -0.00 & -0.15 \\
\hline c33 (E)-2-nonenal & 0.02 & 0.11 & 0.10 & -0.09 & 0.03 \\
\hline c34 1,3-Bis (1,1-di- & & & & & \\
\hline methylethyl)-benzene & -0.18 & 0.13 & -0.09 & 0.02 & -0.14 \\
\hline c35 benzothiazole & -0.05 & -0.15 & -0.13 & -0.24 & -0.12 \\
\hline c37 Dl-limonene & -0.14 & 0.06 & -0.03 & -0.18 & -0.09 \\
\hline c38 Heptanal & -0.20 & 0.17 & 0.04 & 0.08 & -0.16 \\
\hline c40 4-Methyl-phenol & 0.08 & 0.03 & 0.14 & 0.07 & -0.01 \\
\hline c41 2,5-Dimethyl-pyrazine & -0.20 & 0.11 & 0.07 & -0.09 & 0.03 \\
\hline c42 3-Ethyl-2,5-dimethyl-pyrazine & -0.26 & 0.02 & 0.16 & -0.11 & -0.11 \\
\hline c43 Tridecane & 0.02 & -0.05 & -0.09 & 0.01 & -0.06 \\
\hline c44 1-Octen-3-ol & -0.12 & 0.07 & -0.12 & -0.07 & -0.25 \\
\hline c45 1-Octen-3-one & -0.23 & 0.11 & 0.07 & -0.11 & -0.19 \\
\hline c46 1-Pentanol & -0.07 & 0.08 & 0.00 & 0.01 & -0.05 \\
\hline c47 2-Methylene cyclopentanol & -0.10 & 0.02 & 0.12 & -0.15 & 0.10 \\
\hline c48 3-Dodecen-1-al & 0.04 & -0.05 & -0.08 & -0.06 & 0.18 \\
\hline c50 Benzene acetaldehyde & -0.27 & 0.12 & -0.05 & -0.02 & -0.12 \\
\hline c51 1-(1H-pyrrol-2-yl)-ethanone & -0.09 & 0.16 & -0.04 & -0.11 & -0.08 \\
\hline c52 N-caproic acid, vinyl ester & -0.06 & 0.18 & -0.01 & -0.01 & -0.11 \\
\hline c54 Nonanoic acid & -0.18 & 0.07 & 0.12 & -0.15 & -0.01 \\
\hline c55 2-Ethyl-5-methyl-pyrazine & -0.21 & 0.03 & 0.19 & -0.20 & -0.07 \\
\hline c57 2-Ethyl-6-methyl-pyrazine & -0.06 & 0.11 & 0.07 & -0.08 & 0.08 \\
\hline
\end{tabular}


Table 6 (Continued).

\begin{tabular}{|c|c|c|c|c|c|}
\hline \multicolumn{6}{|l|}{ Effect } \\
\hline c58 methyl-pyrazine & -0.14 & -0.02 & 0.21 & -0.18 & -0.10 \\
\hline c60 1-Hexanol & 0.01 & 0.05 & 0.03 & 0.12 & -0.20 \\
\hline c61 1-Pyrrolidine carboxaldehyde & 0.19 & -0.19 & -0.07 & 0.04 & 0.22 \\
\hline c63 (E)-2-octen-1-ol & -0.09 & 0.01 & -0.03 & -0.21 & -0.15 \\
\hline c64 2,4 Decadienal & 0.04 & -0.09 & -0.12 & -0.05 & 0.02 \\
\hline c65 2,4 Heptadienal & 0.11 & -0.09 & 0.12 & 0.14 & -0.02 \\
\hline c66 Octanoic acid & -0.10 & -0.04 & -0.03 & 0.11 & -0.07 \\
\hline c67 Pentanal & 0.10 & -0.07 & 0.09 & 0.10 & -0.02 \\
\hline c69 2-Ethyl-3,5-dimethyl-pyrazine & -0.02 & 0.05 & 0.05 & 0.03 & -0.11 \\
\hline c72 2-Acetyl thiazole & -0.08 & 0.22 & -0.00 & 0.07 & -0.13 \\
\hline c73 2-Butylfuran & 0.03 & 0.00 & 0.08 & 0.16 & -0.10 \\
\hline c74 2-Heptanone & -0.18 & 0.20 & -0.11 & 0.07 & -0.23 \\
\hline c75 (E)-2-heptenal & 0.06 & 0.02 & 0.10 & 0.14 & -0.05 \\
\hline c77 1-Methyl-4-(1-methylethyl)-benz & ne 0.13 & -0.05 & 0.12 & -0.03 & 0.07 \\
\hline c79 2-Ethyl-1-hexanol & -0.11 & 0.21 & -0.11 & 0.19 & -0.03 \\
\hline c80 (E)-2-hexenal & -0.02 & 0.17 & -0.14 & 0.28 & -0.11 \\
\hline c82 (E)-2-octenal & -0.15 & 0.06 & -0.02 & -0.08 & -0.07 \\
\hline c83 1-Propoxy-2-propanol & -0.12 & 0.18 & -0.21 & 0.19 & 0.04 \\
\hline c84 2,5-Octanedione & -0.21 & 0.10 & 0.01 & 0.10 & -0.11 \\
\hline c86 Ethyl-benzene & -0.11 & 0.16 & -0.21 & 0.17 & 0.04 \\
\hline c87 Hexadecane & -0.16 & 0.06 & -0.19 & 0.16 & 0.05 \\
\hline c90 Methyl-pyrazine & -0.10 & -0.01 & -0.13 & -0.06 & -0.09 \\
\hline c91 6-Methyl-2-heptanone & -0.03 & 0.04 & -0.16 & -0.03 & -0.19 \\
\hline c92 1-(4,5-Dihydro- & & & & & \\
\hline 2-thiazolyl)-ethanone & 0.01 & 0.06 & 0.05 & 0.04 & -0.05 \\
\hline
\end{tabular}


Table 6 (Continued).

\begin{tabular}{|c|c|c|c|c|c|}
\hline Effect & Sweet & Sour & Salty & Bitter & Umami \\
\hline c94 Octane & 0.14 & -0.10 & 0.17 & -0.05 & 0.09 \\
\hline c97 1,2-Benzisothiazole & -0.02 & -0.11 & 0.10 & -0.02 & 0.13 \\
\hline c98 2,3-Dimethylbenzaldehyde & 0.15 & -0.15 & 0.23 & -0.05 & 0.54 \\
\hline c99 4-Octen-3-one & -0.03 & -0.05 & 0.09 & 0.05 & 0.20 \\
\hline c100 Benzophenone & -0.00 & 0.04 & 0.02 & 0.08 & 0.19 \\
\hline c101 Heptanoic acid & 0.06 & -0.08 & 0.10 & -0.17 & -0.07 \\
\hline c102 Heptenal & 0.04 & -0.21 & 0.03 & 0.01 & 0.15 \\
\hline c103 Nonadecane & -0.05 & -0.04 & 0.07 & -0.12 & -0.05 \\
\hline c105 Tetradecanal & -0.06 & -0.05 & -0.12 & -0.13 & -0.06 \\
\hline c109 1-Phenyl-ethanone & -0.11 & 0.10 & -0.10 & 0.01 & -0.13 \\
\hline c110 Trans-2-undecen-1-ol & -0.19 & 0.08 & -0.09 & 0.03 & -0.14 \\
\hline c111 Undecanal & -0.01 & -0.07 & -0.10 & -0.22 & 0.03 \\
\hline c112 1-Decanol & -0.02 & -0.01 & 0.20 & -0.01 & -0.09 \\
\hline c114 Octadecane & 0.07 & -0.09 & 0.08 & -0.15 & 0.11 \\
\hline c116 Tetradecane & 0.04 & 0.03 & -0.13 & 0.03 & -0.09 \\
\hline c117 3-Ethyl-2-methyl-1,3-hexadiene & -0.08 & -0.08 & -0.07 & -0.10 & -0.13 \\
\hline c118 2,4 Nonadienal & -0.07 & -0.21 & 0.08 & -0.26 & -0.02 \\
\hline c119 Acetic acid & -0.13 & 0.09 & 0.05 & -0.02 & -0.04 \\
\hline c120 Hentriacontane & -0.06 & 0.04 & 0.02 & -0.12 & -0.13 \\
\hline c121 [(Dodecyloxy)methyl]-oxirane & -0.03 & -0.07 & -0.06 & -0.21 & -0.12 \\
\hline c122 Cyclooctyl alcohol & -0.01 & 0.05 & -0.17 & 0.30 & 0.05 \\
\hline c123 Heneicosane & -0.07 & -0.11 & -0.26 & 0.09 & -0.04 \\
\hline c124 2,5-Dimethyl-heptane & -0.01 & 0.11 & -0.07 & 0.21 & -0.07 \\
\hline c128 Trans, trans-2,4-octadienal & 0.06 & -0.06 & 0.15 & 0.13 & -0.00 \\
\hline c129 2-Dodecen-1-ol & 0.08 & -0.07 & 0.19 & 0.10 & 0.20 \\
\hline
\end{tabular}


Table 6 (Continued).

\begin{tabular}{|c|c|c|c|c|c|}
\hline Effect & Sweet & Sour & Salty & Bitter & Umami \\
\hline \multicolumn{6}{|l|}{ c131 1-[2-(2-Methylbutyl)phenyl] } \\
\hline ethanone & 0.06 & -0.03 & 0.06 & 0.04 & -0.15 \\
\hline c132 (E,E)-2,4-heptadienal & 0.18 & -0.07 & 0.10 & -0.12 & 0.01 \\
\hline c133 4-Ethyl-benzaldehyde & 0.06 & -0.06 & 0.17 & 0.06 & 0.06 \\
\hline c134 1,1'-Oxybis-heptane & -0.01 & -0.03 & 0.17 & 0.14 & -0.11 \\
\hline c135 1-Tetradecanol & 0.02 & 0.02 & -0.11 & 0.10 & -0.11 \\
\hline c138 1,2-Dimethylpyrrolidine & 0.07 & -0.03 & 0.05 & -0.00 & 0.08 \\
\hline c139 2-butyl-2-octenal & 0.04 & 0.08 & -0.12 & 0.03 & -0.12 \\
\hline \multicolumn{6}{|l|}{ c140 N,N'-bis (3-amino- } \\
\hline propyl)-1,3-propanediamine & -0.13 & 0.05 & 0.17 & -0.02 & -0.06 \\
\hline c141 Ethylidene cycloheptane & -0.04 & 0.01 & 0.11 & 0.18 & 0.01 \\
\hline c144 Heptanol & 0.01 & -0.04 & 0.18 & 0.06 & 0.07 \\
\hline c145 (1-Methylbutyl)-oxirane & 0.01 & -0.09 & 0.14 & -0.03 & 0.00 \\
\hline c147 4-Oxononanal & 0.05 & -0.09 & -0.12 & -0.09 & 0.18 \\
\hline c150 Pentadecane & -0.12 & 0.06 & -0.10 & -0.04 & -0.16 \\
\hline c151 Trans-2-tridecenal & -0.11 & -0.08 & -0.09 & -0.14 & -0.05 \\
\hline c152 Dodecanal & -0.10 & -0.14 & -0.08 & -0.22 & -0.07 \\
\hline c154 Octadecanal & 0.10 & -0.08 & 0.12 & -0.03 & 0.44 \\
\hline c155 2,3,5-Trimethyl pyrazine & -0.16 & 0.07 & -0.03 & 0.16 & -0.04 \\
\hline c158 (Z)-2-dodecene & -0.01 & -0.02 & -0.11 & 0.06 & -0.11 \\
\hline c159 (E)-4-dodecene & 0.02 & 0.00 & -0.05 & 0.03 & -0.08 \\
\hline c160 Nonacosane & 0.10 & -0.04 & -0.12 & -0.02 & -0.04 \\
\hline c161 Hexadecanal & 0.05 & 0.11 & 0.01 & 0.14 & 0.11 \\
\hline c162 1,1-Bis(dodecyloxy)-hexadecane & -0.10 & -0.03 & -0.12 & -0.09 & -0.11 \\
\hline c163 Cyclooctane & -0.13 & 0.12 & -0.08 & -0.02 & -0.07 \\
\hline
\end{tabular}


Table 6 (Continued).

\begin{tabular}{|c|c|c|c|c|c|}
\hline Effect & Sweet & Sour & Salty & Bitter & Umami \\
\hline c164 2-Decanone & -0.05 & -0.00 & 0.24 & 0.03 & -0.13 \\
\hline c166 Cycloheptane & 0.09 & -0.06 & 0.20 & 0.00 & 0.08 \\
\hline c167 2-Nonanone & -0.12 & 0.04 & 0.22 & 0.01 & -0.11 \\
\hline \multicolumn{6}{|l|}{ c170 3-(1,1-Dimethylethyl)- } \\
\hline 2,2,4,4-tetramethyl-3-pentanol & -0.04 & -0.04 & 0.26 & -0.05 & -0.07 \\
\hline c171 Butanoic acid & 0.10 & -0.02 & 0.21 & 0.03 & 0.10 \\
\hline c172 Octenal & -0.03 & -0.07 & 0.23 & -0.11 & -0.04 \\
\hline c173 1,3,5,7-Cyclooctatetraene & 0.07 & -0.00 & -0.07 & 0.08 & 0.10 \\
\hline c174 4-(2-Propenyl)-1H-imidazole & 0.12 & -0.06 & -0.06 & -0.08 & 0.18 \\
\hline c175 Chavicol & -0.09 & -0.16 & 0.02 & 0.04 & -0.01 \\
\hline c177 Formic acid, heptyl ester & 0.01 & -0.06 & 0.07 & -0.10 & 0.01 \\
\hline c182 6,7-Dodecanedione & -0.12 & -0.12 & -0.03 & 0.10 & -0.11 \\
\hline c183 Cyclooctanol & -0.15 & 0.05 & 0.01 & -0.01 & 0.07 \\
\hline c184 3-(Methylthio)-propanal & -0.06 & 0.08 & 0.01 & 0.04 & -0.13 \\
\hline c185 2-Methyl-3-octanone & -0.13 & 0.12 & 0.08 & -0.04 & 0.01 \\
\hline c186 2-Dodecenal & -0.00 & 0.02 & -0.02 & -0.03 & 0.07 \\
\hline c188 Dihydro-2(3H)-furanone & -0.03 & 0.03 & -0.01 & -0.07 & 0.01 \\
\hline c189 2-Ethyl-cyclobutanone & 0.00 & 0.08 & 0.02 & -0.01 & 0.04 \\
\hline c190 Nitro-L-arginine & 0.02 & 0.04 & 0.03 & -0.01 & 0.15 \\
\hline \multicolumn{6}{|l|}{ c192 3-(1,1-Dimethylethyl)-2,2, } \\
\hline 4,4-tetramethyl-3-pentanol, & 0.14 & 0.18 & -0.09 & 0.08 & -0.10 \\
\hline c194 Decane & 0.17 & 0.04 & -0.12 & 0.19 & 0.08 \\
\hline c196 3-Methyl-butanal & 0.13 & -0.07 & 0.17 & -0.07 & 0.30 \\
\hline
\end{tabular}


Table 6 (Continued).

\begin{tabular}{|c|c|c|c|c|c|}
\hline \multicolumn{6}{|l|}{ Effect } \\
\hline c197 2(E,E)-2,4-Octadienal & -0.08 & 0.03 & 0.06 & 0.01 & -0.08 \\
\hline c198 Phenyl-oxirane & 0.14 & -0.12 & -0.03 & -0.06 & 0.02 \\
\hline c202 2-Heptanone & 0.09 & 0.05 & -0.12 & 0.04 & -0.02 \\
\hline c203 Formic acid, hexyl ester & -0.03 & 0.01 & 0.03 & -0.08 & -0.02 \\
\hline c205 Delta.-(2)-dodecanol & 0.10 & -0.14 & 0.09 & -0.12 & -0.06 \\
\hline c207 Undecane & 0.07 & -0.06 & -0.02 & 0.01 & -0.04 \\
\hline \multicolumn{6}{|l|}{$\begin{array}{l}\text { c208 N,N'-Dimethyl- } \\
\text { cyclobutane-1,1-bis- }\end{array}$} \\
\hline (methylamine) & 0.02 & -0.23 & -0.06 & -0.15 & 0.09 \\
\hline c210 2-decen-1-ol & 0.22 & 0.04 & 0.18 & 0.04 & 0.02 \\
\hline c212 (1-methylethyl)-benzene & 0.07 & -0.09 & 0.10 & 0.01 & 0.10 \\
\hline c214 4-hydroxy-benzoic acid & 0.16 & -0.12 & 0.10 & -0.17 & 0.15 \\
\hline c215 Propyl-propanedioic acid & 0.04 & -0.19 & -0.10 & -0.13 & -0.08 \\
\hline c217 Cyclooctene & -0.09 & 0.12 & -0.11 & 0.05 & -0.08 \\
\hline \multicolumn{6}{|l|}{ c219 3-(4-Tertiobutylphenyl) } \\
\hline -propanal & -0.07 & 0.08 & -0.12 & 0.08 & -0.06 \\
\hline c220 Trans-2-undecenal & 0.08 & -0.11 & 0.08 & -0.12 & 0.06 \\
\hline c221 4-Hydroxymandelic acid & -0.11 & 0.05 & 0.08 & 0.12 & -0.07 \\
\hline
\end{tabular}

${ }^{\mathrm{a}}$ Simple correlation coefficients $>0.203$ are significant $(\mathrm{P}<0.05)$ 
Table 7. Simple correlation coefficients ${ }^{\mathrm{a}}$ between trained descriptive sensory attributes and volatile compound categories.

\begin{tabular}{|c|c|c|c|c|c|c|}
\hline Effect & $\begin{array}{c}\text { Pork } \\
\text { Identity }\end{array}$ & $\begin{array}{l}\text { Brown/ } \\
\text { Roasted }\end{array}$ & $\begin{array}{l}\text { Fat- } \\
\text { Like }\end{array}$ & $\begin{array}{l}\text { Bloody/ } \\
\text { Serumy }\end{array}$ & Metallic & Astringent \\
\hline Sulfur-containing & -0.16 & 0.09 & -0.07 & -0.04 & -0.12 & 0.00 \\
\hline Nitrogen-containing & 0.16 & 0.33 & -0.23 & -0.25 & -0.12 & -0.13 \\
\hline Aldehydes & -0.15 & -0.10 & -0.15 & 0.04 & 0.17 & 0.12 \\
\hline Alcohols & -0.22 & -0.15 & -0.16 & -0.00 & 0.11 & 0.10 \\
\hline Ketones & -0.21 & -0.02 & -0.17 & -0.01 & 0.11 & 0.11 \\
\hline Acids & -0.12 & -0.12 & -0.12 & 0.03 & 0.13 & 0.10 \\
\hline Alkanes & -0.08 & -0.09 & -0.17 & -0.09 & 0.10 & 0.06 \\
\hline Alkenes & -0.13 & -0.06 & -0.16 & -0.09 & 0.05 & -0.00 \\
\hline Furans & -0.17 & -0.06 & -0.19 & -0.02 & 0.11 & 0.09 \\
\hline Pyrazines & 0.20 & 0.32 & -0.25 & 0.23 & -0.07 & -0.10 \\
\hline Benzenes & -0.18 & -0.06 & -0.25 & -0.06 & -0.01 & 0.04 \\
\hline
\end{tabular}

${ }^{\mathrm{a}}$ Simple correlation coefficients $>0.20$ are significant $(\mathrm{P}<0.05)$. 
Table 7 (Continued).

\begin{tabular}{|c|c|c|c|c|c|}
\hline Effect & Sweet & Sour & Salty & Bitter & Umami \\
\hline Sulfur-containing & -0.10 & -0.02 & -0.04 & -0.13 & -0.14 \\
\hline Nitrogen-containing & -0.26 & 0.05 & 0.12 & -0.16 & -0.07 \\
\hline Aldehydes & -0.19 & 0.24 & -0.01 & 0.12 & -0.20 \\
\hline Alcohols & -0.22 & 0.18 & -0.11 & 0.04 & -0.29 \\
\hline Ketones & -0.24 & 0.14 & -0.06 & -0.01 & -0.30 \\
\hline Acids & -0.08 & 0.21 & 0.06 & 0.02 & -0.13 \\
\hline Alkanes & -0.09 & -0.02 & -0.12 & 0.07 & -0.20 \\
\hline Alkenes & -0.19 & 0.03 & -0.10 & -0.09 & -0.17 \\
\hline Furans & -0.16 & 0.11 & -0.05 & -0.18 & -0.16 \\
\hline Pyrazines & -0.26 & 0.07 & 0.14 & -0.12 & -0.07 \\
\hline Benzenes & -0.10 & 0.10 & -0.03 & -0.01 & -0.14 \\
\hline
\end{tabular}

${ }^{\mathrm{a}}$ Simple correlation coefficients $>0.203$ are significant $(\mathrm{P}<0.05)$ 
Table 8. Stepwise linear regression for prediction of pork identity flavor aromatics as the dependent variable and aromatic volatile compounds as independent variables.

\begin{tabular}{|c|c|c|c|c|}
\hline Step & Variables (Code and Chemical Name) ${ }^{\mathrm{a}}$ & $\begin{array}{c}\text { Estimate }^{\mathrm{a}} \\
\mathrm{x} 10^{-4}\end{array}$ & $\begin{array}{c}\text { Partial } \\
\mathrm{R}^{2}\end{array}$ & $\begin{array}{c}\text { Equation } \\
\mathrm{R}^{2}\end{array}$ \\
\hline Intercept & & 5.66 & & \\
\hline 1 & c171 Butanoic acid & 0.05 & 0.11 & 0.11 \\
\hline 2 & c23 2,4-Decadienal & 0.01 & 0.10 & 0.20 \\
\hline 3 & c141 Ethylidene cycloheptane & 0.11 & 0.08 & 0.28 \\
\hline \multirow[t]{2}{*}{4} & c208 N,N'-Dimethylcyclobutane-1,1- & & & \\
\hline & bis(methylamine) & -0.29 & 0.07 & 0.35 \\
\hline 5 & c20 1-Heptanol & -0.008 & 0.06 & 0.41 \\
\hline \multirow[t]{2}{*}{6} & c92 1-(4,5-Dihydro-2-thiazolyl)- & & & \\
\hline & ethanone & 0.28 & 0.05 & 0.45 \\
\hline 7 & c207 Undecane & -0.15 & 0.04 & 0.49 \\
\hline 8 & c57 2-Ethyl-6-methyl-pyrazine & 0.17 & 0.03 & 0.52 \\
\hline 9 & c52 N-caproic acid, vinyl ester & -0.003 & 0.04 & 0.56 \\
\hline 10 & c6 Acetophenone & 0.07 & 0.02 & 0.58 \\
\hline 11 & c38 Heptanal & -0.001 & 0.03 & 0.61 \\
\hline 12 & c29 1-Octanol & 0.005 & 0.02 & 0.63 \\
\hline 13 & c120 Hentriacontane & 0.12 & 0.02 & 0.65 \\
\hline 14 & c188 Dihydro-2(3H)-furanone & -0.02 & 0.02 & 0.67 \\
\hline 15 & c4 5-Pentyl-2(5H)-furanone & 0.06 & 0.02 & 0.69 \\
\hline 16 & c98 2,3-Dimethylbenzaldehyde & 0.20 & 0.02 & 0.71 \\
\hline 17 & c114 Octadecane & -0.19 & 0.03 & 0.74 \\
\hline 18 & c145 (1-Methylbutyl)-oxirane & 0.08 & 0.02 & 0.76 \\
\hline 19 & c152 Dodecanal & -0.02 & 0.02 & 0.78 \\
\hline \multirow[t]{2}{*}{21} & c219 3-(4-Tertiobutylphenyl)- & & & \\
\hline & propanal & -0.02 & 0.01 & 0.79 \\
\hline 23 & c110 Trans-2-undecen-1-ol & -0.04 & 0.01 & 0.80 \\
\hline 24 & c185 2-Methyl-3-octanone & 0.005 & 0.01 & 0.81 \\
\hline 25 & c162 1,1-Bis(dodecyloxy)-hexadecane & 0.18 & 0.01 & 0.82 \\
\hline 26 & c7 Benzaldehyde & -0.008 & 0.01 & 0.83 \\
\hline 27 & c166 Cycloheptane & 0.02 & 0.01 & 0.84 \\
\hline 28 & c210 2-decen-1-ol & -0.04 & 0.01 & 0.85 \\
\hline 29 & c215 Propyl-propanedioic acid & -0.08 & 0.01 & 0.86 \\
\hline 30 & c94 Octane & 0.05 & 0.01 & 0.86 \\
\hline 31 & c32 2-Docecen-1-al & -0.01 & 0.01 & 0.87 \\
\hline 32 & c220 Trans-2-undecenal & 0.05 & 0.01 & 0.88 \\
\hline 33 & c91 6-Methyl-2-heptanone & -0.04 & 0.01 & 0.88 \\
\hline 34 & c13 N-heptanal & 0.001 & 0.00 & 0.89 \\
\hline 35 & c47 2-Methylene cyclopentanol & -0.04 & 0.00 & 0.89 \\
\hline 37 & c80 (E)-2-hexenal & -0.02 & 0.01 & 0.90 \\
\hline 38 & c121 [(Dodecyloxy)methyl]-oxirane & -0.09 & 0.01 & 0.90 \\
\hline
\end{tabular}


Table 8 (Continued).

\begin{tabular}{|c|c|c|c|c|}
\hline Step & Variables (Code and Chemical Name) ${ }^{\mathrm{a}}$ & $\begin{array}{c}\text { Estimate }^{\mathrm{a}} \\
\times 10^{-4}\end{array}$ & $\begin{array}{c}\text { Partial } \\
\mathrm{R}^{2}\end{array}$ & $\begin{array}{c}\text { Equation }^{\mathrm{b}} \\
\mathrm{R}^{2}\end{array}$ \\
\hline 39 & c82 (E)-2-octenal & 0.003 & 0.00 & 0.90 \\
\hline 42 & c8 3-Ethyl-benzaldehyde & 0.02 & 0.01 & 0.91 \\
\hline 43 & c27 Undecenal & -0.006 & 0.00 & 0.91 \\
\hline 44 & c25 3-Isopropyl-piperidine & 0.09 & 0.00 & 0.91 \\
\hline 45 & c65 2,4 Heptadienal & 0.02 & 0.00 & 0.92 \\
\hline 46 & c75 ((E)-2-heptenal & -0.04 & 0.00 & 0.92 \\
\hline 49 & c3 3-Octanone & -0.003 & 0.01 & 0.92 \\
\hline 50 & c105 Tetradecanal & -0.01 & 0.00 & 0.93 \\
\hline
\end{tabular}

${ }^{a}$ Estimates are the $b$-values for the final regression equation when the defined variable was included and variables are not listed in the order that they entered the equation. 
Table 9. Stepwise linear regression for prediction of fat-like flavor aromatics as the dependent variable and aromatic volatile compounds as independent variables.

\begin{tabular}{|c|c|c|c|c|}
\hline Step & Variables (Code and Chemical Name) ${ }^{\mathrm{a}}$ & $\begin{array}{c}\text { Estimate }^{\mathrm{a}} \\
\mathrm{x} 10^{-4}\end{array}$ & $\begin{array}{c}\text { Partial } \\
\mathrm{R}^{2}\end{array}$ & $\begin{array}{c}\text { Equation }^{\mathrm{b}} \\
\mathrm{R}^{2}\end{array}$ \\
\hline Intercept & & 0.56 & & \\
\hline 1 & c98 2,3-Dimethylbenzaldehyde & 0.70 & 0.14 & 0.14 \\
\hline 2 & c133 4-Ethyl-benzaldehyde & 0.09 & 0.07 & 0.21 \\
\hline 3 & c2 2,4-Nonadienal & 0.03 & 0.04 & 0.25 \\
\hline 4 & c202 2-Heptanone & 0.05 & 0.05 & 0.30 \\
\hline 5 & c14 Nonanal & -0.0008 & 0.05 & 0.35 \\
\hline 6 & c110 Trans-2-undecen-1-ol & -0.09 & 0.04 & 0.38 \\
\hline 7 & c160 Nonacosane & -0.54 & 0.02 & 0.41 \\
\hline 8 & c43 Tridecane & 0.04 & 0.02 & 0.43 \\
\hline 9 & c10 Dodecane & -0.009 & 0.05 & 0.48 \\
\hline 10 & c147 4-oxononanal & -0.37 & 0.02 & 0.50 \\
\hline 11 & c121 [(Dodecyloxy)methyl]-oxirane & 0.12 & 0.01 & 0.51 \\
\hline 12 & c111 undecanal & -0.09 & 0.02 & 0.53 \\
\hline 14 & c183 Cyclooctanol & -0.06 & 0.02 & 0.54 \\
\hline 15 & c37 Dl-limonene & 0.03 & 0.02 & 0.56 \\
\hline 16 & c11 2-Pentyl-furan & -0.003 & 0.02 & 0.59 \\
\hline 17 & c21 (E)-2-decenal & 0.01 & 0.02 & 0.60 \\
\hline 18 & c9 Decanal & -0.02 & 0.02 & 0.62 \\
\hline 19 & c166 Cycloheptane & 0.03 & 0.01 & 0.63 \\
\hline 20 & c161 Hexadecanal & 0.23 & 0.01 & 0.64 \\
\hline 21 & c120 Hentriacontane & -0.14 & 0.01 & 0.66 \\
\hline 22 & c185 2-Methyl-3-octanone & 0.01 & 0.01 & 0.67 \\
\hline 23 & c141 Ethylidene cycloheptane & 0.05 & 0.01 & 0.68 \\
\hline 24 & c184 propanal, 3-(methylthio)- & 0.10 & 0.01 & 0.69 \\
\hline 26 & c50 Benzene acetaldehyde & -0.06 & 0.02 & 0.71 \\
\hline 27 & c35 Benzothiazole & -0.04 & 0.02 & 0.72 \\
\hline 29 & c139 2-butyl-2-octenal & -0.16 & 0.01 & 0.73 \\
\hline 31 & c196 3-Methyl-butanal & -0.04 & 0.01 & 0.74 \\
\hline 32 & c101 Heptanoic acid & -0.05 & 0.01 & 0.75 \\
\hline \multirow[t]{2}{*}{33} & c208 N,N'-Dimethylcyclobutane- & & & \\
\hline & 1,1-bis(methylamine) & 0.18 & 0.01 & 0.76 \\
\hline 34 & c147 4-Oxononanal & -0.43 & 0.02 & 0.78 \\
\hline 35 & c29 1-Octanol & -0.005 & 0.01 & 0.79 \\
\hline 36 & c207 Undecane & 0.10 & 0.01 & 0.80 \\
\hline
\end{tabular}


Table 9 (Continued).

\begin{tabular}{llccc}
\hline & & Estimate $^{\mathrm{a}}$ & Partial $^{2}$ & Equation $^{\mathrm{b}}$ \\
Step & Variables (Code and Chemical Name) & ${\mathrm{x} 10^{-4}}^{\mathrm{a}}$ & $\mathrm{R}^{2}$ & $\mathrm{R}^{2}$ \\
37 & $\mathrm{c} 65$ 2,4 Heptadienal & 0.05 & 0.01 & 0.80 \\
40 & $\mathrm{c} 73$ 2-Butylfuran & -0.12 & 0.02 & 0.82 \\
42 & c210 2-decen-1-ol & 0.04 & 0.01 & 0.82 \\
43 & c128 Trans, trans-2,4-octadienal & 0.10 & 0.01 & 0.83
\end{tabular}

${ }^{\bar{a}}$ Estimates are the $b$-values for the final regression equation when the defined variable was included and variables are not listed in the order that they entered the equation. 
Table 10. Stepwise linear regression for prediction of brown/roasted flavor aromatics as the dependent variable and aromatic volatile compounds as independent variables.

\begin{tabular}{|c|c|c|c|c|}
\hline Step & Variables (Code and Chemical Name) & $\begin{array}{c}\text { Estimate }^{\mathrm{a}} \\
\mathrm{x} 10^{-4}\end{array}$ & $\begin{array}{c}\text { Partial } \\
\mathrm{R}^{2}\end{array}$ & $\begin{array}{c}\text { Equation }^{\mathrm{b}} \\
\mathrm{R}^{2}\end{array}$ \\
\hline Intercept & & 0.79 & & \\
\hline 1 & c42 3-Ethyl-2,5-dimethyl-pyrazine & 0.07 & 0.09 & 0.09 \\
\hline 2 & c91 6-Methyl-2-heptanone & -0.24 & 0.10 & 0.19 \\
\hline 3 & c99 4-Octen-3-one & 0.31 & 0.05 & 0.24 \\
\hline 4 & c18 Phenyl acetaldehyde & 0.06 & 0.06 & 0.30 \\
\hline 5 & c151 Trans-2-tridecenal & 0.07 & 0.06 & 0.36 \\
\hline 6 & c183 Cyclooctanol & 0.10 & 0.06 & 0.42 \\
\hline 7 & c14 Nonanal & -0.001 & 0.07 & 0.48 \\
\hline 8 & c129 2-Dodecen-1-ol & 0.22 & 0.04 & 0.52 \\
\hline 9 & c98 2,3-Dimethylbenzaldehyde & 0.44 & 0.04 & 0.56 \\
\hline 10 & c4 5-Pentyl-2(5H)-furanone & 0.11 & 0.03 & 0.63 \\
\hline 11 & c51 1-(1H-pyrrol-2-yl)-ethanone & 0.12 & 0.04 & 0.63 \\
\hline 12 & c119 Acetic acid & 0.07 & 0.03 & 0.66 \\
\hline 13 & c138 1,2-Dimethylpyrrolidine & 0.16 & 0.03 & 0.69 \\
\hline 14 & c8 3-Ethyl-benzaldehyde & -0.05 & 0.02 & 0.71 \\
\hline 15 & c192 3-(1,1-Dimethylethyl)-2,2,4,4- & & & \\
\hline & tetramethyl-3-pentanol, & -0.03 & 0.02 & 0.73 \\
\hline 16 & c203 Formic acid, hexyl ester & -0.10 & 0.02 & 0.75 \\
\hline 17 & c220 Trans-2-undecenal & 0.11 & 0.01 & 0.76 \\
\hline 18 & c103 Nonadecane & 0.12 & 0.01 & 0.78 \\
\hline 19 & c152 Dodecanal & 0.01 & 0.01 & 0.79 \\
\hline 20 & c44 1-Octen-3-ol & -0.002 & 0.01 & 0.80 \\
\hline 21 & c83 1-Propoxy-2-propanol & 0.05 & 0.01 & 0.81 \\
\hline 22 & c161 Hexadecanal & -0.02 & 0.01 & 0.81 \\
\hline 23 & c185 2-Methyl-3-octanone & -0.009 & 0.01 & 0.82 \\
\hline 24 & c74 2-Heptanone & -0.02 & 0.01 & 0.83 \\
\hline 25 & c166 Cycloheptane & -0.02 & 0.01 & 0.83 \\
\hline 26 & c13 N-heptanal & 0.001 & 0.01 & 0.84 \\
\hline 28 & c189 2-Ethyl-cyclobutanone & -0.01 & 0.01 & 0.84 \\
\hline 29 & c186 2-Dodecenal & 0.02 & 0.01 & 0.85 \\
\hline 30 & c162 1,1-Bis(dodecyloxy)-hexadecane & -0.20 & 0.01 & 0.86 \\
\hline 31 & c163 Cyclooctane & 0.007 & 0.01 & 0.86 \\
\hline 32 & c117 3-Ethyl-2-methyl-1,3-hexadiene & 0.01 & 0.00 & 0.87 \\
\hline 33 & c123 Heneicosane & -0.02 & 0.01 & 0.87 \\
\hline 34 & c141 Ethylidene cycloheptane & -0.06 & 0.00 & 0.88 \\
\hline 35 & c26 Tridecanal & 0.07 & 0.01 & 0.89 \\
\hline 36 & c1 2-Octenal & 0.004 & 0.01 & 0.89 \\
\hline 38 & c139 2-butyl-2-octenal & 0.02 & 0.01 & 0.90 \\
\hline 39 & c207 Undecane & -0.08 & 0.01 & 0.90 \\
\hline
\end{tabular}


Table 10 (Continued).

\begin{tabular}{lllrr}
\hline & & Estimate $^{\mathrm{a}}$ & Partial $^{\text {Pat }}$ & \multicolumn{2}{c}{ Equation $^{\mathrm{b}}$} \\
Step & Variables (Code and Chemical Name) & $\mathrm{x} \mathrm{10}^{-4}$ & $\mathrm{R}^{2}$ & $\mathrm{R}^{2}$ \\
40 & c221 4-Hydroxymandelic acid & -0.03 & 0.01 & 0.91 \\
41 & c84 2,5-Octanedione & -0.005 & 0.00 & 0.91 \\
42 & c133 4-Ethyl-benzaldehyde & -0.04 & 0.00 & 0.91
\end{tabular}

${ }^{a}$ Estimates are the $b$-values for the final regression equation when the defined variable was included and variables are not listed in the order that they entered the equation. 
Table 11. Stepwise linear regression for prediction of bloody/serumy flavor aromatics as the dependent variable and aromatic volatile compounds as independent variables.

\begin{tabular}{|c|c|c|c|c|}
\hline Step & Variables (Code and Chemical Name) ${ }^{\mathrm{a}}$ & $\begin{array}{c}\text { Estimate }^{\mathrm{a}} \\
\mathrm{x} 10^{-4}\end{array}$ & $\begin{array}{c}\text { Partial } \\
\mathrm{R}^{2}\end{array}$ & $\begin{array}{c}\text { Equation }^{\mathrm{b}} \\
\mathrm{R}^{2}\end{array}$ \\
\hline Intercept & & 1.16 & & \\
\hline 1 & c210 2-decen-1-ol & 0.22 & 0.10 & 0.10 \\
\hline 2 & c219 3-(4-tertiobutylphenyl)-propanal & 0.06 & 0.06 & 0.16 \\
\hline 3 & c124 2,5-Dimethyl-heptane & 0.11 & 0.06 & 0.23 \\
\hline 4 & c215 Propyl-propanedioic acid & -0.30 & 0.05 & 0.27 \\
\hline 5 & c72 2-Acetyl thiazole & 0.13 & 0.04 & 0.31 \\
\hline 6 & c58 Trimethyl-pyrazine & -0.03 & 0.05 & 0.36 \\
\hline 7 & c160 Nonacosane & -0.94 & 0.03 & 0.39 \\
\hline 8 & c145 (1-Methylbutyl)-oxirane & -0.14 & 0.03 & 0.42 \\
\hline 9 & c138 1,2-dimethylpyrrolidine & -0.18 & 0.03 & 0.45 \\
\hline 10 & c20 1-Heptanol & 0.01 & 0.03 & 0.48 \\
\hline 11 & c82 (E)-2-octenal & -0.01 & 0.03 & 0.51 \\
\hline 13 & c205 Delta.-(2)-dodecanol & -0.06 & 0.02 & 0.53 \\
\hline 14 & c112 1-Decanol & 0.27 & 0.02 & 0.54 \\
\hline \multirow[t]{2}{*}{15} & c170 3-(1,1-Dimethylethyl)- & & & \\
\hline & 2,2,4,4-tetramethyl-3-pentanol & -0.16 & 0.05 & 0.59 \\
\hline 17 & c117 3-Ethyl-2-methyl-1,3-hexadiene & -0.02 & 0.02 & 0.60 \\
\hline 18 & c155 2,3,5-Trimethyl pyrazine & -0.04 & 0.02 & 0.62 \\
\hline 19 & c69 2-Ethyl-3,5-dimethyl-pyrazine & -0.24 & 0.02 & 0.64 \\
\hline 20 & c6 Acetophenone & -0.11 & 0.02 & 0.66 \\
\hline 21 & c154 Octadecanal & -0.09 & 0.02 & 0.68 \\
\hline 22 & c175 Chavicol & -0.29 & 0.02 & 0.69 \\
\hline \multirow[t]{2}{*}{23} & c208 N,N'-dimethylcyclobutane- & & & \\
\hline & 1,1-bis(methylamine) & -0.22 & 0.02 & 0.71 \\
\hline 24 & c116 Tetradecane & 0.03 & 0.02 & 0.72 \\
\hline 25 & c43 Tridecane & -0.05 & 0.02 & 0.73 \\
\hline 26 & c114 Octadecane & -0.25 & 0.01 & 0.75 \\
\hline 28 & c110 Trans-2-undecen-1-ol & -0.07 & 0.01 & 0.75 \\
\hline 29 & c47 2-Methylene cyclopentanol & -0.06 & 0.01 & 0.76 \\
\hline 30 & c51 1-(1H-pyrrol-2-yl)-ethanone 0.08 & 0.01 & 0.77 & \\
\hline 31 & c30 1-Octen-3-ol & 0.003 & 0.01 & 0.78 \\
\hline 32 & c162 1,1-Bis(dodecyloxy)-hexadecane & 0.37 & 0.01 & 0.79 \\
\hline 33 & c41 2,5-Dimethyl-pyrazine & -0.09 & 0.01 & 0.80 \\
\hline 34 & c23 2,4-Decadienal & -0.008 & 0.01 & 0.81 \\
\hline 36 & c103 Nonadecane & -0.12 & 0.01 & 0.82 \\
\hline 37 & c86 Ethyl-benzene & -0.10 & 0.01 & 0.82 \\
\hline \multirow[t]{2}{*}{38} & c140 N,N'-bis (3-aminopropyl)- & & & \\
\hline & 1,3-propanediamine & 0.26 & 0.01 & 0.83 \\
\hline 39 & c144 Heptanol & -0.07 & 0.01 & 0.85 \\
\hline
\end{tabular}


Table 11 (Continued).

\begin{tabular}{|c|c|c|c|c|}
\hline Step & Variables (Code and Chemical Name) ${ }^{a}$ & $\begin{array}{c}\text { Estimate }^{\mathrm{a}} \\
\mathrm{x} 10^{-4}\end{array}$ & $\begin{array}{c}\text { Partial } \\
\mathrm{R}^{2}\end{array}$ & $\begin{array}{c}\text { Equation } \\
\mathrm{R}^{2}\end{array}$ \\
\hline 42 & c66 Octanoic acid & 0.02 & 0.01 & 0.85 \\
\hline 43 & c152 Dodecanal & -0.01 & 0.01 & 0.86 \\
\hline \multirow[t]{2}{*}{44} & c77 1-Methyl-4-(1-methylethyl) & & & \\
\hline & -benzene & -0.05 & 0.01 & 0.87 \\
\hline 45 & c99 4-Octen-3-one & 0.19 & 0.01 & 0.88 \\
\hline \multirow[t]{2}{*}{46} & c42 3-Ethyl-2,5-dimethyl- & & & \\
\hline & pyrazine & -0.06 & 0.01 & 0.89 \\
\hline 47 & c46 1-Pentanol & 0.008 & 0.01 & 0.89 \\
\hline 48 & c139 2-butyl-2-octenal & -0.21 & 0.01 & 0.90 \\
\hline 49 & c21 (E)-2-decenal & 0.01 & 0.00 & 0.90 \\
\hline 51 & c141 Ethylidene cycloheptane & 0.11 & 0.01 & 0.91 \\
\hline 52 & c91 6-Methyl-2-heptanone & 0.12 & 0.01 & 0.91 \\
\hline 53 & c19 Styrene & 0.04 & 0.01 & 0.92 \\
\hline 54 & c64 2,4-Decadienal & -0.03 & 0.01 & 0.92 \\
\hline 55 & c7 Benzaldehyde & 0.001 & 0.01 & 0.93 \\
\hline 56 & c82 (E)-2-octenal & -0.005 & 0.00 & 0.93 \\
\hline 57 & c203 Formic acid, hexyl ester & -0.08 & 0.00 & 0.94 \\
\hline 58 & c1 2-Octenal & -0.004 & 0.00 & 0.94 \\
\hline
\end{tabular}

${ }^{a}$ Estimates are the $b$-values for the final regression equation when the defined variable was included and variables are not listed in the order that they entered the equation. 
Table 12. Stepwise linear regression for prediction of metallic flavor aromatics as the dependent variable and aromatic volatile compounds as independent variables.

\begin{tabular}{|c|c|c|c|c|}
\hline Step & Variables (Code and Chemical Name) ${ }^{\mathrm{a}}$ & $\begin{array}{c}\text { Estimate }^{\mathrm{a}} \\
\mathrm{x} 10^{-4}\end{array}$ & $\begin{array}{c}\text { Partial } \\
\mathrm{R}^{2}\end{array}$ & $\begin{array}{c}\text { Equation } \\
\mathrm{R}^{2}\end{array}$ \\
\hline Intercept & & 2.07 & & \\
\hline 1 & c208 N,N'-dimethylcyclobutane-1,1- & -032 & 017 & 017 \\
\hline 2 & c138 1,2-dimethylpyrrolidine & -0.14 & 0.07 & 0.24 \\
\hline 3 & c20 1-Heptanol & 0.008 & 0.07 & 0.31 \\
\hline 4 & c102 Heptenal & -0.06 & 0.03 & 0.34 \\
\hline 5 & c42 3-Ethyl-2,5-dimethyl-pyrazine & -0.02 & 0.03 & 0.38 \\
\hline 6 & c215 Propyl-propanedioic acid & -0.12 & 0.03 & 0.41 \\
\hline 7 & c118 2,4 Nonadienal & -0.07 & 0.04 & 0.45 \\
\hline 8 & c23 2,4-Decadienal & -0.006 & 0.03 & 0.48 \\
\hline 9 & c197 (E,E)-2,4-Octadienal & -0.06 & 0.02 & 0.50 \\
\hline 10 & c74 2-Heptanone & 0.01 & 0.03 & 0.53 \\
\hline 11 & c37 Dl-limonene & 0.02 & 0.02 & 0.55 \\
\hline 12 & c139 2-butyl-2-octenal & 0.13 & 0.02 & 0.57 \\
\hline 13 & c1 2-Octenal & -0.003 & 0.02 & 0.59 \\
\hline 14 & c84 2,5-Octanedione & -0.004 & 0.01 & 0.60 \\
\hline 15 & c24 Hexanal & 0.0002 & 0.02 & 0.62 \\
\hline 16 & c90 Methyl-pyrazine & 0.03 & 0.02 & 0.64 \\
\hline 17 & c109 1-Phenyl-ethanone & 0.02 & 0.02 & 0.66 \\
\hline 19 & c141 Ethylidene cycloheptane & 0.04 & 0.01 & 0.67 \\
\hline 20 & c99 4-Octen-3-one & 0.09 & 0.01 & 0.68 \\
\hline 21 & c40 4-Methyl-phenol & -0.02 & 0.01 & 0.69 \\
\hline 22 & c32 2-Docecen-1-al & 0.02 & 0.01 & 0.70 \\
\hline 23 & c35 Benzothiazole & -0.03 & 0.01 & 0.71 \\
\hline 26 & c190 Nitro-L-arginine & -0.10 & 0.01 & 0.72 \\
\hline 28 & c25 3-Isopropyl-piperidine & -0.11 & 0.01 & 0.72 \\
\hline 29 & c210 2-decen-1-ol & 0.04 & 0.01 & 0.74 \\
\hline 30 & c14 Nonanal & 0.0006 & 0.01 & 0.75 \\
\hline 32 & c4 5-Pentyl-2(5H)-furanone & -0.05 & 0.01 & 0.76 \\
\hline 33 & c221 4-hydroxymandelic acid & 0.02 & 0.01 & 0.77 \\
\hline
\end{tabular}

${ }^{a}$ Estimates are the b-values for the final regression equation when the defined variable was included and variables are not listed in the order that they entered the equation. 
Table 13. Stepwise linear regression for prediction of astringent feeling factors as the dependent variable and aromatic volatile compounds as independent variables.

\begin{tabular}{|c|c|c|c|c|}
\hline Step & Variables (Code and Chemical Name) ${ }^{\mathrm{a}}$ & $\begin{array}{c}\text { Estimate }^{\mathrm{a}} \\
\times 10^{-4}\end{array}$ & $\begin{array}{c}\text { Partial } \\
\mathrm{R}^{2}\end{array}$ & $\begin{array}{c}\text { Equation } \\
\mathrm{R}^{2}\end{array}$ \\
\hline Intercept & & 1.79 & & \\
\hline 1 & c138 1,2-dimethylpyrrolidine & -0.14 & 0.08 & 0.08 \\
\hline 2 & c20 1-Heptanol & 0.009 & 0.11 & 0.19 \\
\hline \multirow[t]{2}{*}{3} & c208 N,N'-dimethylcyclobutane- & & & \\
\hline & 1,1-bis(methylamine) & -0.17 & 0.05 & 0.24 \\
\hline 4 & c109 1-Phenyl-ethanone & 0.03 & 0.04 & 0.28 \\
\hline 5 & c42 3-Ethyl-2,5-dimethyl-pyrazine & -0.03 & 0.05 & 0.33 \\
\hline 6 & c118 2,4 Nonadienal & -0.07 & 0.04 & 0.37 \\
\hline 7 & c215 Propyl-propanedioic acid & -0.10 & 0.03 & 0.40 \\
\hline 8 & c23 2,4-Decadienal & -0.006 & 0.03 & 0.43 \\
\hline 10 & c74 2-Heptanone & 0.01 & 0.05 & 0.47 \\
\hline 11 & c101 Heptanoic acid & -0.06 & 0.04 & 0.51 \\
\hline 12 & c61 1-Pyrrolidine carboxaldehyde & -0.12 & 0.02 & 0.53 \\
\hline 13 & c147 4-Oxononanal & 0.29 & 0.02 & 0.55 \\
\hline 14 & c105 Tetradecanal & -0.02 & 0.02 & 0.58 \\
\hline 15 & c72 2-Acetyl thiazole & 0.04 & 0.02 & 0.59 \\
\hline 16 & c52 N-caproic acid, vinyl ester & 0.007 & 0.01 & 0.60 \\
\hline 17 & c217 Cyclooctene & -0.01 & 0.01 & 0.62 \\
\hline 18 & c99 4-Octen-3-one & 0.09 & 0.01 & 0.63 \\
\hline 19 & c32 2-Docecen-1-al & 0.02 & 0.01 & 0.64 \\
\hline 20 & c90 Methyl-pyrazine & -0.04 & 0.03 & 0.67 \\
\hline 21 & c38 Heptanal & -0.0006 & 0.01 & 0.68 \\
\hline 22 & c184 3-(Methylthio)-propanal & 0.07 & 0.02 & 0.70 \\
\hline \multirow[t]{2}{*}{23} & c192 3-(1,1-Dimethylethyl)-2,2,4,4- & & & \\
\hline & tetramethyl-3-pentanol, & 0.02 & 0.02 & 0.71 \\
\hline 24 & c112 1-Decanol & 0.13 & 0.01 & 0.73 \\
\hline 25 & c110 trans-2-undecen-1-ol & 0.03 & 0.01 & 0.74 \\
\hline \multirow[t]{2}{*}{26} & c131 1-[2-(2-Methylbutyl)phenyl] & & & \\
\hline & ethanone & 0.02 & 0.01 & 0.75 \\
\hline 27 & c69 2-Ethyl-3,5-dimethyl-pyrazine & -0.14 & 0.03 & 0.78 \\
\hline \multirow[t]{2}{*}{28} & c162 1,1-Bis(dodecyloxy)- & & & \\
\hline & hexadecane & -0.57 & 0.02 & 0.80 \\
\hline 30 & c91 6-Methyl-2-heptanone & 0.05 & 0.01 & 0.81 \\
\hline 31 & c47 2-Methylene cyclopentanol & 0.04 & 0.01 & 0.82 \\
\hline 32 & c160 Nonacosane & -0.22 & 0.01 & 0.83 \\
\hline 33 & c10 Dodecane & 0.002 & 0.01 & 0.84 \\
\hline 34 & c167 2-Nonanone & -0.08 & 0.01 & 0.85 \\
\hline 35 & c220 trans-2-undecenal & 0.04 & 0.01 & 0.86 \\
\hline 36 & c27 Undecenal & 0.006 & 0.01 & 0.87 \\
\hline
\end{tabular}


Table 13 (Continued).

\begin{tabular}{llccc}
\hline Step & Variables (Code and Chemical Name) & $\begin{array}{c}\text { Estimate }^{\mathrm{a}} \\
\mathrm{x} \mathrm{10}^{-4}\end{array}$ & $\begin{array}{c}\text { Partial }^{2} \\
\mathrm{R}^{2}\end{array}$ & $\begin{array}{c}\text { Equation }^{\mathrm{b}} \\
\mathrm{R}^{2}\end{array}$ \\
\hline 37 & c175 Chavicol & -0.10 & 0.01 & 0.87
\end{tabular}

${ }^{a}$ Estimates are the $b$-values for the final regression equation when the defined variable was included and variables are not listed in the order that they entered the equation. 
Table 14. Stepwise linear regression for prediction of sour basic taste as the dependent variable and aromatic volatile compounds as independent variables.

\begin{tabular}{|c|c|c|c|c|}
\hline Step & Variables (Code and Chemical Name) ${ }^{\mathrm{a}}$ & $\begin{array}{l}\text { Estimate }^{\mathrm{a}} \\
\mathrm{x} 10^{-4}\end{array}$ & $\begin{array}{l}\text { Partial } \\
\mathrm{R}^{2}\end{array}$ & $\begin{array}{c}\text { Equation }^{\mathrm{b}} \\
\mathrm{R}^{2}\end{array}$ \\
\hline Intercept & & 1.80 & & \\
\hline 1 & c20 1-Heptanol & 0.01 & 0.06 & 0.06 \\
\hline 2 & c72 2-Acetyl thiazole & 0.10 & 0.05 & 0.12 \\
\hline 3 & c32 2-Docecen-1-al & 0.03 & 0.05 & 0.16 \\
\hline 4 & c118 2,4 Nonadienal & -0.11 & 0.05 & 0.21 \\
\hline 5 & $\begin{array}{l}\text { c208 N,N'-dimethylcyclobutane-1,1- } \\
\text { bis(methylamine) }\end{array}$ & -0.22 & 0.04 & 0.25 \\
\hline 6 & $\begin{array}{l}\text { c192 3-(1,1-Dimethylethyl)-2,2,4,4- } \\
\text { tetramethyl-3-pentanol,-- }\end{array}$ & 0.03 & 0.04 & 0.29 \\
\hline 7 & c117 3-Ethyl-2-methyl-1,3-hexadiene & -0.01 & 0.03 & 0.31 \\
\hline 8 & c90 Methyl-pyrazine & -0.06 & 0.03 & 0.35 \\
\hline 9 & c83 1-Propoxy-2-propanol & 0.08 & 0.03 & 0.38 \\
\hline 10 & c51 1-(1H-pyrrol-2-yl)-ethanone & 0.08 & 0.03 & 0.41 \\
\hline 11 & c110 Trans-2-undecen-1-ol & 0.07 & 0.02 & 0.44 \\
\hline 12 & c185 2-Methyl-3-octanone & 0.009 & 0.02 & 0.46 \\
\hline 13 & c161 Hexadecanal & 0.27 & 0.02 & 0.48 \\
\hline 15 & c4 5-Pentyl-2(5H)-furanone & -0.07 & 0.02 & 0.51 \\
\hline 16 & c8 3-Ethyl-benzaldehyde & 0.05 & 0.03 & 0.55 \\
\hline 18 & c103 Nonadecane & -0.10 & 0.02 & 0.55 \\
\hline 19 & c135 1-Tetradecanol & -0.21 & 0.02 & 0.57 \\
\hline 21 & c215 Propyl-propanedioic acid & -0.13 & 0.02 & 0.58 \\
\hline 22 & c74 2-Heptanone & 0.02 & 0.02 & 0.60 \\
\hline 23 & c84 2,5-Octanedione & -0.009 & 0.02 & 0.62 \\
\hline 25 & c33 (E)-2-nonenal & -0.02 & 0.02 & 0.63 \\
\hline 26 & c118 2,4 Nonadienal & -0.08 & 0.02 & 0.65 \\
\hline 27 & c61 1-Pyrrolidine carboxaldehyde & -0.19 & 0.02 & 0.67 \\
\hline 28 & c102 Heptenal & -0.06 & 0.01 & 0.68 \\
\hline 29 & c175 Chavicol & -0.18 & 0.01 & 0.70 \\
\hline 30 & c184 3-(Methylthio)-propanal & 0.13 & 0.01 & 0.71 \\
\hline 31 & $\begin{array}{l}\text { c92 1-(4,5-Dihydro-2-thiazolyl)- } \\
\text { ethanone }\end{array}$ & 0.23 & 0.01 & 0.72 \\
\hline 32 & c99 4-Octen-3-one & 0.14 & 0.01 & 0.74 \\
\hline 33 & c87 Hexadecane & 0.09 & 0.01 & 0.75 \\
\hline 34 & c122 Cyclooctyl alcohol & -0.07 & 0.01 & 0.77 \\
\hline 35 & c214 4-hydroxy-benzoic acid & -0.16 & 0.01 & 0.78 \\
\hline 36 & c207 Undecane & 0.10 & 0.01 & -0.79 \\
\hline 37 & c164 2-Decanone & 0.12 & 0.01 & 0.80 \\
\hline 38 & c18 Phenyl acetaldehyde & -0.04 & 0.02 & 0.82 \\
\hline 39 & c198 Phenyl-oxirane & -0.08 & 0.01 & 0.83 \\
\hline
\end{tabular}


Table 14 (Continued).

\begin{tabular}{|c|c|c|c|c|}
\hline Step & Variables (Code and Chemical Name) ${ }^{\mathrm{a}}$ & $\begin{array}{l}\text { Estimate }^{\mathrm{a}} \\
\mathrm{x} 10^{-4}\end{array}$ & $\begin{array}{c}\text { Partial } \\
\mathrm{R}^{2}\end{array}$ & $\begin{array}{c}\text { Equation } \\
\mathrm{R}^{2}\end{array}$ \\
\hline 41 & c43 Tridecane & -0.02 & 0.01 & 0.83 \\
\hline 42 & c116 Tetradecane & 0.03 & 0.02 & 0.85 \\
\hline 43 & c52 N-caproic acid, vinyl ester & 0.006 & 0.01 & 0.86 \\
\hline 44 & c212 (1-methylethyl)-benzene & -0.10 & 0.01 & 0.87 \\
\hline 45 & c133 4-Ethyl-benzaldehyde & 0.03 & 0.01 & 0.87 \\
\hline 46 & c173 1,3,5,7-Cyclooctatetraene & 0.09 & 0.01 & 0.88 \\
\hline 47 & c22 2,3-Octanedione & -0.003 & 0.01 & 0.89 \\
\hline 49 & c203 Formic acid, hexyl ester & 0.06 & 0.01 & 0.89 \\
\hline 50 & c221 4-hydroxymandelic acid & 0.03 & 0.01 & 0.90 \\
\hline 51 & c27 Undecenal & -0.009 & 0.01 & 0.91 \\
\hline 52 & c155 2,3,5-Trimethyl pyrazine & 0.01 & 0.00 & 0.91 \\
\hline 53 & c177 Formic acid, heptyl ester & 0.06 & 0.01 & 0.92 \\
\hline 55 & c15 Nonenal & -0.02 & 0.01 & 0.92 \\
\hline 56 & c185 2-Methyl-3-octanone & -0.004 & 0.00 & 0.92 \\
\hline 58 & c6 Acetophenone & 0.05 & 0.01 & 0.92 \\
\hline 61 & c150 Pentadecane & 0.08 & 0.00 & 0.92 \\
\hline 62 & c19 Styrene & 0.03 & 0.00 & 0.93 \\
\hline 63 & c75 (E)-2-heptenal & 0.005 & 0.01 & 0.93 \\
\hline 67 & c197 (E,E)-2,4-Octadienal & 0.07 & 0.01 & 0.93 \\
\hline 68 & c9 Decanal & -0.02 & 0.00 & 0.94 \\
\hline 70 & c27 Undecenal & -0.008 & 0.00 & 0.94 \\
\hline 71 & c159(E)-4-dodecene & -0.08 & 0.00 & 0.94 \\
\hline 72 & c45 1-Octen-3-one & 0.01 & 0.00 & 0.95 \\
\hline 73 & c55 2-Ethyl-5-methyl-pyrazine & -0.05 & 0.00 & 0.95 \\
\hline 74 & c44 1-Octen-3-ol & -0.0009 & 0.00 & 0.95 \\
\hline 75 & c40 4-Methyl-phenol & -0.02 & 0.00 & 0.96 \\
\hline
\end{tabular}

${ }^{a}$ Estimates are the $b$-values for the final regression equation when the defined variable was included and variables are not listed in the order that they entered the equation. 
Table 15. Stepwise linear regression for prediction of salty basic taste as the dependent variable and aromatic volatile compounds as independent variables.

\begin{tabular}{|c|c|c|c|c|}
\hline Step & Variables (Code and Chemical Name) ${ }^{\mathrm{a}}$ & $\begin{array}{l}\text { Estimate }^{\mathrm{a}} \\
\quad \times 10^{-4}\end{array}$ & $\begin{array}{c}\text { Partial } \\
\mathrm{R}^{2}\end{array}$ & $\begin{array}{l}\text { Equation }^{\mathrm{b}} \\
\mathrm{R}^{2}\end{array}$ \\
\hline Intercept & & 1.21 & & \\
\hline 1 & c123 Heneicosane & -0.21 & 0.07 & 0.07 \\
\hline \multirow[t]{2}{*}{2} & c170 3-(1,1-Dimethylethyl)- & & & \\
\hline & 2,2,4,4-tetramethyl-3-pentanol & 0.03 & 0.06 & 0.13 \\
\hline 3 & c98 2,3-Dimethylbenzaldehyde & 0.21 & 0.05 & 0.18 \\
\hline 4 & c86 Ethyl-benzene & -0.08 & 0.04 & 0.22 \\
\hline 5 & c18 Phenyl acetaldehyde & 0.02 & 0.05 & 0.27 \\
\hline 6 & c32 2-Docecen-1-al & -0.02 & 0.05 & 0.32 \\
\hline 7 & c129 2-Dodecen-1-ol & 0.09 & 0.03 & 0.35 \\
\hline 8 & c94 Octane & 0.04 & 0.04 & 0.39 \\
\hline 9 & c210 2-decen-1-ol & 0.05 & 0.04 & 0.42 \\
\hline 10 & c55 2-Ethyl-5-methyl-pyrazine & 0.04 & 0.03 & 0.45 \\
\hline 12 & c33 (E)-2-nonenal & 0.008 & 0.02 & 0.47 \\
\hline 13 & c91 6-Methyl-2-heptanone & -0.06 & 0.04 & 0.50 \\
\hline 14 & c51 1-(1H-pyrrol-2-yl)-ethanone & -0.04 & 0.02 & 0.53 \\
\hline 15 & c74 2-Heptanone & -0.009 & 0.02 & 0.55 \\
\hline 16 & c154 Octadecanal & -0.07 & 0.02 & 0.57 \\
\hline 17 & c119 Acetic acid & -0.02 & 0.01 & 0.58 \\
\hline 18 & c118 2,4 Nonadienal & 0.04 & 0.01 & 0.59 \\
\hline 19 & c196 3-Methyl-butanal & 0.03 & 0.02 & 0.61 \\
\hline 21 & c217 Cyclooctene & -0.02 & 0.02 & 0.62 \\
\hline 22 & c192 3-(1,1-Dimethylethyl)-2,2,4,4- & & & \\
\hline \multirow[t]{2}{*}{23} & $\begin{array}{l}\text { tetramethyl-3-pentanol, } \\
\text { c170 3-(1,1-Dimethylethyl)- }\end{array}$ & -0.01 & 0.02 & 0.64 \\
\hline & 2,2,4,4-tetramethyl-3-pentanol & 0.02 & 0.01 & 0.65 \\
\hline 24 & c19 Styrene & 0.02 & 0.01 & 0.66 \\
\hline 25 & c20 1-Heptanol & -0.004 & 0.02 & 0.68 \\
\hline 26 & c65 2,4 Heptadienal & 0.02 & 0.02 & 0.70 \\
\hline 27 & c73 2-Butylfuran & -0.07 & 0.03 & 0.72 \\
\hline 28 & c48 3-Dodecen-1-al & -0.005 & 0.02 & 0.74 \\
\hline 29 & c45 1-Octen-3-one & 0.01 & 0.02 & 0.76 \\
\hline 32 & c21 (E)-2-decenal & 0.004 & 0.01 & 0.77 \\
\hline 34 & c212 (1-methylethyl)-benzene & 0.13 & 0.02 & 0.78 \\
\hline 36 & c185 2-Methyl-3-octanone & 0.004 & 0.02 & 0.79 \\
\hline \multirow[t]{2}{*}{37} & c140 N,N'-bis (3-aminopropyl)- & & & \\
\hline & 1,3-propanediamine & 0.11 & 0.01 & 0.80 \\
\hline 39 & c112 1-Decanol & 0.12 & 0.01 & 0.80 \\
\hline 40 & c188 Dihydro-2(3H)-furanone & 0.007 & 0.01 & 0.81 \\
\hline 41 & c147 4-Oxononanal & -0.15 & 0.01 & 0.82 \\
\hline
\end{tabular}


Table 15 (Continued).

\begin{tabular}{|c|c|c|c|c|}
\hline Step & Variables (Code and Chemical Name) ${ }^{a}$ & $\begin{array}{c}\text { Estimate }^{\mathrm{a}} \\
\mathrm{x} 10^{-4}\end{array}$ & $\begin{array}{c}\text { Partial } \\
\mathrm{R}^{2}\end{array}$ & $\begin{array}{c}\text { Equation } \\
\mathrm{R}^{2}\end{array}$ \\
\hline 42 & c40 4-Methyl-phenol & 0.01 & 0.01 & 0.83 \\
\hline 44 & c69 2-Ethyl-3,5-dimethyl-pyrazine & -0.05 & 0.01 & 0.83 \\
\hline 45 & c52 N-caproic acid, vinyl ester & 0.002 & 0.01 & 0.84 \\
\hline 46 & c99 4-Octen-3-one & 0.06 & 0.01 & 0.85 \\
\hline 47 & c97 1,2-Benzisothiazole & -0.03 & 0.01 & 0.85 \\
\hline 48 & c141 Ethylidene cycloheptane & 0.03 & 0.01 & 0.86 \\
\hline 50 & c26 Tridecanal & -0.02 & 0.01 & 0.86 \\
\hline 51 & c171 Butanoic acid & -0.02 & 0.01 & 0.87 \\
\hline 53 & c84 2,5-Octanedione & -0.003 & 0.01 & 0.88 \\
\hline
\end{tabular}

${ }^{a}$ Estimates are the $b$-values for the final regression equation when the defined variable was included and variables are not listed in the order that they entered the equation. 
Table 16. Stepwise linear regression for prediction of bitter basic taste as the dependent variable and aromatic volatile compounds as independent variables.

\begin{tabular}{|c|c|c|c|c|}
\hline Step & Variables (Code and Chemical Name) ${ }^{\mathrm{a}}$ & $\begin{array}{c}\text { Estimate }^{\mathrm{a}} \\
\mathrm{x} 10^{-4}\end{array}$ & $\begin{array}{c}\text { Partial } \\
\mathrm{R}^{2}\end{array}$ & $\begin{array}{c}\text { Equation } \\
\mathrm{R}^{2}\end{array}$ \\
\hline Intercept & & 1.91 & & \\
\hline 1 & c122 Cyclooctyl alcohol & 0.10 & 0.09 & 0.09 \\
\hline 2 & c80 (E)-2-hexenal & 0.04 & 0.09 & 0.18 \\
\hline 3 & c4 5-Pentyl-2(5H)-furanone & -0.08 & 0.09 & 0.26 \\
\hline 4 & c30 1-Octen-3-ol & 0.003 & 0.05 & 0.32 \\
\hline 5 & c152 Dodecanal & -0.01 & 0.04 & 0.36 \\
\hline 6 & c101 Heptanoic acid & -0.05 & 0.03 & 0.39 \\
\hline 7 & c58 Trimethyl-pyrazine & 0.01 & 0.03 & 0.42 \\
\hline 8 & c124 2,5-Dimethyl-heptane & 0.04 & 0.03 & 0.45 \\
\hline 9 & c64 2,4 Decadienal & -0.03 & 0.03 & 0.48 \\
\hline 10 & c138 1,2-dimethylpyrrolidine & -0.09 & 0.03 & 0.50 \\
\hline 11 & c164 2-Decanone & 0.13 & 0.03 & 0.53 \\
\hline 12 & c184 3-(Methylthio)-propanal & 0.08 & 0.02 & 0.55 \\
\hline 13 & c66 Octanoic acid & 0.02 & 0.02 & 0.58 \\
\hline 14 & c25 3-Isopropyl-piperidine & -0.10 & 0.02 & 0.60 \\
\hline 15 & c141 Ethylidene cycloheptane & 0.04 & 0.02 & 0.61 \\
\hline 16 & c32 2-Docecen-1-al & 0.02 & 0.01 & 0.63 \\
\hline 18 & c214 4-hydroxy-benzoic acid & -0.13 & 0.02 & 0.63 \\
\hline 19 & c145 (1-Methylbutyl)-oxirane & -0.05 & 0.02 & 0.65 \\
\hline 20 & c220 trans-2-undecenal & -0.06 & 0.02 & 0.67 \\
\hline 21 & c147 4-Oxononanal & -0.15 & 0.01 & 0.68 \\
\hline 22 & c99 4-Octen-3-one & 0.10 & 0.01 & 0.69 \\
\hline 23 & c197 (E,E)-2,4-Octadienal & 0.05 & 0.01 & 0.71 \\
\hline 24 & c22 2,3-Octanedione & -0.001 & 0.01 & 0.72 \\
\hline 25 & c6 Acetophenone & 0.04 & 0.01 & 0.73 \\
\hline 26 & c221 4-hydroxymandelic acid & 0.02 & 0.01 & 0.74 \\
\hline 27 & c21 (E)-2-decenal & -0.005 & 0.01 & 0.75 \\
\hline 31 & c173 1,3,5,7-Cyclooctatetraene & 0.09 & 0.01 & 0.75 \\
\hline 34 & c48 3-Dodecen-1-al & -0.008 & 0.02 & 0.75 \\
\hline 35 & c183 Cyclooctanol & 0.03 & 0.01 & 0.76 \\
\hline 36 & c29 1-Octanol & -0.005 & 0.01 & 0.77 \\
\hline 37 & c51 1-(1H-pyrrol-2-yl)-ethanone & 0.04 & 0.01 & 0.78 \\
\hline 38 & $\begin{array}{l}\text { c208 N,N'-dimethylcyclobutane- } \\
\text { 1.1-bis(methylamine) }\end{array}$ & 0.23 & 0.01 & 0.79 \\
\hline
\end{tabular}


Table 16 (Continued).

\begin{tabular}{|c|c|c|c|c|}
\hline Step & Variables (Code and Chemical Name) ${ }^{a}$ & $\begin{array}{c}\text { Estimate }^{\mathrm{a}} \\
\mathrm{x} 10^{-4}\end{array}$ & $\begin{array}{c}\text { Partial } \\
\mathrm{R}^{2}\end{array}$ & $\begin{array}{c}\text { Equation } \\
\mathrm{R}^{2}\end{array}$ \\
\hline 39 & c151 Trans-2-tridecenal & -0.02 & 0.01 & 0.80 \\
\hline 40 & c1 2-Octenal & -0.003 & 0.01 & 0.82 \\
\hline 41 & c84 2,5-Octanedione & -0.004 & 0.01 & 0.82 \\
\hline 42 & c14 Nonanal & -0.0004 & 0.01 & 0.83 \\
\hline
\end{tabular}

${ }^{\bar{a}}$ Estimates are the $b$-values for the final regression equation when the defined variable was included and variables are not listed in the order that they entered the equation. 


\section{APPENDIX B}

\section{FIGURES}

Figure 1. Flavor aromatic compound categories least squares means for the cut by internal endpoint degree of doneness interaction.

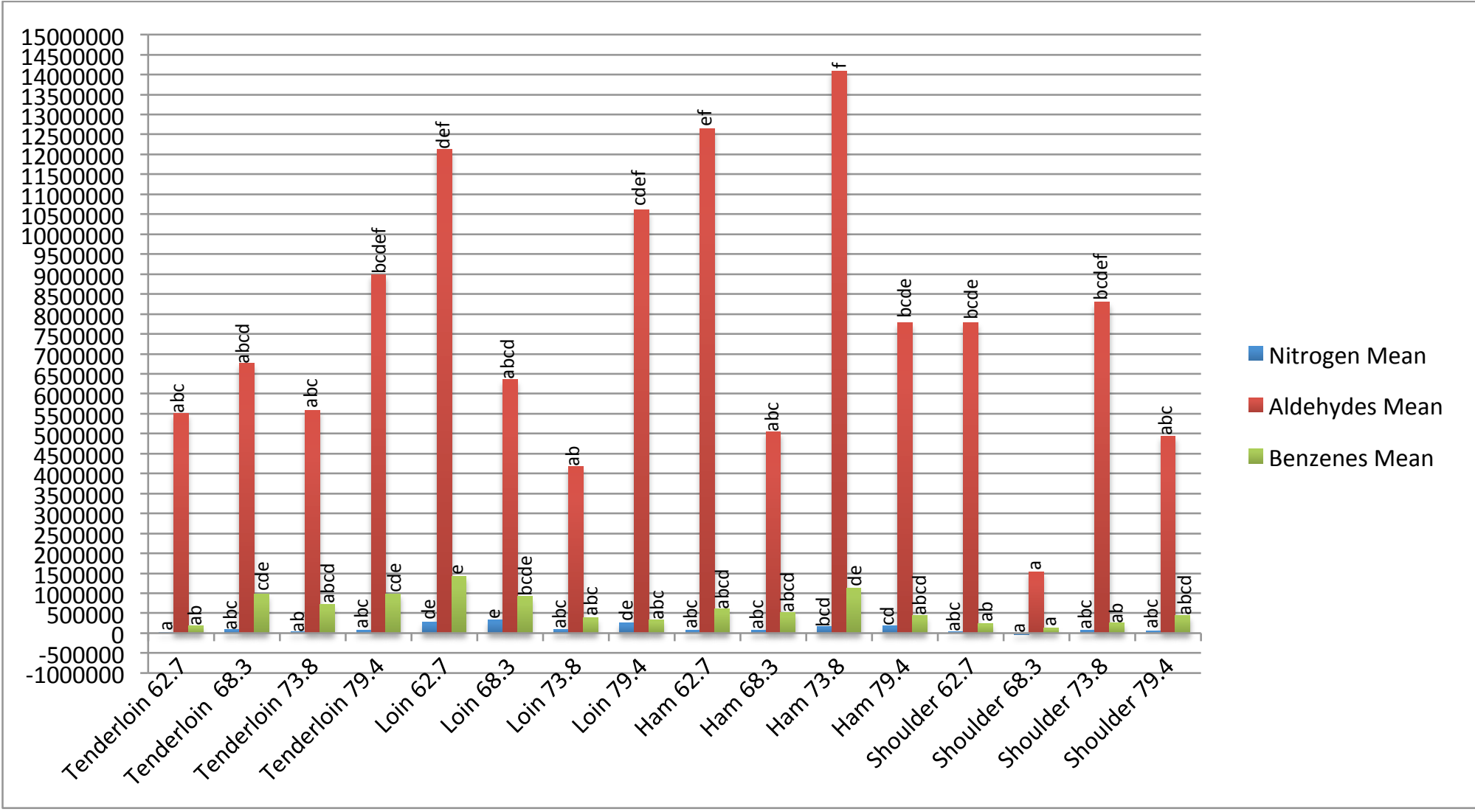


Figure 2. Partial least squares regression biplot $\left(\mathrm{R}^{2}=92.6 \%\right)$ of trained descriptive flavor attributes from the Pork Lexicon (blue), volatile aromatic compound categories (red), and 16 treatments (green).

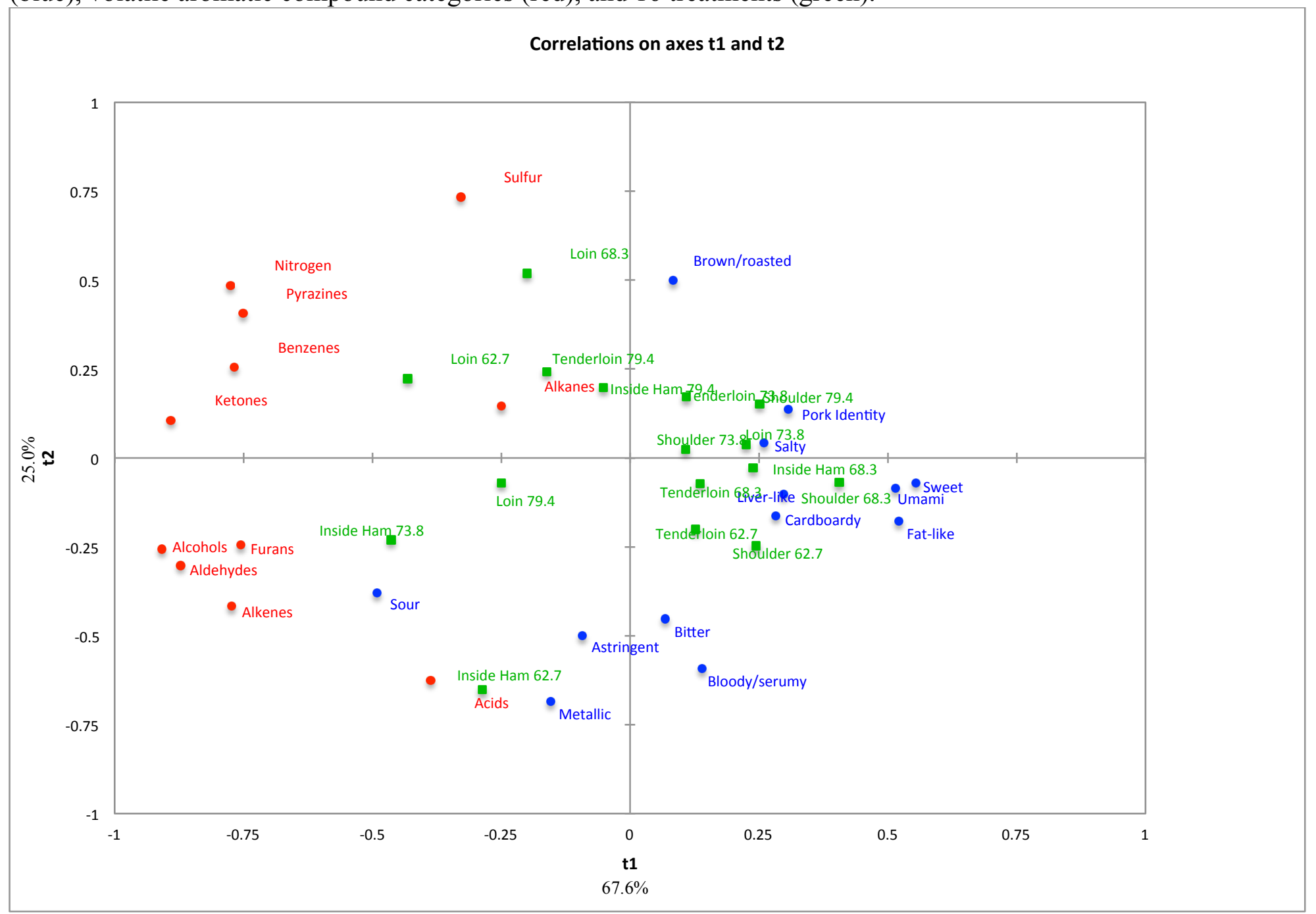


Figure 3. Partial least squares regression biplot $\left(\mathrm{R}^{2}=82.0 \%\right)$ of trained descriptive flavor attributes from the Pork Lexicon (blue), 157 volatile aromatic compounds (red), and 16 treatments (green).

Correlations on axes $\mathrm{t} 1$ and $\mathrm{t} 2$

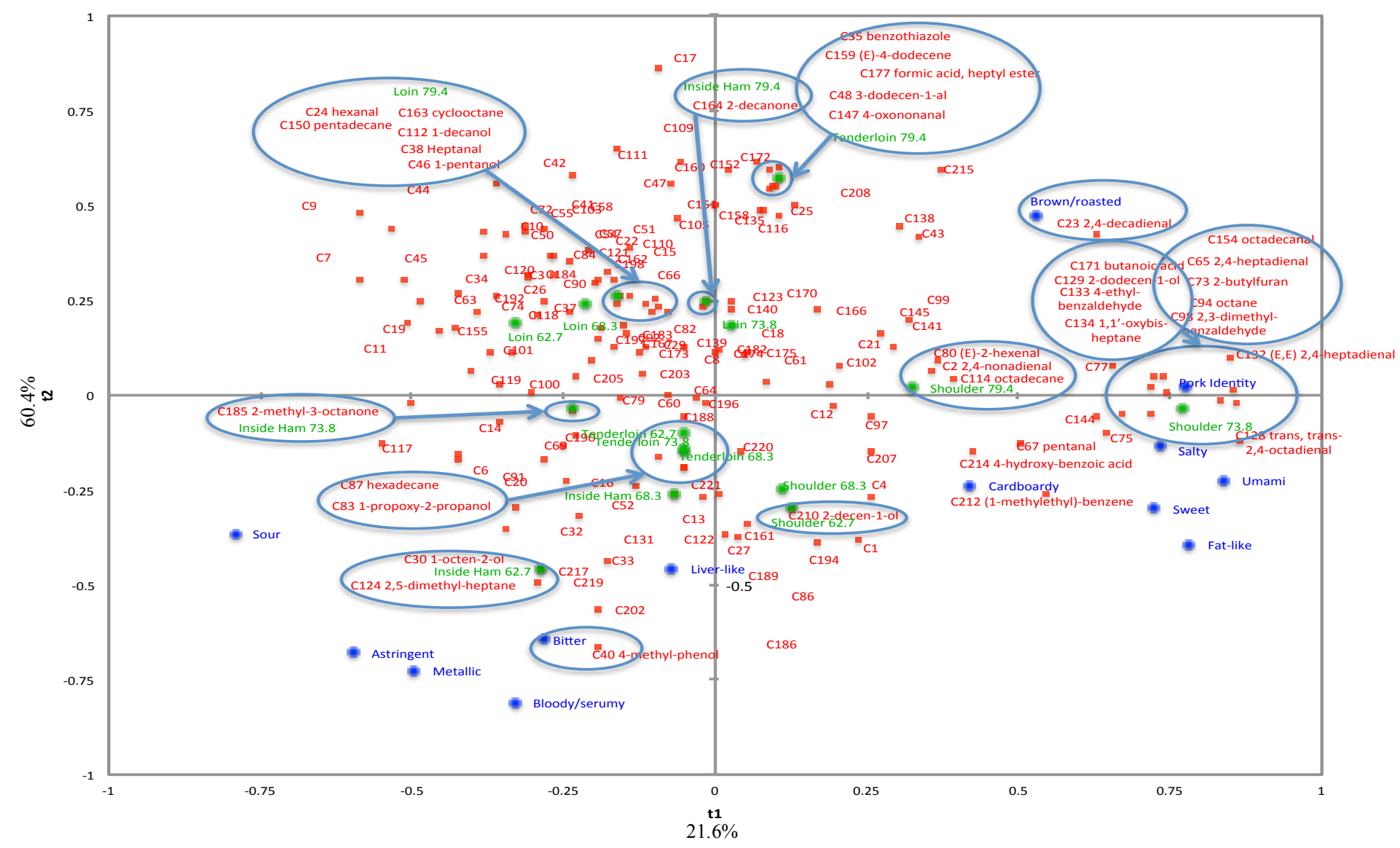

